\title{
CYCLIC FATIGUE OF NEAR-ISOTROPIC GRAPHITE: INFLUENCE OF STRESS CYCLE AND NEUTRON IRRADIATION
}

\author{
by \\ R. J. PRICE
}

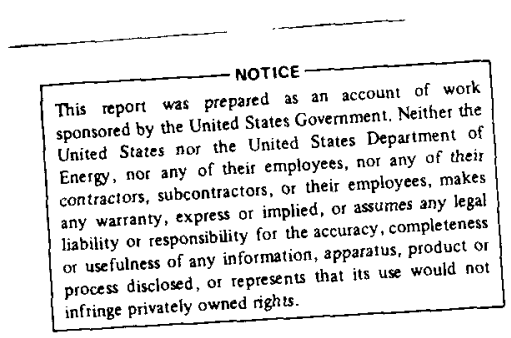

This is a preprint of an article to be submitted (in abbreviated form) to Carbon.

Work supported by

Department of Energy

Contract EY-76-C-03-0167, Project Agreement No. 17

This document is

PLiallCLY RELEASABLE hasre Osc'll came

Date: $06 / 26 / 2007$

\section{GENERAL ATOMIC COMPANY}




\section{DISCLAIMER}

This report was prepared as an account of work sponsored by an agency of the United States Government. Neither the United States Government nor any agency Thereof, nor any of their employees, makes any warranty, express or implied, or assumes any legal liability or responsibility for the accuracy, completeness, or usefulness of any information, apparatus, product, or process disclosed, or represents that its use would not infringe privately owned rights. Reference herein to any specific commercial product, process, or service by trade name, trademark, manufacturer, or otherwise does not necessarily constitute or imply its endorsement, recommendation, or favoring by the United States Government or any agency thereof. The views and opinions of authors expressed herein do not necessarily state or reflect those of the United States Government or any agency thereof. 


\section{DISCLAIMER}

Portions of this document may be illegible in electronic image products. Images are produced from the best available original document. 
$\bullet$ 
CYCLIC FATIGUE OF NEAR-ISOTROPIC GRAPHITE:

INFLUENCE OF STRESS CYCLE AIND NEUTRON IRRADIATION

by

R. J. Price

General Atomic Company

10955 John Jay llopkins Dr.

San Diego, California 92121

ABSTRACT

For this study, near-isotropic graphites $\mathrm{H}-451$ and PGX were tested in uniaxial cyclic fatigue, and fatigue life (S-N) curves were generated to a maximum of $10^{5}$ cycles. The stress ratio, $R$ (minimum stress during a cycle divided by maximum stress) ranged from -1 to t0.5. With $R=-1$, the homologous stress limits (maximum applied fatigue stress divided by the tensile strength) for $50 \%$ specimen survival to $10^{5}$ cycles averaged 0.63 in the axial direction and 0.74 in the radial direction. Corresponding homologous stress limits for $99 \%$ specimen survival ( $99 / 95$ tolerance limfts) were 0.48 and 0.53. Higher R-values resulted in longer fatigue lives and increased stress 1imits. H-451 graphite specimens irradiated with fast neutrons at 1173 to $1263 \mathrm{~K}$ at fluences of up to $10^{26} \mathrm{n} / \mathrm{m}^{2}$ (equivalent fission fluence) showed fatigue stress limits of about twice the unirradiated levels when the unirradiated tensile strength was used as the basis for normalization. 
-

$\bullet$ 
CONTENTS

ABSTRACT . . . . . . . . . . . . . . . . . . . .

1. INTRODUCTION ...................... . . . . . . . . .

2. EXPERIMENTATION ..................... . . . . .

2.1. Material .. . . . . ......... 2-1

2.2. Specimens ................. . 2-2

2.3. Apparatus .................. 2-2

2.4. Irradiation . . . . . . . . . . . . . 2-2

3. RESULTS . . . . . . . . . . . . . . . . . . 3-1

3.1. Unirradiated Specimens . . . . . . . . . . . . 3-1

3.2. Irradiated Specimens . . . . . . . . . . . . 3-7

4. DISCUSSION .................... . . . . . . 4-1

5. SUMMARY AND CONCLUSIONS . . . . . . . . . . . . . . 5-1

6. ACKNOWLEDGEMENTS .. . . . . . . . . . . . . . 6-1

REFERENCES . . . . . . . . . . . . . . . . . . . . R-1

APPENDIX SAMLING PLAN AND TEST DATA . . . . . . . . . . A-1

FIGURES

1. Fatigue test data on H-451 graphite, axial orientation, quarter-length edge location, in air at ambient temperature. Log-log plot of normalized maximum stress versus number of cycles to fallure with $\mathrm{R}=-1$............. 3-3

2. Constant life fatigue diagram (Goodman diagram) for $\mathrm{H}-451$ graphite, axial orientation, tested in air at ambient temperature ................. 3-8

3. Ambient temperature fatigue test data for $\mathrm{H}-451$ graphite, axial orientation, Irradiated to $3.8 \times 10^{25} \mathrm{n} / \mathrm{m}^{2}$ (equivalent fission fluence) at $1173 \mathrm{~K}\left(900^{\circ} \mathrm{C}\right)$. Log- $\log$ plot of normalized peak stress versus number of cycles to failure, with stress ratio, $\mathrm{R}=-1 . . . . . . . . . . . . .3-11$

4. Fatigue stress limits for survival of H-451 graphite to $10^{5}$ cycles, normalized to the unfrradiated tensile strength, versus the fast neutron fluence at an irradiation temperature of 1173 to $1263 \mathrm{~K}\left(900^{\circ}\right.$ to $\left.990^{\circ} \mathrm{C}\right)$. . . . . . . . . . 3-13 


\section{FIGURES (Continued)}

A-1. Slab diagram for $\mathrm{H}-451$ graphite . . . . . . . . . A-3

$\mathrm{A}-2$. Coring plan for $\mathrm{H}-451$ graphite . . . . . . . . . . A-4

A-3. Slab diagram for PGX graphite . . . . . . . . . . A-5

A-4. Coring plan for PGX graphite . . . . . . . . . . A-6

A-5. Fatigue test data on $\mathrm{H}-451$ graphite, axial orientation, quarter-length edge location, in air at ambient temperature. Log-log plot of normalized maximum stress versus number of cycles to failure with $\mathrm{R}=-1$. . . . . . . . . A $\mathrm{A}-32$

A-6. Fatigue test data on H-451 graphite, axial orientation, quarter-length edge location, in air at ambient temperature. Log-log plot of normalized maximum stress versus number of cycles to failure with $R=-0.5$. . . . . . . . . . A-33

A-7. Fatigue test data on $\mathrm{H}-451$ graphite, axial orientation, quarter-length edge location, in air at ambient temperature. Log-log plot of normalized maximum stress versus number of cycles to failure with $\mathrm{R}=0 .$. . . . . . . . . . A-34

A-8. Fatigue test data on $\mathrm{H}-451$ graphite, axial orientation, quarter-length edge location, in air at ambient temperature. Log-log plot of normalized maximum stress versus number of cycles to failure with $\mathrm{R}=0.5$. . . . . . . . . . A-35

A-9. Fatigue test data on $\mathrm{H}-451$ graphite, radial orientation, quarter-length edge location, in air at ambient temperature. Log-log plot of normalized maximum stress versus number of cycles to failure with $R=-1$. . . . . . . . . . .

A-10. Fatigue test data on $\mathrm{H}-451$ graphite, radial orientation, quarter-length edge location, in air at ambient temperature. Log-log plot of normalized maximum stress versus number of cycles to failure with $\mathrm{R}=-0.5$. . . . . . . . .

A-11. Fatigue test data on $\mathrm{H}-451$ graphite, radial orientation, quarter-length edge location, in air at ambient temperature. Log-log plot of normalized maximum stress versus number of cycles to failure with $\mathrm{R}=0 . . . . . . . . . . .4 A-38$

A-12. Fatigue test data on $\mathrm{H}-451$ graphite, radial orientation, quarter-length edge location, in air at ambient temperature. Log-log plot of normalized maximum stress versus number of cycles to failure with $\mathrm{R}=0.5$. . . . . . . . . .

A-13. Fatigue test data for PGX graphite, axial orientation, end one-third radius location, in air at ambient temperature. Log-log plot of normalized maximum stress versus number of cycles to failure with stress ratio $\mathrm{R}=-1, \ldots . .$. . . 


\section{FIGURES (Continued)}

A-14. Fatigue test data for PGX graphite, axial orientation, end one-third radius location, in air at ambient temperature.

Log- $\log$ plot of normalized maximum stress versus number of cycles to failure with stress ratio $\mathrm{R}=0$. . . . . . . A-41

A-15. Fatigue test data for PGX graphite, radial orientation, end one-third radius location, in air at ambient temperature. Log-log plot of normalized maximum stress versus number of cycles to failure with stress ratio $R=-1$. . . . . . . A-42

A-16. Fatigue test data for PGX graphite, radial orientation, end one-third radius location, in air at ambient temperature. Log-log plot of normalized maximum stress versus number of cycles to failure with stress ratio $\mathrm{R}=0$. . . . . . . . $\mathrm{A}-43$

A-17. Ambient temperature fatigue test data for $\mathrm{H}-451$ graphite, axial orientation, Irradiated to $3.8 \times 10^{25} \mathrm{n} / \mathrm{m}^{2}$ (equivalent fission fluence) at $1173 \mathrm{~K}\left(900^{\circ} \mathrm{C}\right)$. Log-log plot of normalized peak stress versus number of cycles to failure, with stress ratio, $\mathrm{R}=-1$. . . . . . . . . . . . . . . $\mathrm{A}-44$

A-18. Ambient temperature fatigue test data for $\mathrm{H}-451$ graphite, radial orientation, Irradiated to $5.7 \times 1025 \mathrm{n} / \mathrm{m}^{2}$ (E $>29 \mathrm{fJ}$ ) at 1223 to $1263 \mathrm{~K}\left(950^{\circ}\right.$ to $\left.990^{\circ} \mathrm{C}\right)$. Log-log plot of normalized peak stress versus number of cycles to fallure, with stress ratio, $R=-1$............. . . A-45

A-19. Ambient temperature fatigue test data for H-451 graphite, axial orientation, irradiated to $8.5 \times 1025 \mathrm{n} / \mathrm{m}^{2}(\mathrm{E}>29 \mathrm{fJ}){ }_{\mathrm{HTGR}}$ at 1223 to $1263 \mathrm{~K}\left(950^{\circ}\right.$ to $\left.990^{\circ} \mathrm{C}\right)$. Log-log plot of normalized peak stress versus the number of cycles to failure, with stress ratio, $R=-1$. . . . . . . . . . . . $\mathrm{A}-46$

A-20. Constant life fatigue diagram (Goodman diagram) for H-451 graphite, axial orientation, tested in air at ambient temperature ................ . A-47

A-21. Constant 11fe fatigue diagram (Goodman diagram) for H-451 graphite, radial orientation, tested in air at ambient temperature................ A-48

A-22. Constant life fatigue diagram (Goodman diagram) for PGX graphite, axial orfentation, tested in air at ambient temperature .. . . . . . . . . . . . . . A-49

A-23. Constant 1ife fatigue diagram (Goodman diagram) for PGX graphite, radial orientation, tested in air at ambient temperature ............... A-50 
TABLES

1. Mean tensile strength of unirradiated H-451 and PGX graphite specimens used in fatigue study . . . . . . . . .

2. Results of statistical analysis of fatigue data for unirradiated H-451 graphite . . . . . . . . . . . 3-5

3. Results of statistical analysis of fatigue data for unirradiated PGX graphite . . . . . . . . . . . . 3-6

4. Irradiation conditions and mean tensile strength of irradiated H-451 graphite used in fatigue study . . . . . . 3-9

5. Results of statistical analysis of fatigue data for H-451 graphite irradiated at $1173-1263 \mathrm{~K}$. . . . . . . . 3-12

A-1. Fatigue tests on $\mathrm{H}-451$ graphite . . . . . . . . . . . A-7

A-2. Fatigue tests on $\mathrm{H}-451$ graphite . . . . . . . . . . . . . A-8

A-3. Fatigue tests on $\mathrm{H}-451$ graphite . . . . . . . . . . . A-10

A-4. Fatigue tests on $\mathrm{H}-451$ graphite . . . . . . . . . . . . A-11

$\mathrm{A}-5$. Fatigue tests on $\mathrm{H}-451$ graphite . . . . . . . . . . . A-12

$\mathrm{A}-6$. Fatigue tests on $\mathrm{H}-451$ graphite . . . . . . . . . . A-13

A-7. Fatigue tests on $\mathrm{H}-451$ graphite . . . . . . . . . . A $\mathrm{A}-14$

A-8. Fatigue tests on H-451 graphite . . . . . . . . . . A-15

A-9. Fatigue tests on H-451 graphite . . . . . . . . . . A-16

A-10. Fatigue tests on $\mathrm{H}-451$ graphite . . . . . . . . . . . A-17

A-11. Fatigue tests on PGX graphite . . . . . . . . . . . A-18

A-12. Fatigue tests on PGX graphite . . . . . . . . . . . A-19

A-13. Fatigue tests on PGX graphite . . . . . . . . . . . " A-21

A-14. Fatigue tests on PGX graphite . . . . . . . . . . A-23

A-15. Fatigue tests on PGX graphite . . . . . . . . . . . A-24

A-16. Fatigue tests on PGX graphite . . . . . . . . . A-25

A-17. Capsule irradiation OG-1 fatigue tests on H-451 graphite . . A-26

A-18. Capsule irradiation OG-1 fatigue tests on H-451 graphite . . A-27

A-19. Capsule irradiations $O G-1$ and $O G-2$ fatigue tests on $H-451$ graphite... . . . . . . . . . . . . . A-28

A-20. Capsule irradiations $\mathrm{OG}-1$ and $\mathrm{OG}-2$ fatigue tests on $\mathrm{H}-451$ graphite . . . . . . . . . . . . . . . A-29

A-21. Capsule irradiations OG-1, 2 and 3 fatigue tests on $H-451$ graphite . . . . . . . . . . . . . . . $\mathrm{A}-30$

A-22. Capsule irradiations $O G-1,2$ and 3 fatigue tests on $H-451$ graphite...................... $\mathrm{A}-31$ 


\section{INTRODUCTION}

Graphite components in high-temperature gas-cooled nuclear reactors (HTGR) are subject to cyclic stresses from power cycling, operating víbrations, and possibly seismic shaking. Design of the components requires a knowledge of the cyclic fatigue behavior of graphite under loading cycles with different ratios of minimum stress to maximum stress (R-value) and under fast neutron irradiation. The inherent scatter in mechanical property determinations on graphites requires that sufficient tests be made for statistical analysis.

Most previously reported measurements on the cyclic fatigue properties of graphites (Ref. 1-9) are too limited in scope to be directly used in engineering design. The most extensive data are those of Leichter and Robinson (Ref. 5), who used rotating beam tests (corresponding to an R-value of -1) on Poco AXF graphite, together with previously reported data on other grades, to make a plot of homologous stress (maximum applied fatigue stress divided by the tensile strength) versus the number of cycles to fallure (S-N curve). The curve has the same form as $S-N$ curves for many metals, with an apparent endurance limit of about 0.64 times the first cycle strength for a survival probability of $50 \%$ and 0.47 times the first cycle strength for a survival probability of $99 \%$.

Bullock (Ref. 9) has reported data from uniaxlal fatigue tests on ATJ graphite which show a higher endurance limit for specimens cycled between zero stress and tension $(R=0)$ than for specimens cycled between compression and tension $(R=-1)$. Similar trends are apparent in data reported by Brocklehurst (Ref. 8). The only reported fatigue measurements on neutronirradiated graphite are those by Brocklehurst (Ref. 8), who subjected a few specimens of a gilsocarbon-based 1sotroplc graphite Irradiated to a fluence 
of $2.5 \times 10^{25} \mathrm{n} / \mathrm{m}^{2}$ (Dido nickel equivalent) at $1173 \mathrm{~K}\left(900^{\circ} \mathrm{C}\right.$ ) to flexural fatigue tests. When plotted on an $\mathrm{S}-\mathrm{N}$ curve in terms of homologous stress, the points fell into the same scatter band as unirradiated specimens.

The present work consisted of uniaxial fatigue tests on $\mathrm{H}-451$ graphite (Great Lakes Carbon Company) and PGX graphite (Union Carbide Corporation) with R-values ranging from -1 to t0.5. Additional tests were conducted on $\mathrm{H}-451$ graphite irradiated to fluences of up to $10^{26} \mathrm{n} / \mathrm{m}^{2}$ [equivalent fission fluence for graphite damage (Ref. 10)] at 1173 to $1263 \mathrm{~K}$ (900 to $990^{\circ} \mathrm{C}$ ). 


\section{EXPERIMENTATION}

\section{1. MATERIAL}

H-451 is an extruded, near-isotropic, petroleum coke-based, nuclear grade graphite made by Great Lakes Carbon Company. It is the reference material for the fuel and replaceable reflector blocks in HTGRs. The extruded $\log$ size is $0.46 \mathrm{~m}$ in diameter by $0.86 \mathrm{~m}$ long. Specimens for the unirradiated fatigue tests were taken in both axial and radial orientations a quarter of the way along the length of the parent $10 \mathrm{~g}$ and between 25 and $100 \mathrm{~mm}$ from the edge. Specimens for irradiation testing were taken from near the $\log$ axis at the mid-length location of a different $10 \mathrm{~g}$. Graphite from the latter location is typically of lower strength than graphite from the former location.

Grade PGX is a large diameter, molded, petroleum coke-based graphite made by Union Carbide Corporation. It is the reference material for support floor blocks in HTGRs. The fabricated $\log$ size is $1.14 \mathrm{~m}$ in diameter by $1.83 \mathrm{~m}$ long. Fatigue specimens were taken in the axial and radial orientations between 50 and $150 \mathrm{~mm}$ from the end of the $1 \mathrm{og}$ and between 150 and $280 \mathrm{~mm}$ from the $10 \mathrm{~g}$ axis. No irradiations were carried out on PGX specimens.

For a given serfes of tests, spectmens were taken from locations spread unfformly over the sampling zone to prevent possible blas from local inhomogeneities in strength. The locations of individual specimens are given in the Appendix. 


\subsection{SPECIMENS}

Except for the specimens subjected to neutron Irradiation, cylindrical specimens $12.7 \mathrm{~mm}$ in diameter by 25.4 long were used. Space limitations in the irradiation capsules restricted the size of the irradiated specimens to $5.1 \mathrm{~mm}$ in diameter by $10.2 \mathrm{~mm}$ long. Prior to testing, the specimens were cemented between cylindrical steel end-pieces with epoxy cement. The assemblies were held in $\mathrm{V}^{\prime}$-block j1gs while the cement hardened to ensure coaxial alignment.

\subsection{APPARATUS}

All tests were run in air at ambient temperature. Tests were conducted in a modifled Fatigue Dynamics Model VSP 150 crank-and-lever fatigue machine equipped with a load cell and a spectally constructed test cage. A pair of opposed loading rams in the cage move on coaxial linear ball bearings to ensure uniaxial loading in both tenston and compression. The specimen endpieces are seated in machined recesses in the rams.

The maximum and minimum load during a cycle were set at the start of the test and checked occastonally during the test. Tests were run at $7 \mathrm{~Hz}$ until the specimen fractured or unt11 100,000 cycles were reached without fracture.

\subsection{IRRADIATION}

Three groups of specimens of $\mathrm{H}-451$ graphite were Irradiated $1 \mathrm{n}$ graphite cructbles in temperature-controlled capsules in the C-3 position of the Oak Ridge reactor. Irradiation conditions are given in Section 3.2. The fast neutron fluence was measured from the activation of iron and titanium dosimeters and is expressed as the equivalent fission fluence for graphte damage (EFFGD) (Ref, 10) and also in terms of neutrons with energies greater than $29 \mathrm{fJ}(0.18 \mathrm{Mev})$ in a typical HTGR spectrum. The temperatures were measured with chromel-alumel thermocouples. The temperatures fluctuated by $\pm 20 \mathrm{~K}$ during the irradiations. 


\section{RESULTS}

\subsection{UNIRRADIATED SPECIMENS}

For each material and orientation, the first test series consisted of 30 to 35 control tensile tests on standard fatigue specimens mounted in the fatigue machine. These tests established the mean tensile strengths, which are listed in Table 1. Individual test data are given in the Appendix.

Fatigue tests were run using R-values of $-1,-0.5,0$, and +0.5 for H-451 graphite and -1 and 0 for PGX graphite. Forty to 50 specimens were included in each series of tests. Between seven and ten specimens were cycled at each of five maximum stress levels, which ranged from 0.6 to 1.0 times the mean tensile strength. The stress levels were selected to avoid an excessive number of run-outs beyond 100,000 cycles. Individual test data, showing maximum and minimum stresses and the number of cycles at failure, are listed in the Appendix.

A typical S-N curve, in which the logarithm of the maximum stress, $S$, is plotted against the logarithm of the number of cycles at fallure, $N$, is shown in Fig. 1 for axial specimens of H-451 graphite run with an R-value of -1 . The stresses are normalized by dividing by the mean tensile strength. The tensile data and first-cycle failures are plotted at $N=0.25$, and run-outs (specimens which survived 100,000 cycles without fallure) are shown as open circles at $\mathrm{N}=100,000$. A complete set of $\mathrm{S}-\mathrm{N}$ curves is included in the Appendix.

The S-N curves have the same form as those of many metals, except that the scatter band is wider. The data do not extend to high enough values of $N$ to confirm the existence of an absolute endurance limft suggested by Leichter and Robinson's measurements on Poco graphite (Ref. 5). 
TABLE 1

MEAN TENSILE STRENGTH OF UNIRRADIATED H 451 AND PGX GRAPHITE SPECIMENS USED IN FATIGUE STUDY

\begin{tabular}{c|c|c|c}
\hline \multirow{2}{*}{ Grade } & Location in Log & Orientation & $\begin{array}{c}\text { Mean Tensile Strength } \\
\text { ( } \begin{array}{c}\text { Standard Deviation) } \\
\text { (MPa) }\end{array}\end{array}$ \\
\hline H-451 & Quarter-length, edge & Axial & $18.9 \pm 1.8$ \\
H-451 & Quarter-length, edge & Radial & $13.9 \pm 2.3$ \\
PGX & End, one-third radius & Axial & $7.6 \pm 0.4$ \\
\hline
\end{tabular}




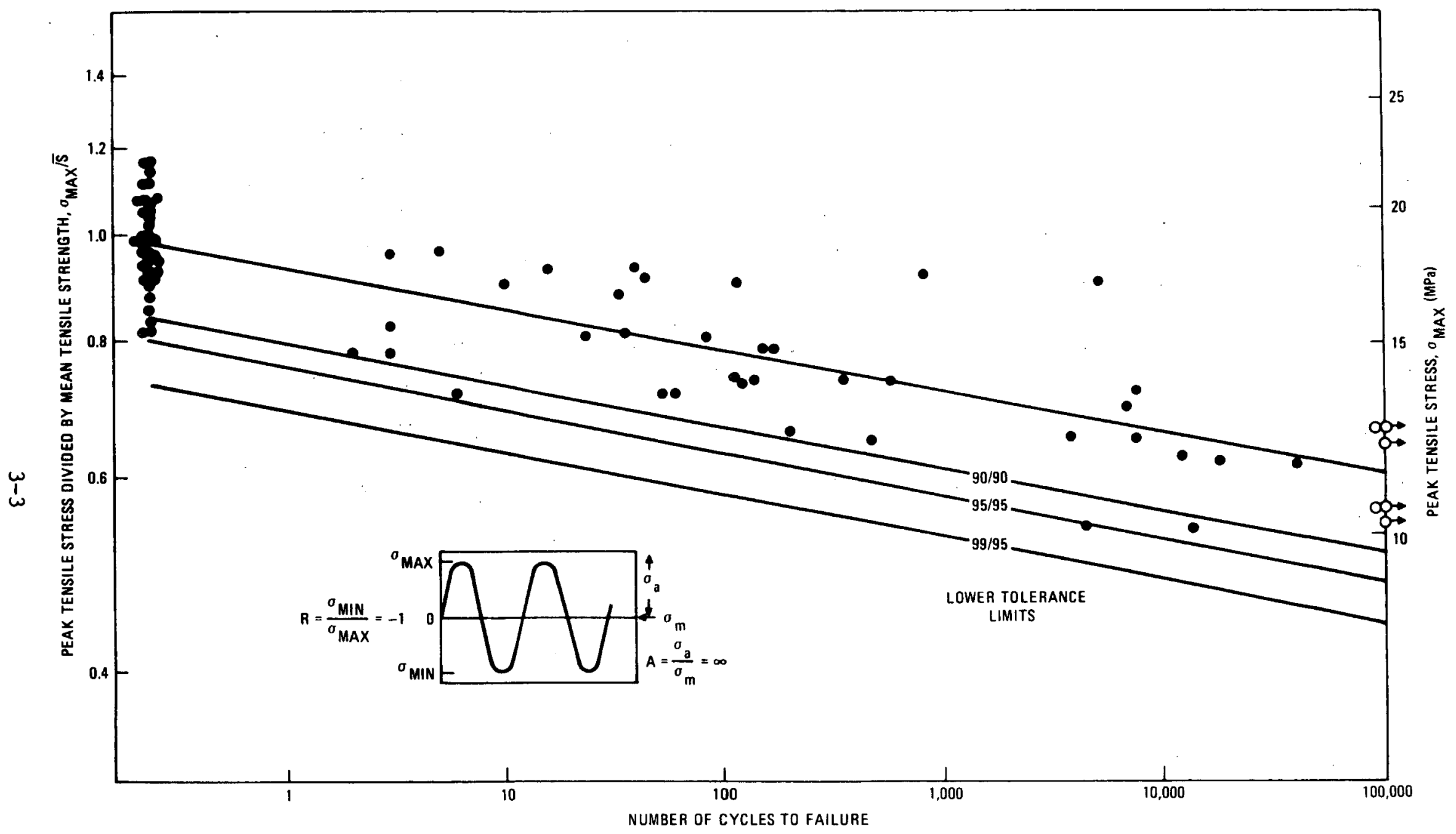

Fig. 1. Fatigue test data on H-451 graphite, axial orientation, quarter-length edge location, in air at ambient temperature. Log-log plot of normalized maximum stress versus number of cycles to failure with $\mathrm{R}=-1$. Lower $\mathrm{x} / \mathrm{y}$ tolerance limits represent the limits above which at 1 east $\mathrm{x} \%$ of all data would fall, with $y \%$ confidence. 
The curves were statistically analyzed using a model different from those reported previously. The usual practice has been to deduce the $\mathrm{N}-$ value corresponding to a particular fallure probability from the dispersion of $\log (\mathrm{N})$ values at a given stress setting, assuming a We1bu11 or a Gaussian distribution. This procedure has several disadvantages when applied to graphite; in particular, ft provides no information on low failure probabilities in the high-cycle regime. The problem is best approached by inverting the usual practice and assuming that for a constant life the fallure stresses follow a specific distribution (Ref. 5). For present purposes, the following statistical model was assumed:

$$
\log _{10}\left(\frac{\sigma_{\max }}{\overline{\mathrm{S}}}\right)=\alpha+\beta \log _{10}(\mathrm{~N})+\varepsilon,
$$

where $\sigma_{\max }$ is the peak tensile stress, $\bar{S}$ is the mean tensile strength, $\alpha$ and $\beta$ are constants, and $\varepsilon$ is a random variable distributed normally with a mean of zero and a standard deviation $s$. The data were analyzed according to the model of Eq. 1, including the tensile tests at $\mathrm{N}=0.25$ but excluding the specimens which ran out beyond $10^{5}$ cycles. The least-squares straight line through the data and the $\mathrm{x} / \mathrm{y}$ lower tolerance limits (representing the limits above which at least $x \%$ of all observations would fall, with $y \%$ confidence) were calculated for the $x / y$ combinations $90 / 90,95 / 95$ and $99 / 95$ and are included in Fig. 1. The data support the linear relationship between $\log \left(\sigma_{\max }\right)$ and $\log (\mathrm{N})$ assumed in Eq. 1. Results of the statistical analyses are summarlzed in Tables 2 and 3.

The downward slope of the S-N curves ( $\beta$ in Tables 2 and 3 ) became steeper as the stress ratio $R$ decreased (i.e., as the stress became compressive during a part of the cycle). For example, the homologous stress limit for $50 \%$ survival to $10^{5}$ cycles in axial spectmens of $\mathrm{H}-451$ graphite decreased from 0.81 at $R=0.5$ to 0.60 at $R=-1$. There was some tendency for the scatter band to increase at low values of $R$, as Indicated by an increase in $s$ (Tables 2 and 3 ). 
TABLE 2

RESULTS OF STATISTICAL ANALYSIS OF FATIGUE DATA FOR UNIRRADIATED H-451 GRAPHITE

\begin{tabular}{|c|c|c|c|c|c|c|}
\hline \multirow[b]{2}{*}{ Orientation } & \multirow{2}{*}{$\begin{array}{l}\text { Stress Ratio, R } \\
\qquad\left(\frac{\sigma_{\min }}{\sigma_{\max }}\right)\end{array}$} & \multirow{2}{*}{$\begin{array}{l}\text { Intercept of } \\
\text { Least Squares } \\
\text { Line, } \alpha(a)\end{array}$} & \multirow{2}{*}{$\begin{array}{l}\text { Slope of } \\
\text { Least Squares } \\
\text { Line, } \beta(a)\end{array}$} & \multirow{2}{*}{$\begin{array}{l}\text { Standard } \\
\text { Deviation } \\
\quad \mathrm{s}(\mathrm{a})\end{array}$} & \multicolumn{2}{|c|}{$\begin{array}{l}\text { Homologous Stress Limit }\left(\frac{\sigma_{\max }}{\overline{\bar{S}}}\right) \\
\text { for Survival to } 10^{5} \text { Cycles }(a)\end{array}$} \\
\hline & & & & & $50 \%$ Probability & $\begin{array}{l}99 / 95 \text { Lower } \\
\text { Tolerance Limit }\end{array}$ \\
\hline Axial & 0.5 & -0.023 & -0.014 & 0.042 & 0.81 & 0.60 \\
\hline Axial & 0 & -0.025 & -0.026 & 0.038 & 0.70 & 0.54 \\
\hline Axial & -0.5 & -0.019 & -0.037 & 0.052 & 0.63 & 0.44 \\
\hline Axial & -1.0 & -0.032 & -0.038 & 0.048 & 0.60 & 0.44 \\
\hline Radial & 0.5 & -0.010 & -0.004 & 0.056 & 0.93 & 0.62 \\
\hline Radia1 & 0 & -0.019 & -0.016 & 0.057 & 0.80 & 0.54 \\
\hline Radial & -0.5 & -0.018 & -0.021 & 0.059 & 0.75 & 0.50 \\
\hline Radial & -1.0 & -0.025 & -0.020 & 0.058 & 0.75 & 0.50 \\
\hline
\end{tabular}

(a) Based on the model of Eq. 1. 
TABLE 3

RESULTS OF STATISTICAL ANALYSIS OF FATIGUE DATA FOR UNIRRADIATED PGX GRAPHITE

\begin{tabular}{|c|c|c|c|c|c|c|}
\hline \multirow[b]{2}{*}{ Orientation } & \multirow{2}{*}{$\begin{array}{l}\text { Stress Ratio, R } \\
\left(\frac{\sigma_{\min }}{\sigma_{\max }}\right)\end{array}$} & \multirow{2}{*}{$\begin{array}{l}\text { Intercept of } \\
\text { Least Squares } \\
\text { Line, } \alpha(a)\end{array}$} & \multirow{2}{*}{$\begin{array}{l}\text { Slope of } \\
\text { Least Squares } \\
\text { Line, } \beta(a)\end{array}$} & \multirow{2}{*}{$\begin{array}{l}\text { Standard } \\
\text { Deviation, } \\
\quad \text { s(a) }\end{array}$} & \multicolumn{2}{|c|}{$\begin{array}{l}\text { Homologous Stress Limit }\left(\frac{\max }{\bar{S}}\right) \\
\text { for Survival to } 10^{5} \text { Cycles }(a)\end{array}$} \\
\hline & & & & & $50 \%$ Probability & $\begin{array}{l}99 / 95 \text { Lower } \\
\text { Tolerance Limit }\end{array}$ \\
\hline \multirow[t]{2}{*}{ Axial } & 0 & -0.026 & -0.021 & 0.031 & 0.74 & 0.60 \\
\hline & -1 & -0.013 & -0.034 & 0.035 & 0.66 & 0.52 \\
\hline \multirow[t]{2}{*}{ Radial } & 0 & -0.009 & -0.013 & 0.040 & 0.85 & 0.64 \\
\hline & -1 & -0.017 & -0.023 & 0.042 & 0.74 & 0.56 \\
\hline
\end{tabular}

(a) Based on the model of Eq. 1. 
For engineering design it is conventent to plot the results on a constant life fatigue diagram (Goodman diagram), which relates fatigue life to the following interdependent loading cycle parameters: maximum stress, minimum stress, stress amplitude, and mean stress. Figure 2 shows an example of a Goodman diagram relating the loading cycle parameters for $50 \%$ survival to $10^{2}, 10^{3}, 10^{4}$ and $10^{5}$ cycles in axlal specimens of $\mathrm{H}-451$ graphite. A full set of Goodman diagrams is included in the Appendix.

When normalized by dividing by the mean tensile strength, the homologous stress limits for radial specimens were somewhat greater than those for axial specimens under simflar conditions (Tables 2 and 3). Th1s was true for both H-451 graphite and PGX graphite, in spite of the fact that the former has an extruded texture and the latter has a molded texture. In most cases, the homologous stress limtts for PGX graphite were slightly higher than those for $\mathrm{H}-451$ graphite.

Under reversed stress cycling $(R=-1)$, the homologous stress limits for survival of axial specimens to $10^{5}$ cycles averaged 0.63 for $50 \%$ survival and 0.48 for $99 \%$ survival ( $99 / 95$ tolerance limt $)$. These averages agree well with Leichter and Robinson's results (Ref. 5). The homologous stress limits for radial specimens averaged a little higher $(0.74$ and 0.53 , respectively).

\subsection{IRRADIATED SPECIMENS}

Three groups of 42 specimens of $\mathrm{H}-451$ graphite were irradiated at 1173 to $1263 \mathrm{~K}$ to different neutron exposures. The 1rradiation conditions are listed in Table 4. Ten specimens out of each group were tensile-tested in the fatigue machine to establish the mean tensile strength. The values are listed in Table 4, together with the strengths of untrradiated compantons from the same log. All groups showed the expected Increase in strength after 1rradiation (Ref. 11). The remainder of the specimens in each group were used for tension-compression fatigue tests $(R=-1)$. 


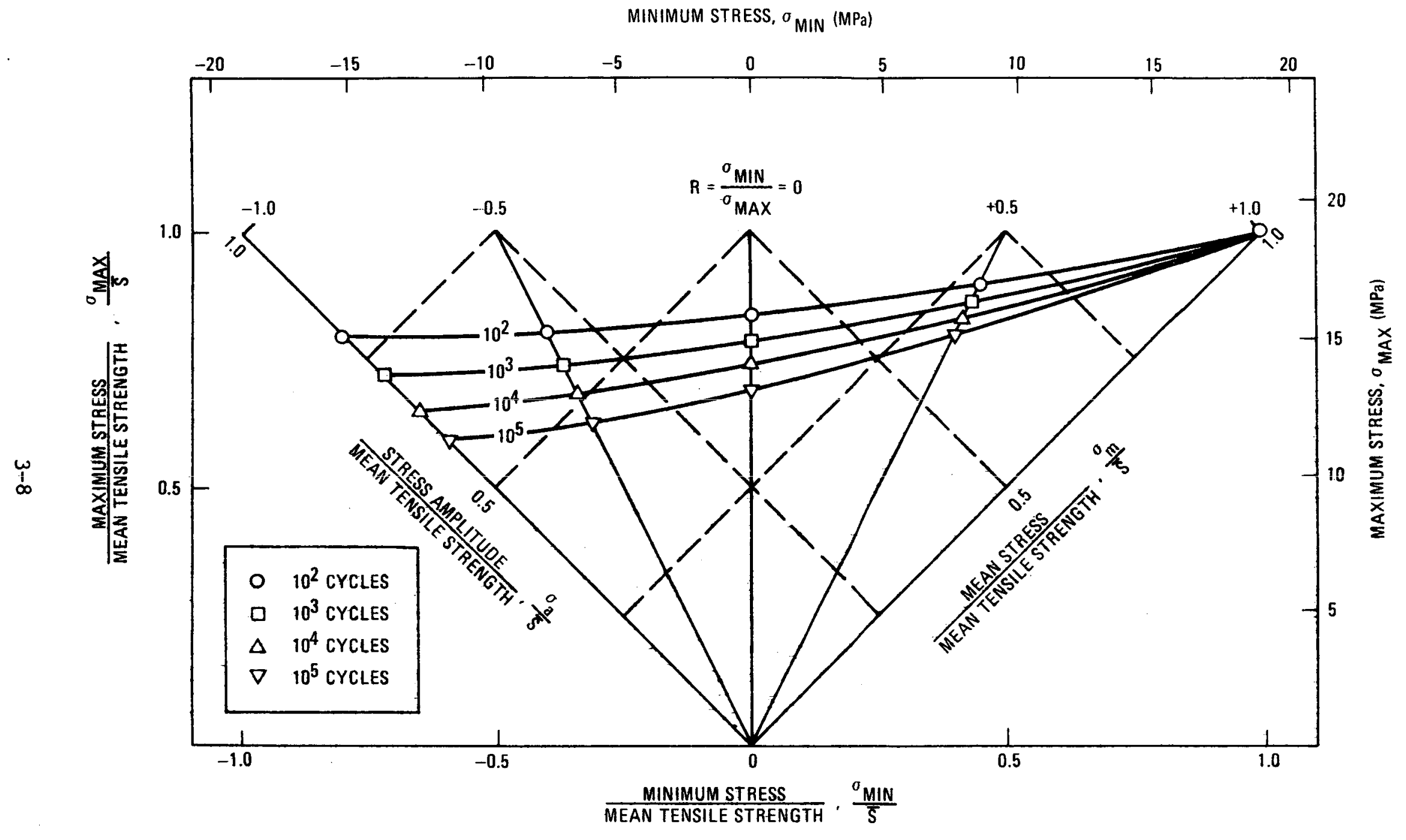

Fig. 2. Constant life fatigue diagram (Goodman diagram) for H-451 graphite, axial orientation, tested in air at ambient temperature 
TABLE 4

IRRADIATION CONDITIONS AND MEAN TENSILE STRENGTH OF IRRADIATED

H-451 GRAPHITE USED IN FATIGUE STUDY

(All Specimens Midlength-Center Location)

\begin{tabular}{|c|c|c|c|c|c|c|}
\hline \multirow[b]{2}{*}{ Orientation } & \multicolumn{2}{|c|}{ Fast Neutron Fluence $\left(10^{25} \mathrm{n} / \mathrm{m}^{2}\right)$} & \multirow[b]{2}{*}{$\frac{\text { Irradiation }}{\mathrm{K}}$} & \multirow[b]{2}{*}{${ }^{\circ} \mathrm{C} C$} & \multirow{2}{*}{$\begin{array}{c}\text { Mean Tensile Strength } \\
( \pm \text { Standard Deviation) } \\
(\text { MPa) }\end{array}$} & \multirow{2}{*}{$\begin{array}{c}\text { Mean Tensile Strength of } \\
\text { Unirradiated Companions } \\
( \pm \text { Standard Deviation) } \\
(\mathrm{MPa})\end{array}$} \\
\hline & $\begin{array}{c}\begin{array}{c}\text { Equivalent Fission } \\
\text { Fluence }\end{array} \\
\end{array}$ & $\mathrm{E}>29 \mathrm{fJ}, \mathrm{HTGR}$ & & & & \\
\hline Axial & 3.8 & 3.0 & 1173 & 900 & $14.5 \pm 2.1$ & $10.8 \pm 0.9$ \\
\hline Radial & 7.1 & 5.7 & $1223-1263$ & $950-990$ & $22.4 \pm 2.6$ & $11.5 \pm 1.7$ \\
\hline Axial & 10.6 & 8.5 & $1173-1243$ & $900-970$ & $20.2 \pm 1.9$ & $10.8 \pm 0.9$ \\
\hline
\end{tabular}


Eight specimens were cycled at each of four stress levels until they failed or reached 100,000 cycles without failure. Individual test data are given in the Appendix.

A homologous stress $\mathrm{S}-\mathrm{N}$ curve for axial specimens of $\mathrm{H}-451$ graphite irradiated to $3.8 \times 10^{25} \mathrm{n} / \mathrm{m}^{2}$ (EFFGD) at $1173 \mathrm{~K}$ is shown in Fig. 3. Comparison between Fig. 1 and Fig. 3 shows that the homologous stress limits for fatigue endurance are increased by neutron irradiation. The results of statistical analysis of the S-N curves for all the irradiated H-451 specimens are given in Table 5. The homologous stress limits for survival to $10^{5}$ cycles are substantially higher than for unirradiated H-451 tested with $R=-1$ (Table 2), at least for the axial specimens. The homologous stress $99 / 95$ lower tolerance limit is lower at higher fluences as the result of increased data scatter, but it remains above the unirradiated level. The increased scatter may be caused by slight warpage in the highly irradiated specimens, which interferes with accurate uniaxial alignment.

If the fatigue stress limits are normalized by dividing by the unirradiated tensile strength instead of the irradiated tensile strength, the limits increase by more than a factor of two during irradiation. The stress limits for $50 \%$ survival to $10^{5}$ cycles and the $99 / 95$ lower tolerance limits normalized to the unirradiated strength are plotted against neutron fluence in Fig. 4. 


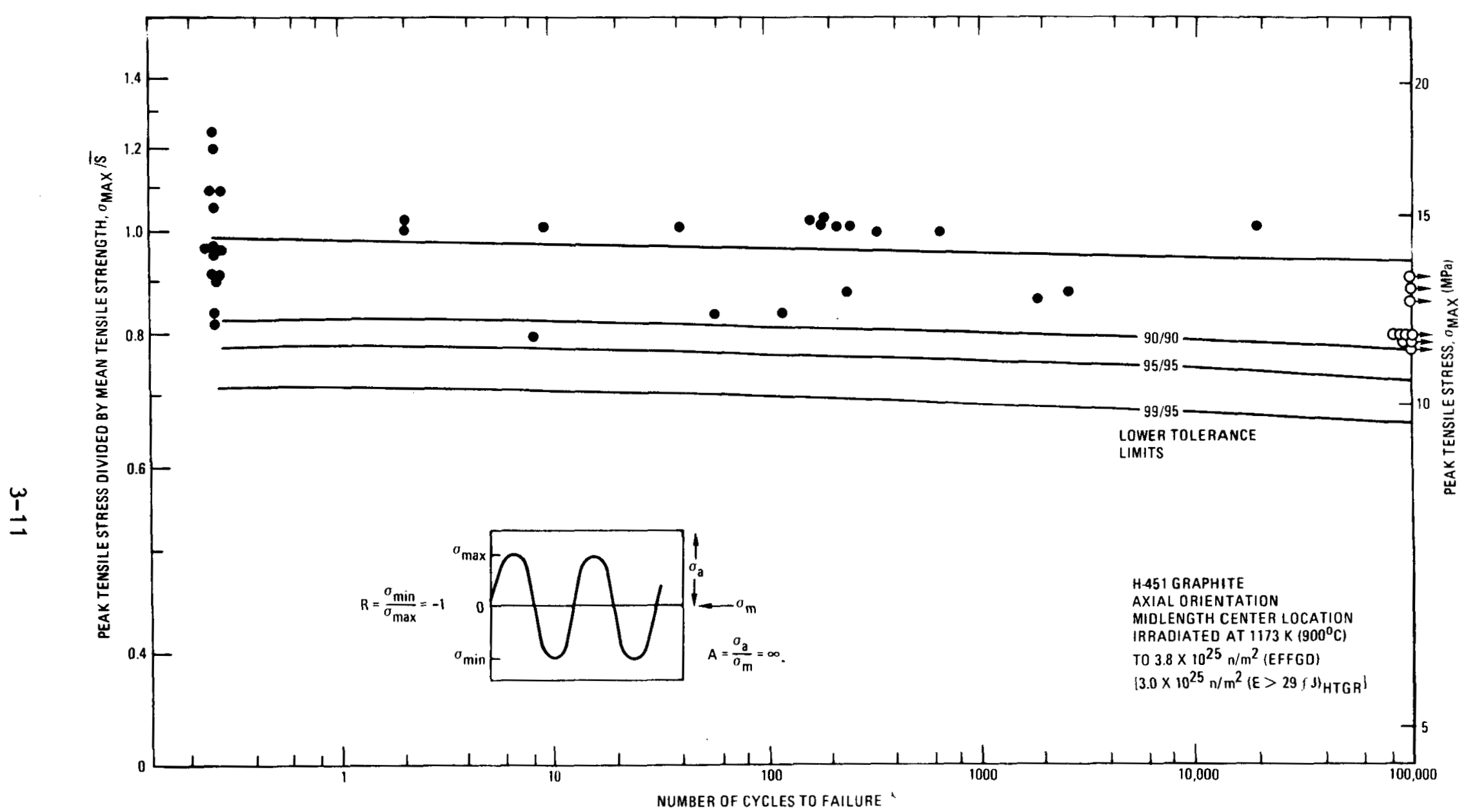

Fig. 3. Ambient temperature fatigue test data for $\mathrm{H}-451$ graphite, axial orientation, irradiated to $3.8 \times 10^{25} \mathrm{n} / \mathrm{m}^{2}$ (equivalent fission fluence) at $1173 \mathrm{~K}\left(900^{\circ} \mathrm{C}\right.$ ). Log- $10 \mathrm{~g}$ plot of normalized peak stress versus number of cycles to failure, with stress ratio, $R=-1$. Lower $x / y$ tolerance limits represent the limits above which $x \%$ of all observations would fall, with y\% confidence. Open circles represent run-outs. 
TABLE 5

RESULTS OF STATISTICAL ANALYSIS OF FATIGUE DATA FOR H-451 GRAPHITE IRRADIATED AT 1173 - $1263 \mathrm{~K}$ (Stress Ratio, $\mathrm{R}=1$ )

\begin{tabular}{|c|c|c|c|c|c|c|}
\hline \multirow[b]{2}{*}{ Orientation } & \multirow{2}{*}{$\begin{array}{l}\text { Fast Neutron } \\
\text { Fluence }\left(10^{25} \mathrm{n} / \mathrm{m}^{2}\right) \\
\text { (EFFGD) }\end{array}$} & \multirow{2}{*}{$\begin{array}{l}\text { Intercept of } \\
\text { Least Squares } \\
\text { Line, } \alpha(a)\end{array}$} & \multirow{2}{*}{$\begin{array}{c}\text { Slope of } \\
\text { Least Squares } \\
\text { Line, } \beta(a)\end{array}$} & \multirow{2}{*}{$\begin{array}{c}\text { Standard } \\
\text { Deviation, } \\
\text { s }(a)\end{array}$} & \multicolumn{2}{|c|}{$\begin{array}{l}\text { Homologous Stress Limit }\left(\frac{\sigma_{\max }}{\bar{\delta}}\right) \\
\text { for Survival to } 10^{5} \text { Cycles }(a)\end{array}$} \\
\hline & & & & & $50 \%$ Probability & $\begin{array}{l}99 / 95 \text { Lower } \\
\text { Tolerance Limit }\end{array}$ \\
\hline Axia1 & 3.8 & -0.010 & -0.004 & 0.046 & 0.93 & 0.66 \\
\hline Axial & 10.6 & -0.033 & -0.012 & 0.056 & 0.81 & 0.51 \\
\hline
\end{tabular}

${ }^{(a)}$ Based on the model of Eq. 1 . 


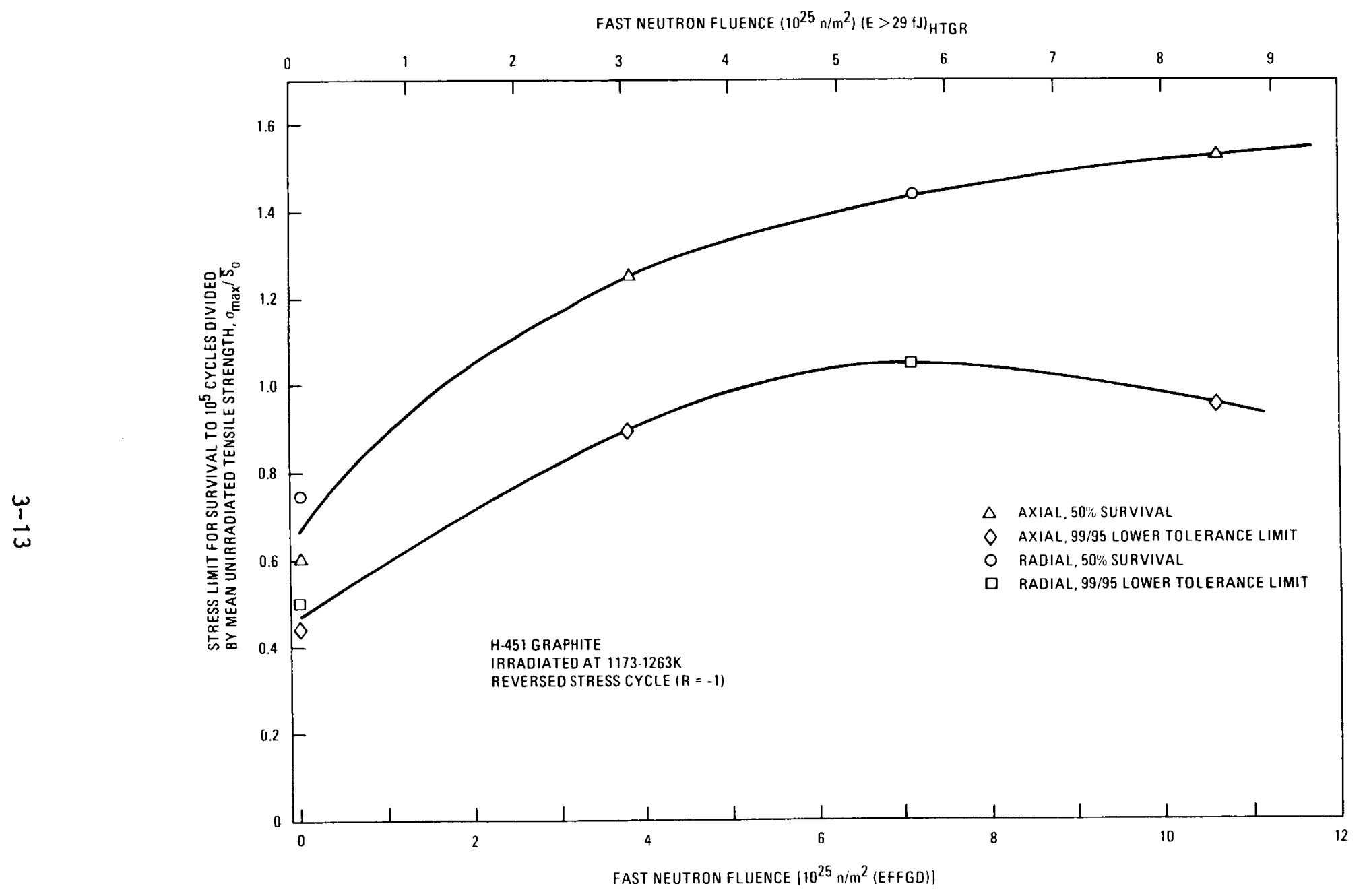

Fig. 4. Fatigue stress limits for survival of H-451 graphite to $10^{5}$ cycles, normalized to the unirradiated tensile strength, versus the fast neutron fluence at an irradiation temperature of 1173 to $1263 \mathrm{~K}\left(900^{\circ}\right.$ to $\left.990^{\circ} \mathrm{C}\right)$ 


\section{DISCUSSION}

The general form of the $\mathrm{S}-\mathrm{N}$ curves for graphite (Fig. 1) resembles that of many metals. In addition, the dependence of the fatigue stress limits on the stress ratio $R$ (Fig. 2) is similar to metallic behavior, with more fatigue damage occurring during a tension-compression cycle $(R=-1)$ than during a tensile stress cycle $(R \geq 0)$. Marshall and Priddle (Ref. 7) measured the fatigue crack growth rate, $\frac{\mathrm{da}}{\mathrm{dN}}$, in isotropic graphite as a function of the applied stress intensity range, $\Delta \mathrm{K}$, and found the following relationship:

$$
\frac{\mathrm{da}}{\mathrm{dN}} \propto\left(\Delta \mathrm{K}-\Delta \mathrm{K}_{\mathrm{o}}\right)^{4},
$$

where $\Delta \mathrm{K}_{0}$ is the threshold stress intensity range for crack propagation. This relationship is similar to that often found with metals. It seems reasonable to conclude that cyclic fatigue in graphite, as in metals, takes place by limited plastic flow at the tip of the advancing fatigue crack. This contrasts with the behavior of most ceramic materials and of 1sotropic pyrolytic carbons, whose dislocations are almost immobile (Ref. 12) and which are resistant to cyclic fatigue (Ref. 13).

Neutron irradiation reduces the mobility of basal dislocations in graphite. The resulting reduction in plasticity at the tip of a fatigue crack may slow crack growth and account for the increased fatigue resistance of irradiated materials found in this study.

Brocklehurst (Ref. 8) has recently used Marshall and Priddle's crack propagation relationship (Eq. 2) to predict the effect of the stress cycle on fatigue 1ife. With the crack growth parameters measured by Marshall and Priddle, the model predicts no fatigue effects for $R \geq 0.5$ and $a$ 
homologous stress 1imit of about 0.6 for $50 \%$ specimen survival to $10^{5}$ cycles when $R=0$. Fatigue effects for negative $R$-values are not directly predicted, because Marshall and Priddle's data did not include compressive cycling. However, Brocklehurst estimated a homologous stress limit of about 0.5 at $10^{5}$ cycles at $R=-1$, using the assumption that compressive stresses are $20 \%$ as effective as tensile stresses in propagating fatigue cracks. The homologous stress limits found in this study (Tables 2 and 3 ) are lower than these predictions at $R=0.5$ and higher than those predicted at $R=0$ and $R=-1$. The discrepancy suggests that the crack growth parameters for $\mathrm{H}-451$ and $\mathrm{PGX}$ graphites differ from those for the materials used by Marshall and Priddle. The differences in fatigue properties between the two grades, as well as between axial and radial orientations, suggest that crack growth parameters depend on the graphite microstructure. 


\section{SUMMARY AND CONCLUSIONS}

More than 800 uniaxial cyclic fatigue tests at ambient temperature were made on near-isotropic graphites $\mathrm{H}-451$ and PGX. Tests were run at $7 \mathrm{~Hz}$ to $10^{5}$ cycles or unt1l the specimen fractured. The stress ratio, $\mathrm{R}$ (minimum stress during a cycle divided by maximum stress) ranged from -1 to +0.5. Specimens of H-451 graphite irradiated at 1173 to $1253 \mathrm{~K}$ (900 to $990^{\circ} \mathrm{C}$ ) to neutron fluences up to $10^{26} \mathrm{n} / \mathrm{m}^{2}$ (equivalent fission fluence) were included. The following observations were made:

1. The graphites showed cyclic fatigue life curves ( $\mathrm{S}-\mathrm{N}$ curves) generally resembling those of metals, but with more scatter (Fig. 1).

2. For reversed stress cycling $(R=-1)$, the homologous stress limits (maximum applied fatigue stress divided by the tensile strength) for $50 \%$ specimen survival to $10^{5}$ cycles averaged 0.63 in the axial direction and 0.74 in the radial direction. Corresponding homologous stress limits for $99 \%$ specimen survival (99/95 tolerance $11 \mathrm{mits}$ ) were 0.48 and 0.53 (Tables 2 and 3 ).

3. The fatigue life and the homologous stress limits increased as $\mathrm{R}$ increased. The results can be plotted on a Goodman diagram (Fig. 2).

4. Neutron irradiation increases the homologous stress limits for fatigue endurance. If the unirradiated tensile strength is used as the basis for normalization, the fatigue stress limits are about doubled by Irradiation. 
5. Fatigue in graphite probably takes place by limited plastic flow at the tip of the advancing fatigue crack.

6. Fatigue behavior varies with both orfentation and the grade of graphite. Fatigue life predictions based on crack growth relationships for other graphites are therefore subject to error. 


\section{ACKNOWLEDGEMENTS}

This work was supported by the United States Energy Research and Development Administration (now the Department of Energy) under contract EY-76-C-03-0167. The assistance for experiments of M. G. Dunlap, C. H. Richards, and J. R. Whaley is gratefully acknowledged. 


\section{REFERENCES}

1. Green, L., "The Behavior of Graphite Under Alternating Stress," J. App1. Mech., 18 (1951), p. 345.

2. Dally, J. W., and L. N. Hjelm, "Proof-Testing Graphite and Its Design Implications," J. Am. Ceram. Soc., 48 (1965), p. 338.

3. Barabanov, V. N., et al., "Some Special Features of the Method of Testing Graphite for Fatigue in Alternate-Reversing Bending, and the Results Obtained," Ind. Lab. (USSR), 32 (1966), p. 567.

4. Bazaj, D. K., and E. E. Cox, "Stress-Concentration Factors and NotchSensitivity of Graphite," Carbon, 7, (1969), p. 689.

5. Leichter, H. L. and E. Robinson, "Fatigue Behavior of a High Density Graphite and General Design Correlation," J. Am. Ceram. Soc., 53 (1970), p. 197.

6. Wilkins, B. J. S., "Probability of Failure of Brittle Materials Subjected to Dynamic or Static Fatigue," J. Materials, 7 (1972), p. 251.

7. Marsha11, P., and E. K. Priddle, "Room Temperature Fatigue Crack Propagation in Reactor Graphites," Carbon, 11 (1973), p. 541.

8. Brocklehurst, J. E., "Fracture In Polycrystalline Graphite," Chem. Phys. Carbons, 13 (1977), p. 145.

9. Bullock, R. E., "Fatigue Behavior of ATJ Graphite," J. Materials Science, 12 (1977), p. 1215.

10. ASTM Standard E525-74, "Standard Recommended Practice for Reporting Dosimetry Results on Nuclear Graphite," Annual Book of ASTM Standards, 45 (1976), p. 951.

11. Price, R. J., "Tensile Propertles of Neutron-Irradiated Graphites," in Extended Abstracts of the Thirteenth Biennial Conference on Carbon (American Carbon Society, 1977), p. 242. 
12. Tsuzuku, T., "Mechanical Energy Losses Due to Motion of Dislocations in Graphite and Carbons," Carbon, 1 (1963), p. 25.

13. Schoen, F. J., "On the Fatigue Behavior of Pyrolytic Carbon," Carbon, 11 (1973), p. 413. 
APPENDIX

SAMPLING PLAN AND TEST DATA

A-1 
APPENDIX

SAMPLING PLAN AND TEST DATA

\section{A. 1. SAMPLING PLAN}

The specimens of unirradiated $\mathrm{H}-451$ graphite were taken from $\log 5651-$ 90 (Great Lakes Carbon Company Lot No. 408, piece No. 48), slab 5B. The location of slab 5B in the parent $\log$ is shown in Fig. A-1. The positions of individual specimens and their reference numbers are shown in Fig. A-2. Irradiated specimens of H-451 graphite were taken from the midlength-center zone of log 5651-28 (Great Lakes Carbon Company Lot No. 266, piece No. 18).

Specimens of PGX graphite were taken from a slab from log 6484-74 (Union Carbide Corporation $\log$ No. 3C5-4). The location of the slab in the parent $\log$ and the location of the test specimens in the slab are shown in Figs. $A-3$ and $A-4$, respectively.

\section{A. 2. TEST DATA}

Individual test data are 1isted in Tables A-1 through A-22. Tables A-1 through A-10 record data on unirradiated $\mathrm{H}-451$ graphite, Tables A-11 through A-16 record data on unirradiated PGX graphite, and Tables A-17 through A-22 record data on irradiated $\mathrm{H}-451$. In each case the results of control tensile tests precede the tabulated fatigue data.

A full set of S-N curves appears in Figs. A-5 through A-19. The order of presentation is the same as for the tabulated data.

Figures A-20 through A-23 are constant life fatigue diagrams (Goodman diagrams) showing the homologous stress amplitude and mean stress for survival to $10^{2}, 10^{3}, 10^{4}$, or $10^{5}$ cycles for a $50 \%$ survival probability. 


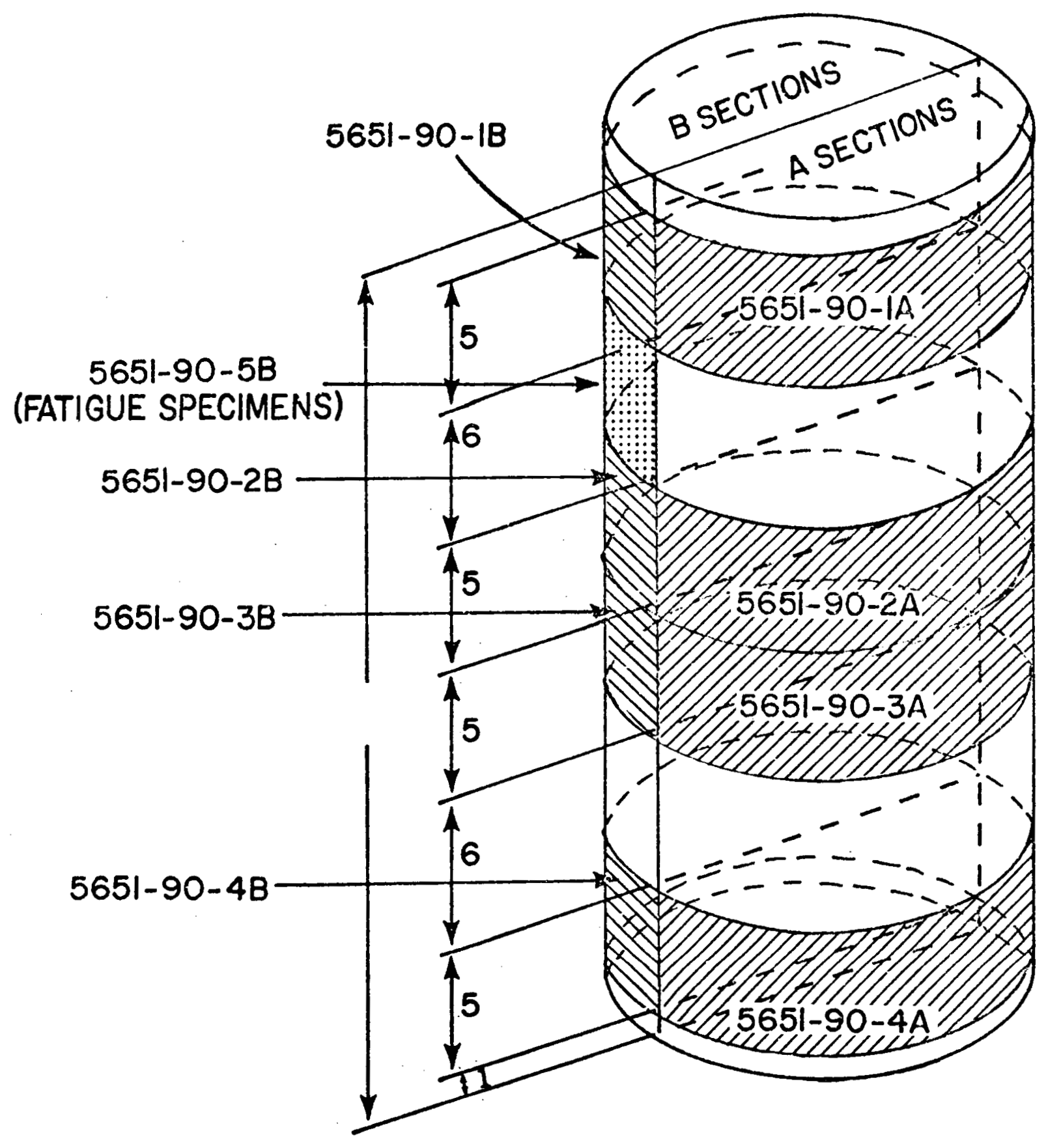

Fig. A-1. S1ab diagram for H-451 graphite 


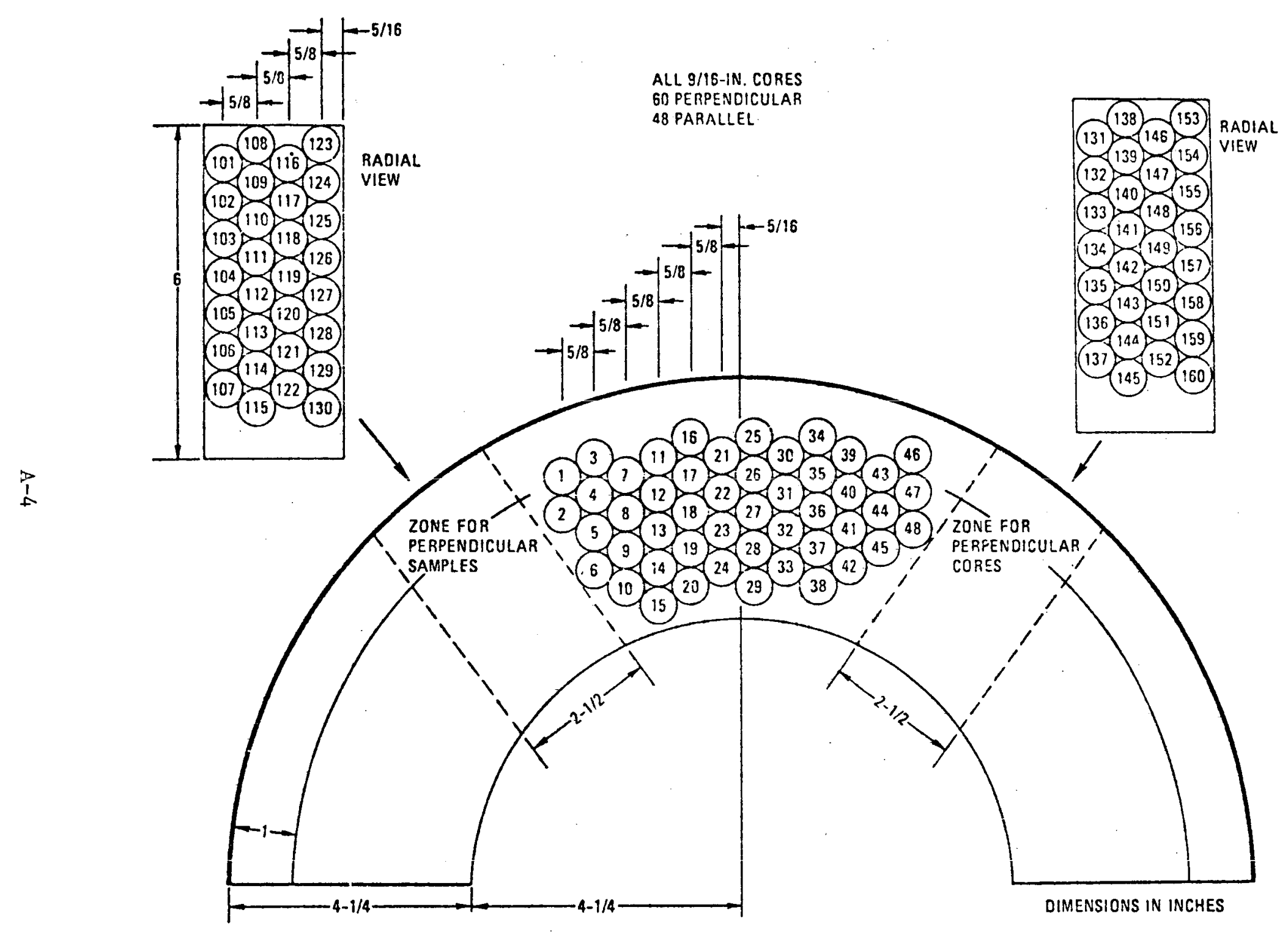

Fig. A-2. Coring plan for $\mathrm{H}-451$ graphite 

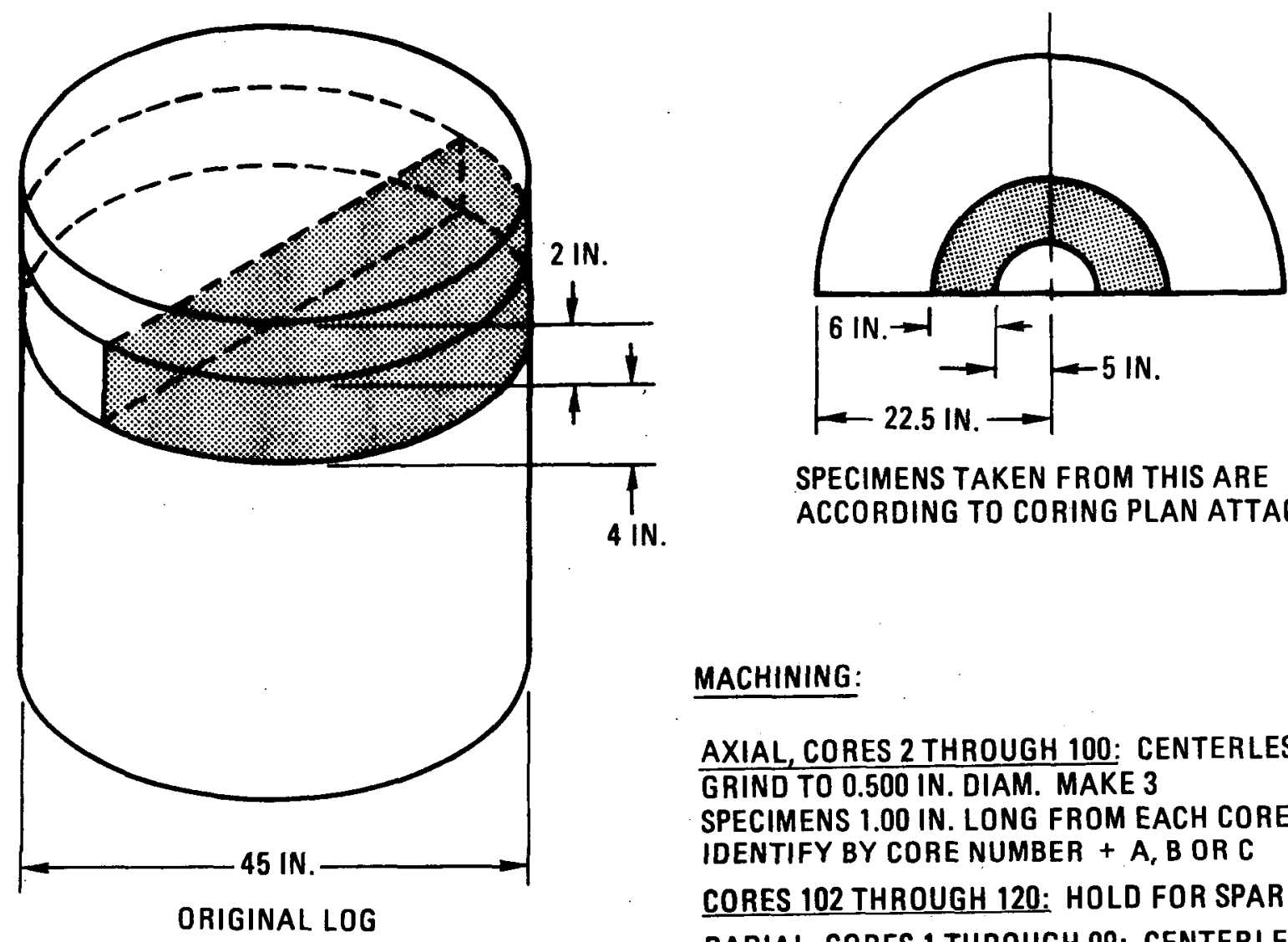

SPECIMENS TAKEN FROM THIS ARE ACCORDING TO CORING PLAN ATTACHED

\section{MACHINING:}

AXIAL, CORES 2 THROUGH 100: CENTERLESS GRIND TO 0.500 IN. DIAM. MAKE 3 SPECIMENS 1.00 IN. LONG FROM EACH COREIDENTIFY BY CORE NUMBER + A, B OR C CORES 102 THROUGH 120: HOLD FOR SPARES RADIAL, CORES 1 THROUGH 99: CENTERLESS GRIND TO 0.500 IN. DIAM. MAKE 4 SPECIMENS 1.00 IN. LONG FROM EACH CORE. IDENTIFY BY CORE NUMBER + A, B, C OR D.

CORES 81 THROUGH 99: HOLD FOR SPARES

Fig. A-3. Slab diagram for PGX graphite 
FATIGUE SPECIMENS $0^{\circ}$

SLAB $6 A X \quad 270^{\circ}$ to $0^{\circ}$

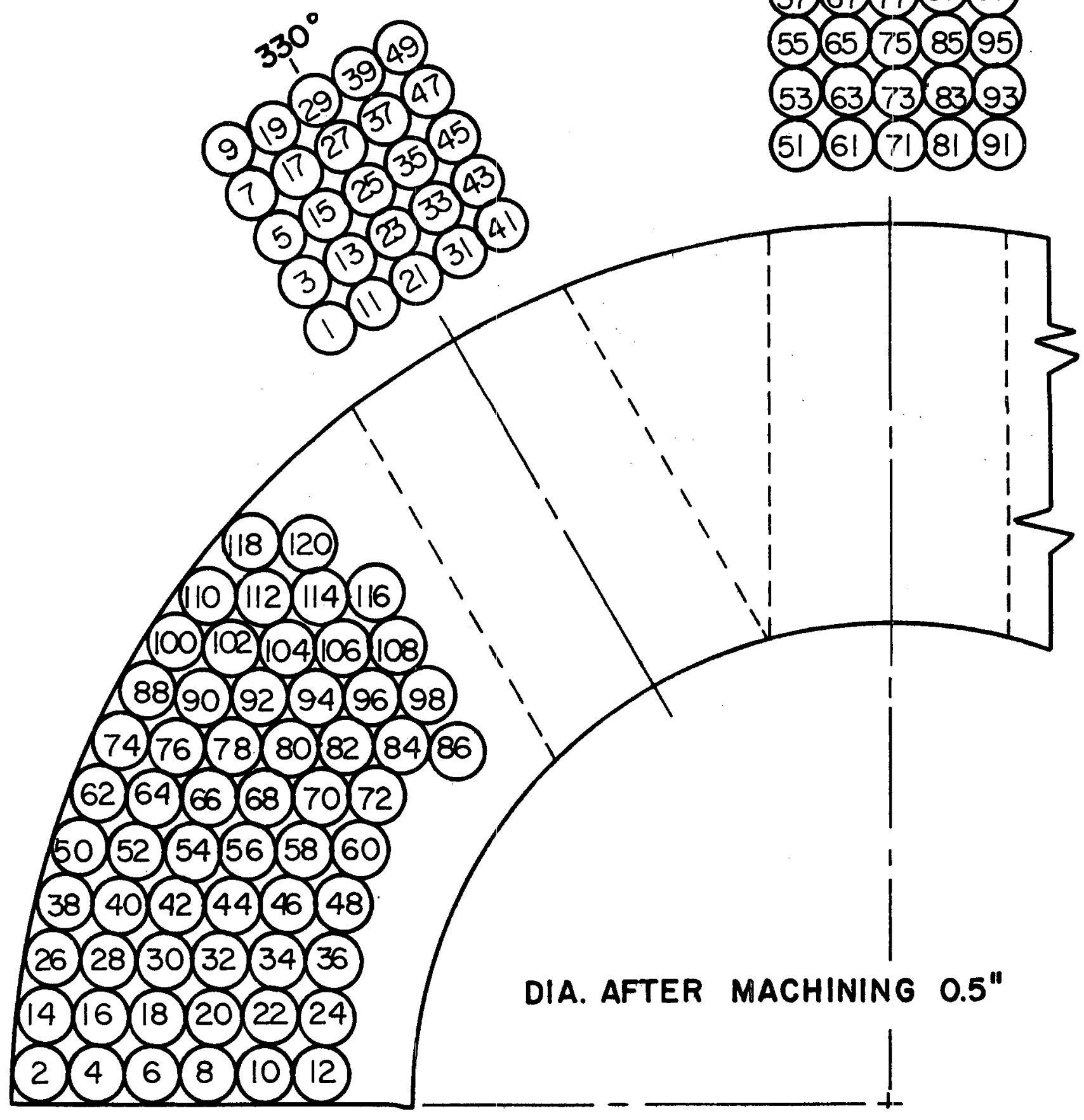

Fig. A-4. Coring plan for PGX graphite 
TABLE $A-1$

FATIGUE TESTS ON H-45\$ GRAPHITE

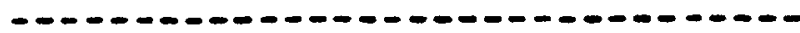

$\begin{array}{ll}\text { LOT NO: } 408 & \text { LOGNO: } 565:-90 \\ \text { ORIENTATION: AXIAL } & \text { LOCATION: OUARTER-LENGTH EDGE }\end{array}$

CONTROL TENSILE TESTS

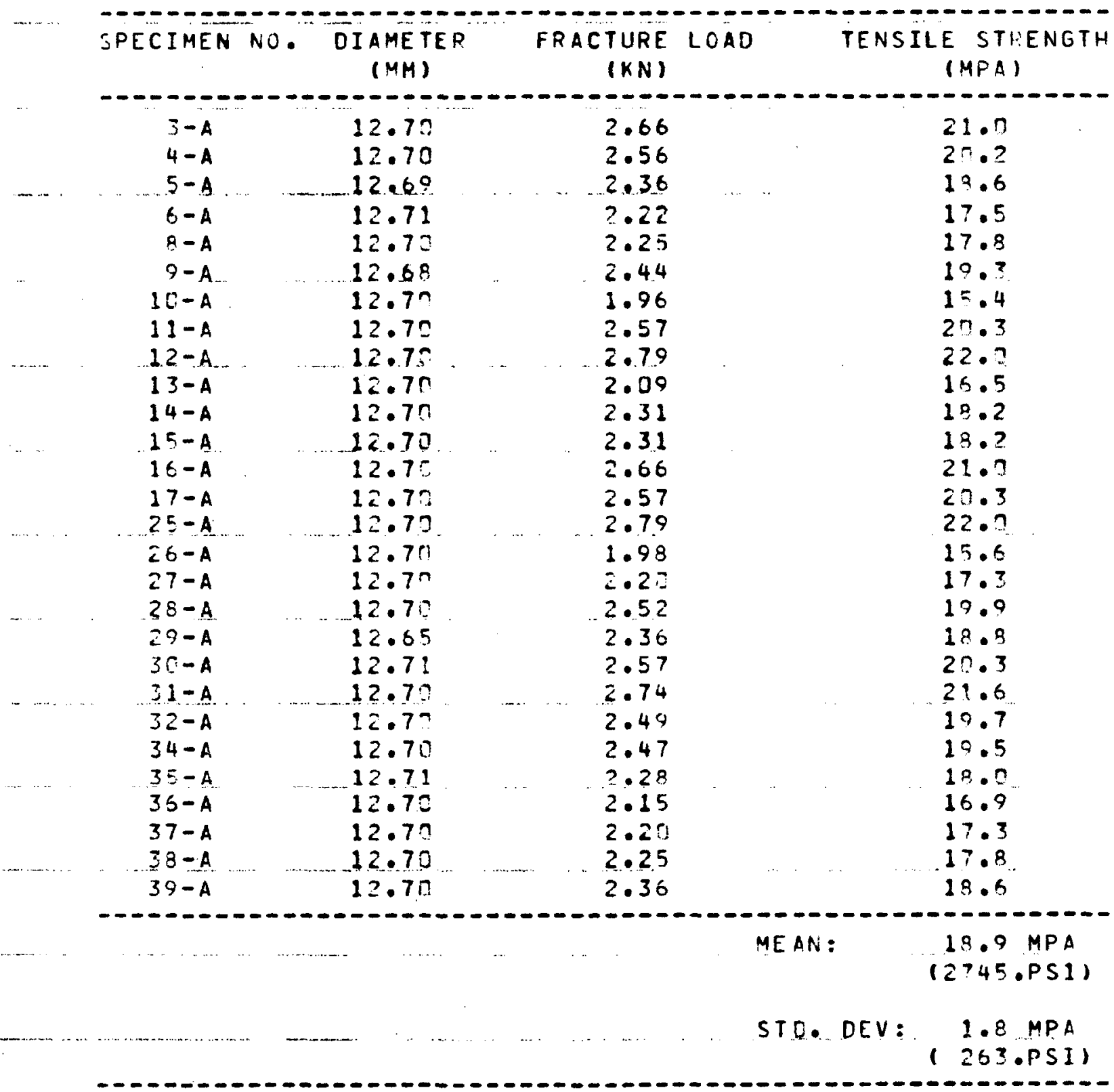


TABLE A-2

FATIGUE TESTS CN H-451 GRAPHITE

LOT NO: 478

ODIENTATION: AXIAL LOCATION: CUARTER-LENGTH EDGE

STRESS RATIO, R (MIN. STRESS, MAX. STRESS): -1.0

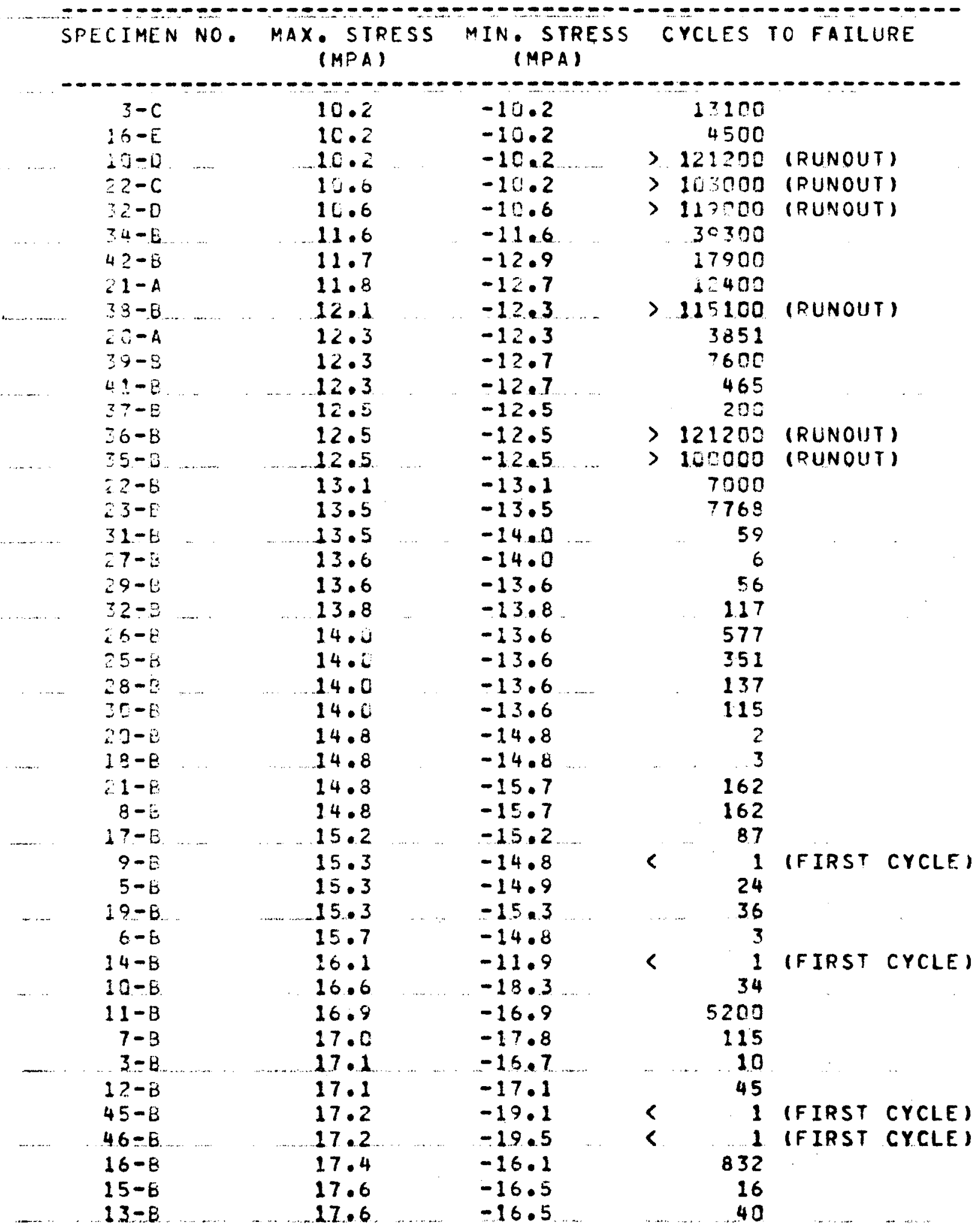


TABLE A-2 (Continued)

\begin{tabular}{llllll}
$47-6$ & 17.8 & -18.6 & $<$ & 1 (FIRST CYCLE) \\
$48-B$ & 18.6 & -19.0 & $<$ & 1 (FIRST CYCLF) \\
$18-A$ & 19.0 & -19.0 & $<$ & 1 (FIRST CYCLE) \\
$19-A$ & 19.1 & -19.1 & $<$ & 1 (FIRST CYCLE) \\
$43-8$ & 19.7 & -19.7 & & 5 & \\
$44-B$ & 19.7 & -19.9 & & 3 & \\
\hline
\end{tabular}


TABLE A-3

FATIGUE TESTS ON H-45I GRAPHITE

- - - - - - - - - - - - - - - - - - - - - - -

\section{LOT NO: 408}

ORIENTATION: $A X I A L$
LOG NO: 5651-9C

LOCATION: QUARTER-LENGTH EDGE

STRESS RATIO, R IMIN. STRESS, MAX. STRESS): -.5

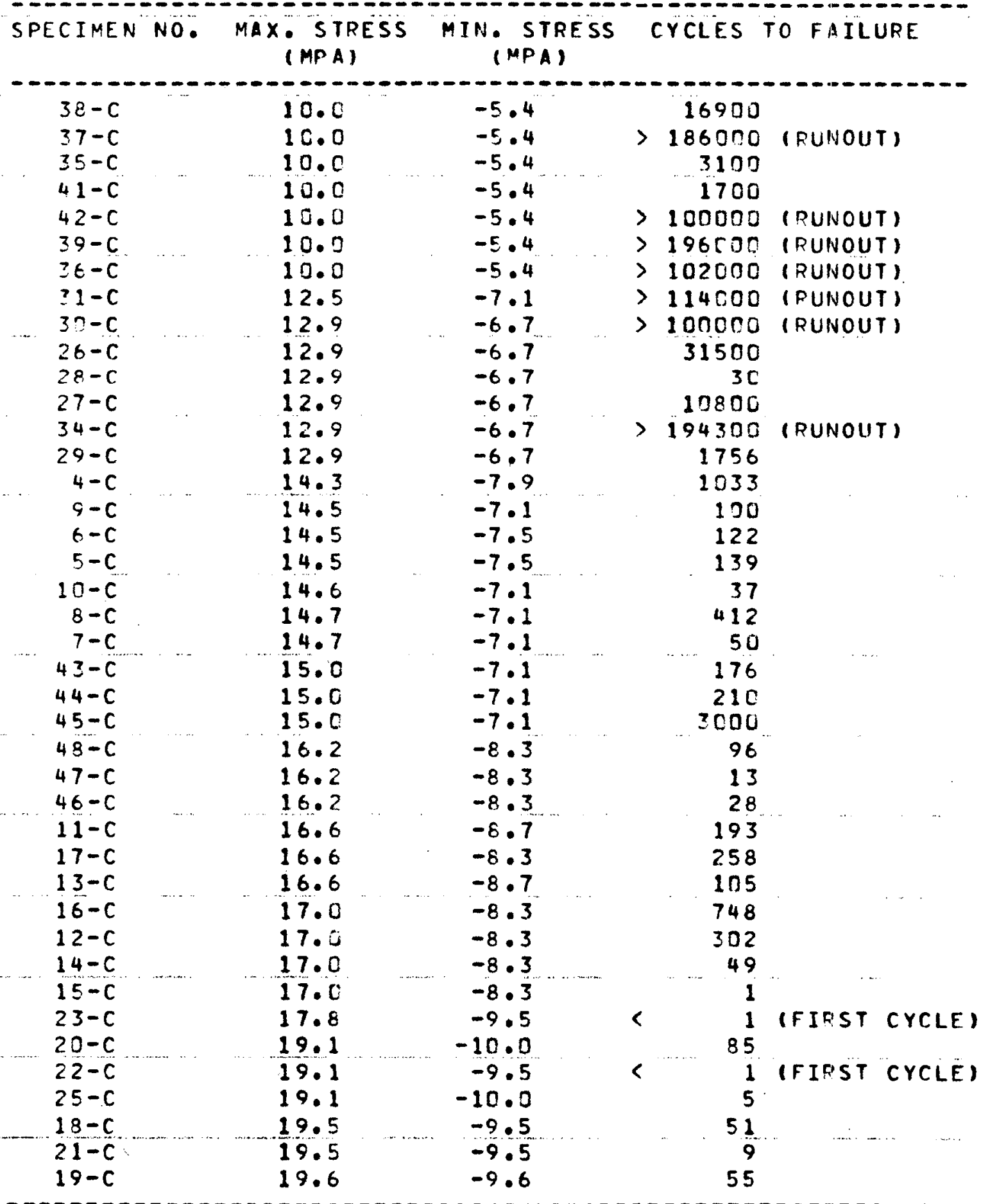


TABLE A-4

FATIGUE TESTS ON H-451 GRAPHITE

LOT NO: 408

ORIENTATION: AXIAL
LOG NO: $5651-90$

LOCATION: QUARTER-LFNGTH EDGE

STRESS RATIO, R (MIN. STRESS, MAX. STRESS): . O

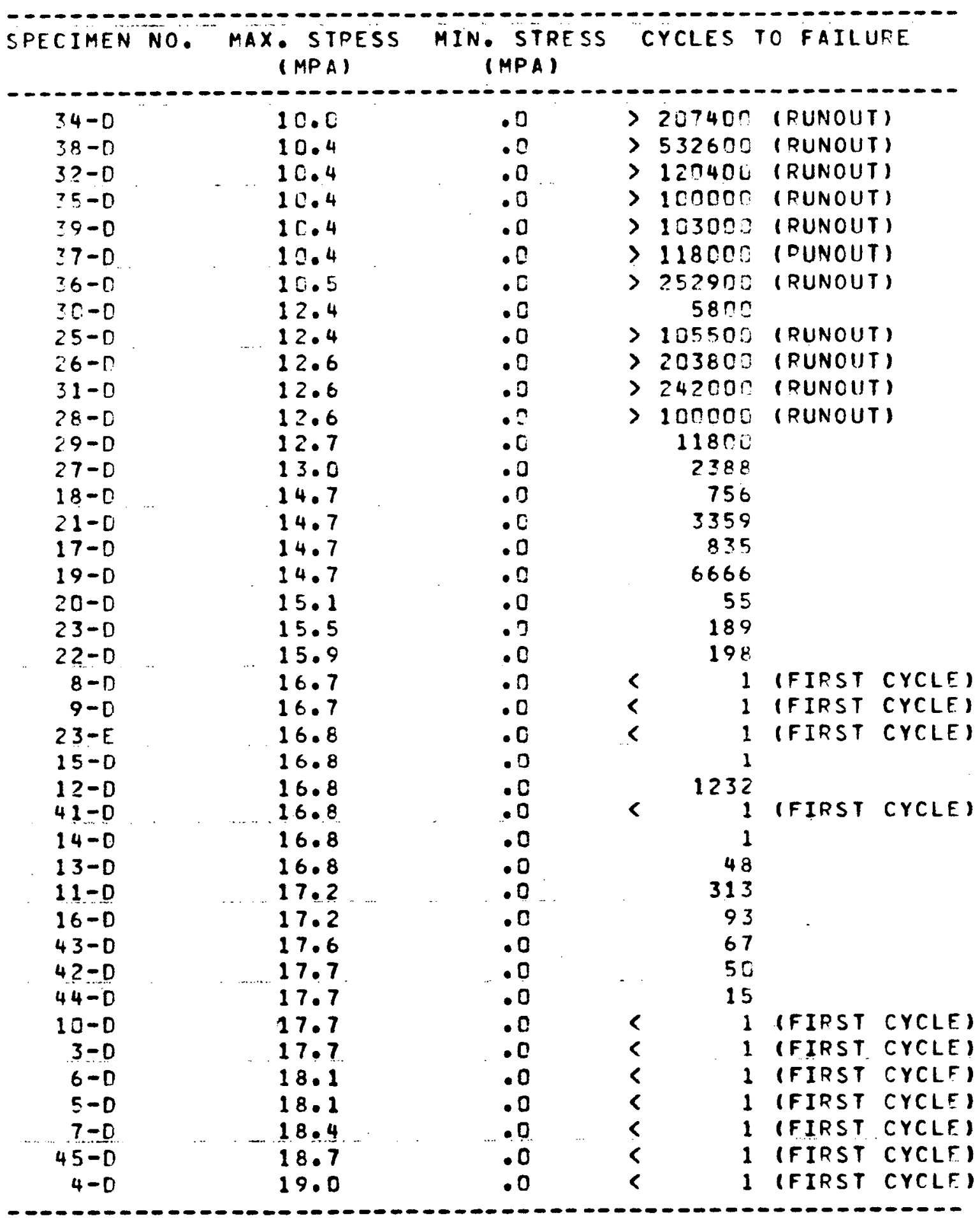


TABLE A-5

FATIGUE TESTS ON H-451 GRAPHITE.

LOT NO: 408

ORIENTATION: AXIAL
LOG NO: $5651-90$

LOCATION: QUARTFR-LFNGTH FOGE

STRESS RATIO, R IMIN. STRESS/ MAX. STRESSI: . 5

\begin{tabular}{|c|c|c|c|c|c|c|}
\hline SPECIMEN NO. & $\begin{array}{c}\text { MAX - STPESS } \\
\text { (MPA) }\end{array}$ & $\begin{array}{l}\text { MIN. STRESS } \\
\text { (MPA) }\end{array}$ & & EYCLES & TO FAILL & URE \\
\hline $4-E$ & 10.0 & $5 . c$ & $>$ & 139800 & I RUNOUI & \\
\hline $\begin{aligned} & 5-E \\
& ?-F\end{aligned}$ & 10.0 & 5.0 & $>$ & $\begin{array}{l}293300 \\
10 n \pi 00\end{array}$ & (PUNOUT & \\
\hline $34-E$ & 14.1 & 7.1 & $>$ & 119300 & (RUNOU & \\
\hline $3 E-E$ & 14.1 & 7.1 & $>$ & 101300 & IPUNOU & \\
\hline $2 \varepsilon-E$ & 14.1 & 7.1 & $>$ & 103200 & (RUNOU & \\
\hline $46-C$ & 14.1 & 7.1 & $>$ & 220200 & (RUNOU) & \\
\hline $35-E$ & 14.1 & $7 \cdot 1$ & $>$ & 305300 & I RUNOU & \\
\hline $48-C$ & 14.1 & $7 \cdot 1$ & $>$ & 126300 & (RUNOU & \\
\hline $3 t-E$ & 14.1 & $7 \cdot 1$ & $>$ & 109200 & (PUNOU & \\
\hline $\begin{array}{l}47-C \\
29-E\end{array}$ & $\begin{array}{l}14.1 \\
14.3\end{array}$ & $\begin{array}{l}7.1 \\
7.1\end{array}$ & $>$ & $\begin{array}{r}104100 \\
382\end{array}$ & EFUNOU & \\
\hline $43-A$ & 14.9 & 7.5 & $>$ & $1044 ? 0$ & IRUNOU & \\
\hline $15-E$ & $15 . \bar{C}$ & $8 \cdot 3$ & $<$ & 1 & IFIRST & CYCLE) \\
\hline $45-A$ & 15.0 & $7 \cdot 5$ & & 725 & & \\
\hline $4 E-A$ & 15.0 & $7 \cdot 5$ & & 4 & & \\
\hline $47-A$ & 15.0 & $7 \cdot 5$ & & 2530 & & \\
\hline $42-A$ & 15.0 & 7.5 & $>$ & 100000 & IRUNOU & \\
\hline $48-A$ & 15.0 & $7 \cdot 5$ & & 1759 & & \\
\hline $44-A$ & 15.0 & 7.5 & & 455 & & \\
\hline $46-E$ & 15.8 & 8.7 & $<$ & 1 & IFIRST & CYCLFI \\
\hline $22-E$ & 16.6 & 8.3 & & 56 & & \\
\hline $12-E$ & 16.6 & 8.3 & $>$ & 248800 & (RUNOUT & \\
\hline $27-E$ & 16.6 & $8 \cdot 3$ & & 4844 & & \\
\hline $23-E$ & 16.6 & $8 \cdot 3$ & & 900 & & \\
\hline $26-E$ & 16.6 & 8.3 & & 621 & & \\
\hline $14-E$ & 16.6 & $8 \cdot 3$ & & 380 & & \\
\hline $44-E$ & 16.8 & 8.7 & $<$ & 1 & IFIRST & CYCLFI \\
\hline $41-E$ & 17.1 & 9.6 & $<$ & 1 & IFIRST & CYCLE) \\
\hline $45-F$ & 17.1 & 8.7 & $<$ & 1 & IFIRST & CYCLEI \\
\hline $37-E$ & 17.2 & 9.6 & $<$ & 1 & IF IRST & CYCLEI \\
\hline $6-E$ & 17.4 & 9.5 & $<$ & 1 & IFIRST & CYCLFI \\
\hline $43-E$ & 17.5 & 8.7 & & 39 & & \\
\hline $42-E$ & 17.5 & 8.7 & & 464 & & \\
\hline $9-E$ & 17.5 & 9.6 & $<$ & 1 & IFIRST & (YCLE) \\
\hline $47-E$. & 17.5 & 8.7 & & 423 & & \\
\hline $38-E$ & 17.5 & 9.6 & $<$ & 1 & (FIRST & (YCLE) \\
\hline $48-E$ & 17.5 & 8.7 & & 3 & & \\
\hline $11-E$ & 18.7 & 9.1 & & 1367 & & \\
\hline $8-E$ & 19.1 & 9.5 & & 94 & & \\
\hline 7-E & 19.1 & 9.6 & & 175 & & \\
\hline
\end{tabular}


TABLE A-6

FATIGUE TESTS ON H-45! GRAPHITE

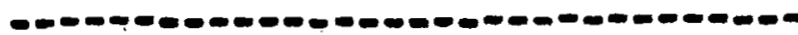
LOT NOI 408
L.OG NO: 565l-9n
ORIENTATIONI RADIAL
LUCATIONI QUARTER-LENGTH EOGE

CONTROL TENSILF. TESTS

\begin{tabular}{|c|c|c|c|c|}
\hline SPECIMEN NO. & $\begin{array}{l}\text { DENSITY } \\
\text { (MG/M\$3) }\end{array}$ & $\begin{array}{l}\text { UIA. } \\
\text { (MM) }\end{array}$ & $\begin{array}{l}\text { FRACTURE } \\
\text { LOAD (KN) }\end{array}$ & $\begin{array}{c}\text { TENSILE STRENGTH } \\
\text { (MPA) }\end{array}$ \\
\hline $\begin{array}{l}101 A \\
103 A \\
105 A \\
107 A \\
109 A \\
111 A \\
113 A \\
115 A \\
117 A \\
119 A \\
121 A \\
123 A \\
125 A \\
127 A \\
129 A \\
131 A \\
133 A \\
135 A \\
137 A \\
139 A \\
141 A \\
143 A \\
145 A \\
147 A \\
149 A \\
153 A \\
155 A \\
157 A \\
159 A\end{array}$ & $\begin{array}{l}1.742 \\
1.743 \\
1.740 \\
1.749 \\
1.744 \\
1.746 \\
1.746 \\
1.741 \\
1.752 \\
1.744 \\
1.741 \\
1.753 \\
1.744 \\
1.747 \\
1.747 \\
1.736 \\
1.740 \\
1.738 \\
1.736 \\
1.739 \\
1.734 \\
1.738 \\
1.736 \\
1.739 \\
1.732 \\
1.736 \\
1.733 \\
1.789 \\
1.730\end{array}$ & $\begin{array}{l}12.70 \\
12.70 \\
12.70 \\
12.70 \\
12.70 \\
12.70 \\
12.70 \\
12.70 \\
12.70 \\
12.70 \\
12.70 \\
12.71 \\
12.70 \\
12.69 \\
12.70 \\
12.63 \\
12.71 \\
12.70 \\
12.70 \\
12.65 \\
12.71 \\
12.70 \\
12.70 \\
12.70 \\
12.70 \\
12.71 \\
12.71 \\
12.70 \\
12.70\end{array}$ & $\begin{array}{l}1.51 \\
1.88 \\
1.63 \\
1.58 \\
1.56 \\
1.50 \\
1.59 \\
1.55 \\
1.90 \\
1.80 \\
1.71 \\
1.69 \\
1.31 \\
1.47 \\
1.70 \\
1.89 \\
1.86 \\
1.43 \\
1.70 \\
1.82 \\
1.78 \\
1.77 \\
1.85 \\
1.48 \\
1.75 \\
2.46 \\
2.18 \\
2.53 \\
2.28\end{array}$ & $\begin{array}{l}11.9 \\
14.8 \\
12.9 \\
12.5 \\
12.3 \\
11.8 \\
12.6 \\
12.2 \\
15.0 \\
14.2 \\
13.5 \\
13.3 \\
10.3 \\
11.6 \\
13.4 \\
15.1 \\
14.7 \\
11.3 \\
13.4 \\
14.5 \\
14.0 \\
14.0 \\
14.6 \\
11.7 \\
13.8 \\
19.4 \\
17.2 \\
20.0 \\
18.0\end{array}$ \\
\hline MEAN I & 1.743 & & MEAP & $\begin{array}{l}13.9 \text { MPA } \\
(2021 . P S I)\end{array}$ \\
\hline str. & .011 & & STO & $\begin{array}{ll}\text { DEVI } & 2.3 \text { MPA } \\
(335 . P S I)\end{array}$ \\
\hline
\end{tabular}


TABLE A-7

FATIGUE TESTS ON H-45I GRAPHITE

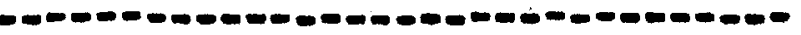

LOT NOI 408

ORIENTATION: RADIAL
LOO NOI $5651-90$

LOCATIONI QUARTER-LENGTH EDGE

STRESS RATIO, R (MIN. STRESS / MAX. STRESS): -1.0

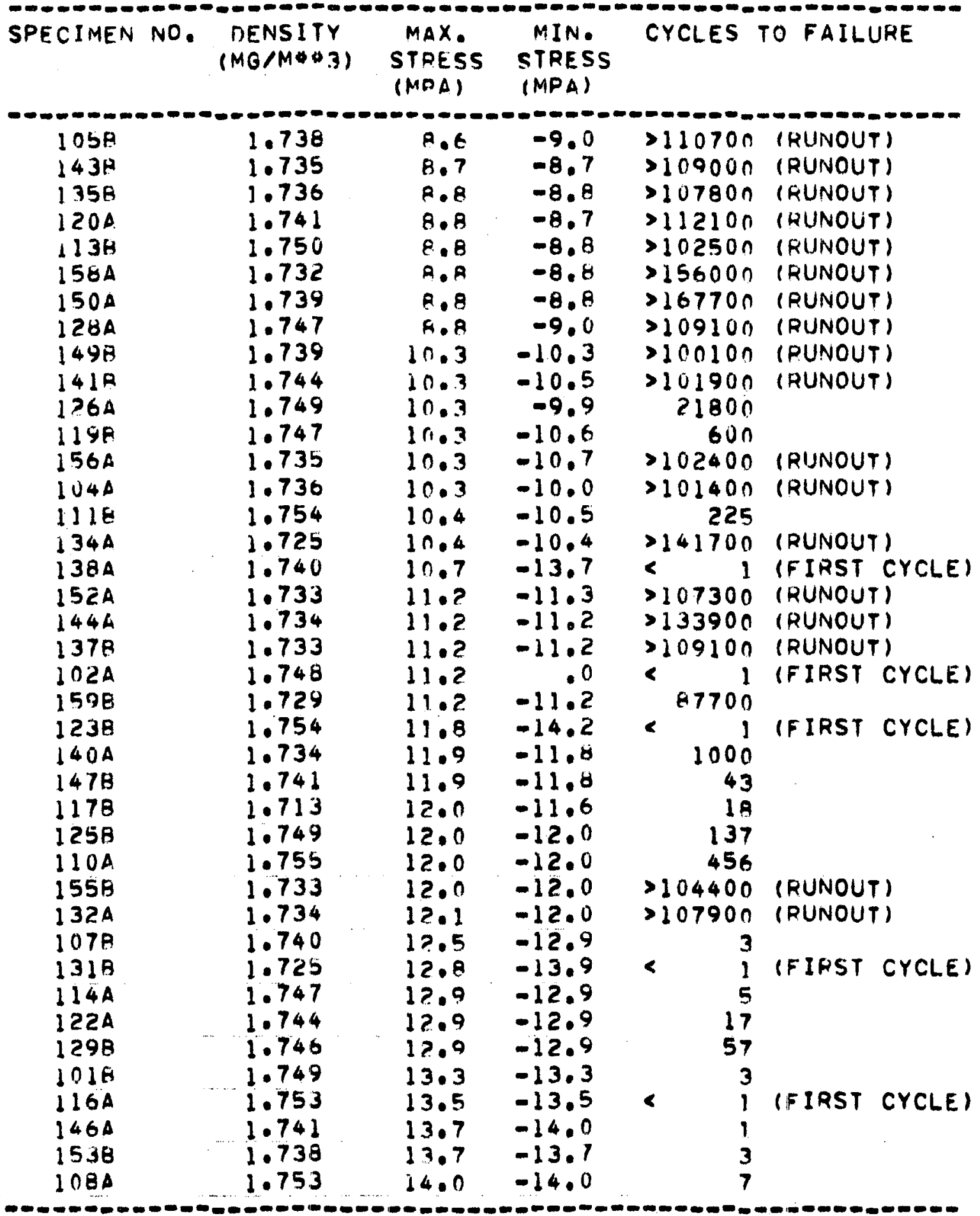


TABLE A-8

FATIGUE TESTS ON MASEL GRAPHITE

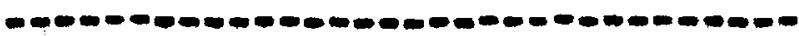

LOT NOI 408

ORIENTATION: RADIAL.
LUG NOI 5651-90

LUCATIONI QUARTER-LENGTH EDGE

STRESS RATIO, R (MIN. STRESS / MAX. STPESS) $1 . .5$

SPFCIMEN NO. DFNSITY MAX. MIN. CYCLES TO FAILURE
(MG/MO3) STRESS STRESS
(MPA) (MPA)

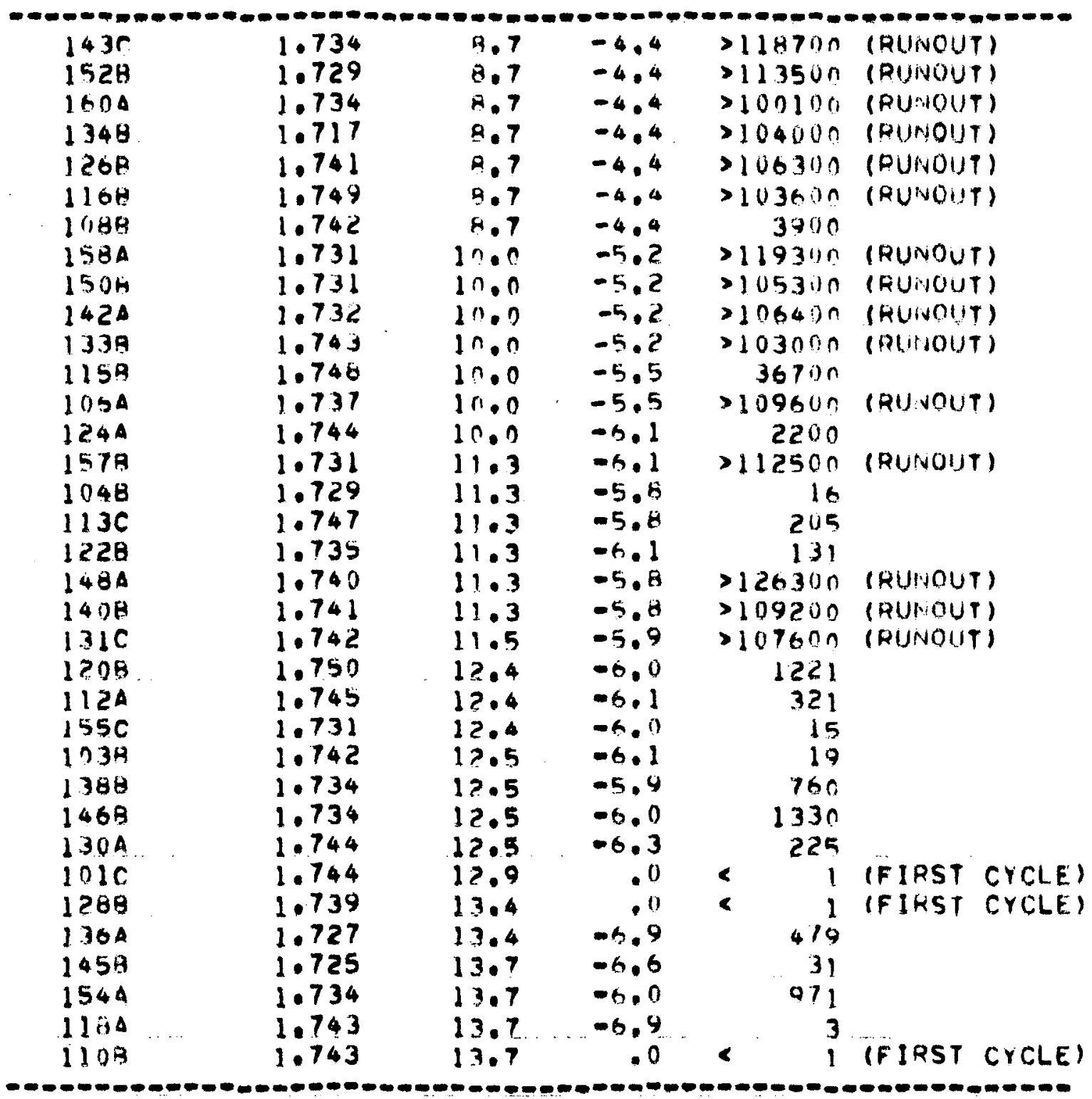


FATIOUE TESTS ON HEABI GRAPHITE

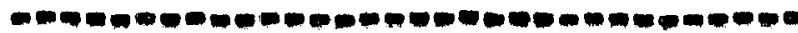

LOT NOP 08

ORIENTATIONI RADIAL
LOG NOI $5651=90$

LOCATIONI OUARTERILENOTH EDOE

STRESS RATIO, R IMIN. STRESS / MAX. STRESSII $: 0$

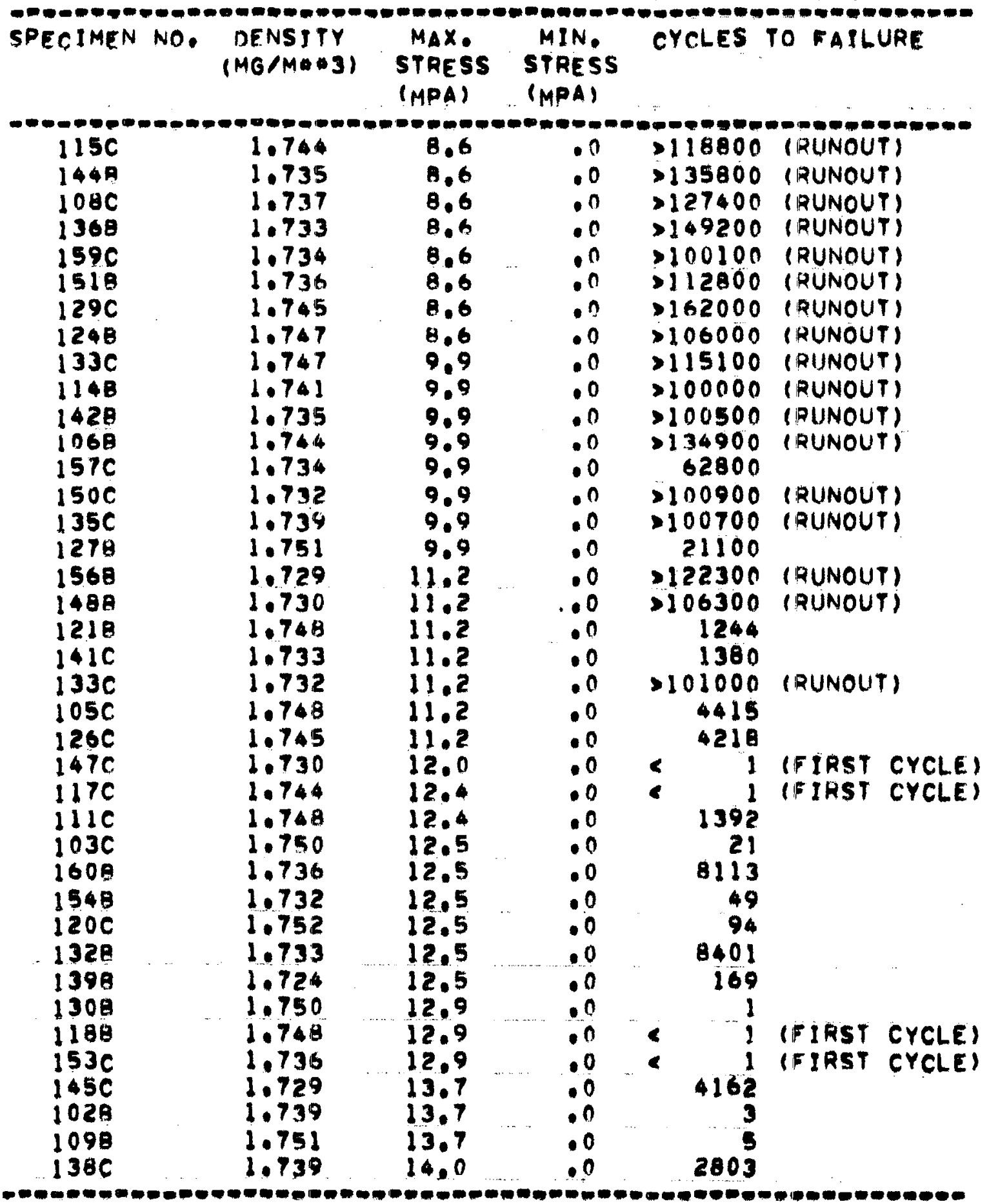


TABLE A-11

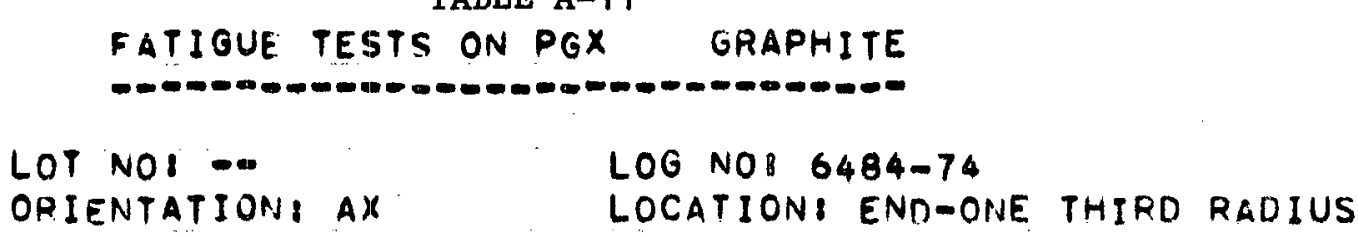

CONTROL TENSILE TESTS

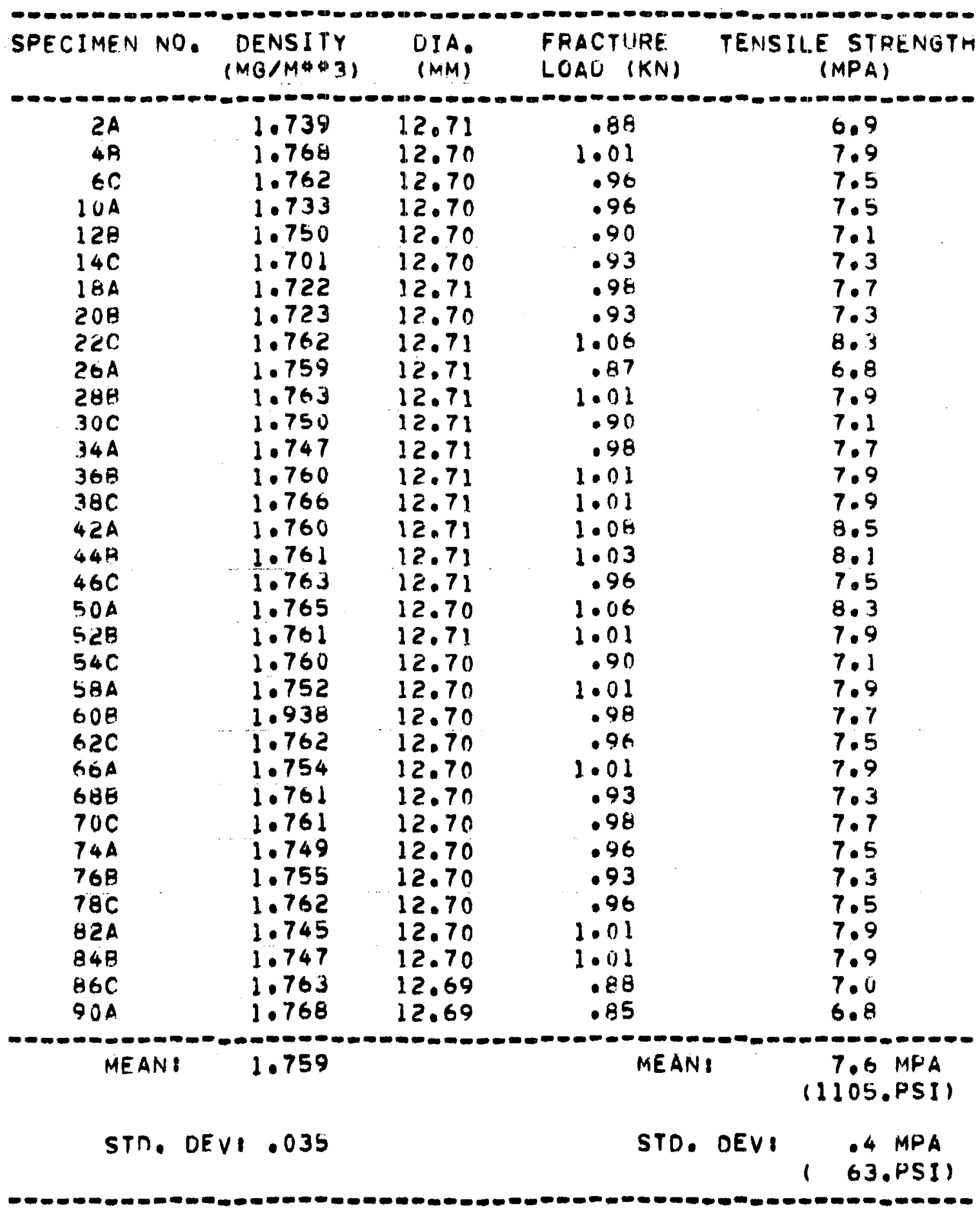


LOT NOI - -

ORIENTATION: AX
LOG NO: 6484-74

LOCATION: END-ONE THIRD RADIUS

STRESS RATIO, R (MIN. STRESS / MAX. STRESS): - 1.0

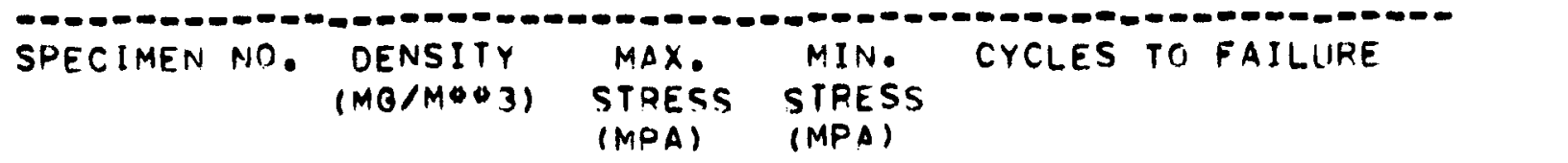

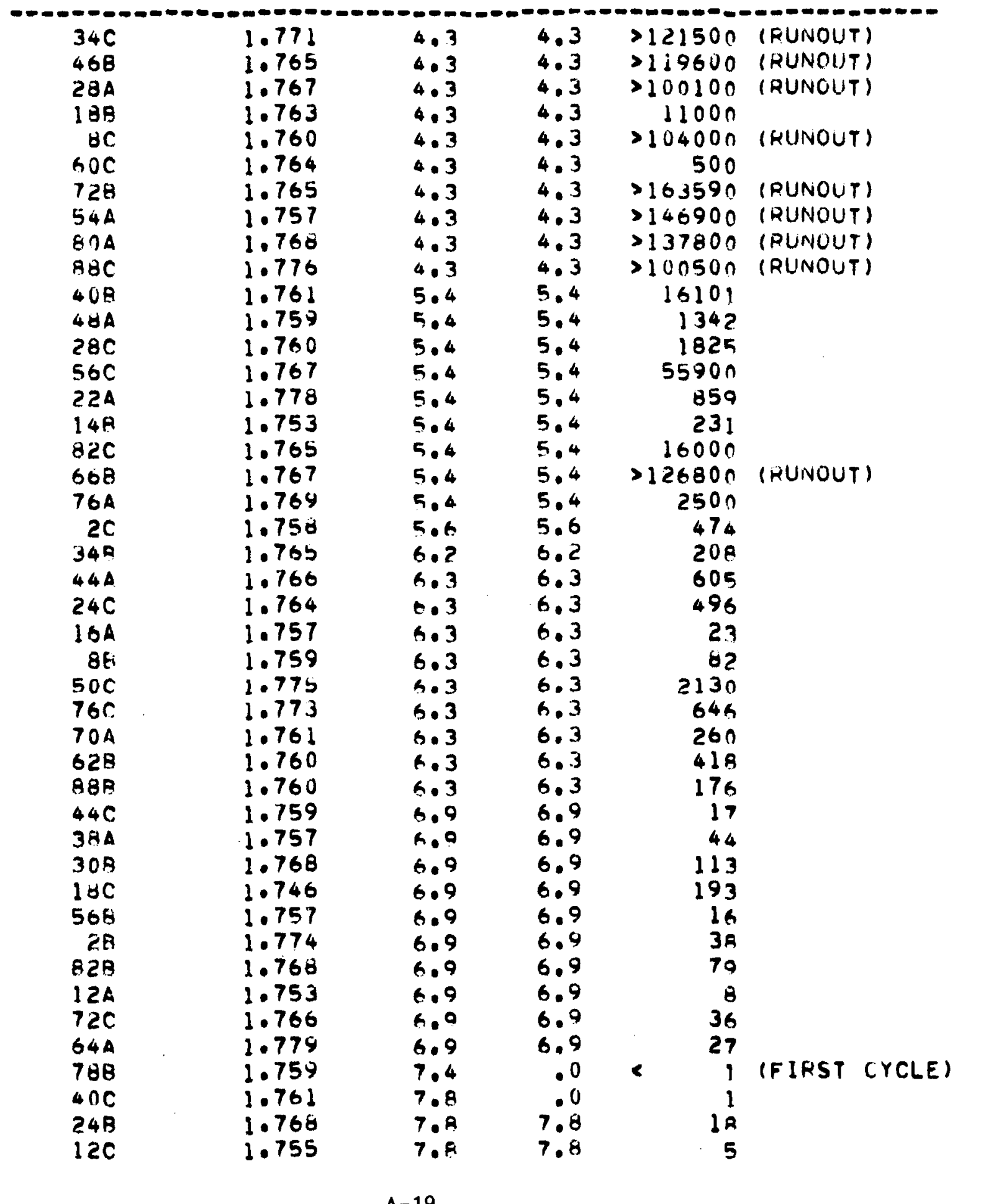


TABLE A-12 (Continued)

\begin{tabular}{|c|c|c|c|c|}
\hline $\begin{array}{l}50 B \\
32 A \\
6 A \\
66 C \\
60 A \\
98 A\end{array}$ & $\begin{array}{l}1.768 \\
1.765 \\
1.760 \\
1.763 \\
1.772 \\
1.770\end{array}$ & $\begin{array}{l}7.8 \\
7.8 \\
7.8 \\
7.8 \\
7.8 \\
7.8\end{array}$ & $\begin{array}{r}7.0 \\
7.8 \\
7.8 \\
7.8 \\
.0 \\
7.8\end{array}$ & $\begin{array}{r}2 \\
8 \\
3 \\
12 \\
1 \\
3\end{array}$ \\
\hline
\end{tabular}


TABLE $A-13$

FATIGUE TESTS OH PQX GRAPHITE

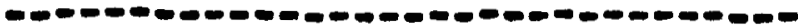

LOT NOI LOG NOI $6484-74$
ORIENTATIONI AX LOCATIONI END-ONE THIRD RADIUS

STRESS RATIO, R (MIN. STRESS / MAX. STRESS): . 0

SPECIMFN NO. DENSITY MAX. MIN, CYCLES TO FAILUHE
(MG/MOQ3) STPESS STRESS
(MPA) (MPA)

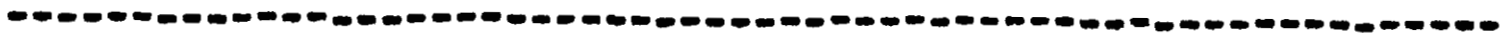

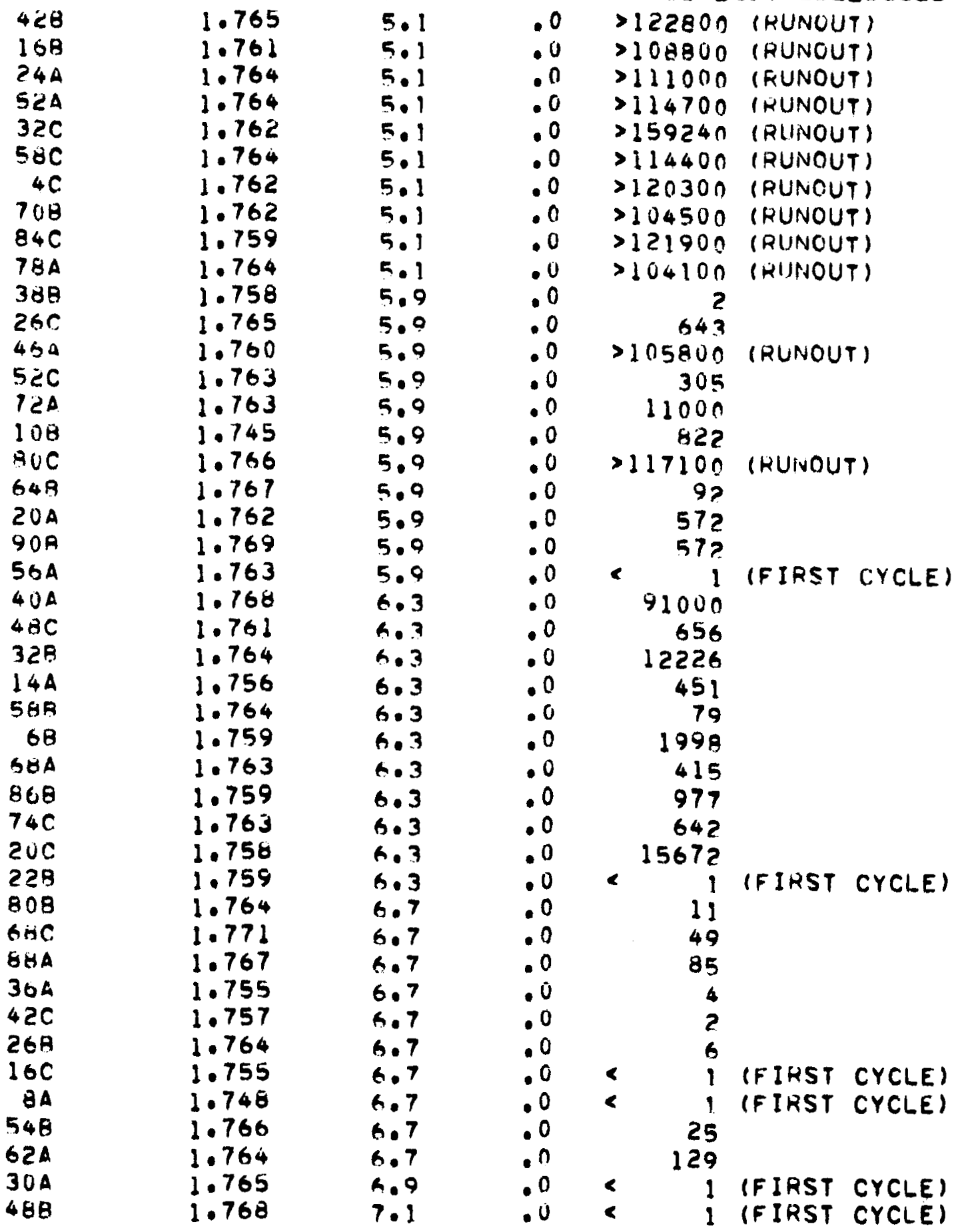


TABLE A-13 (Continued)

\begin{tabular}{|c|c|c|c|c|c|c|c|}
\hline $\begin{array}{r}36 C \\
10 C \\
64 C \\
4 A\end{array}$ & $\begin{array}{l}1.765 \\
1.749 \\
1.765 \\
1.764\end{array}$ & $\begin{array}{l}7.1 \\
7.1 \\
7.5 \\
7.9\end{array}$ & $\begin{array}{l}.0 \\
.0 \\
.0 \\
.0\end{array}$ & < & $\begin{array}{r}1 \\
1 \\
15 \\
1\end{array}$ & $\begin{array}{l}\text { IFIRST } \\
\text { IFIRST } \\
\text { IFIRST }\end{array}$ & $\begin{array}{l}\text { CYCLE) } \\
\text { CYCLE) }\end{array}$ \\
\hline
\end{tabular}


TABLE A-14

FATIGUE TESTS ON PGX

GRAPHITE

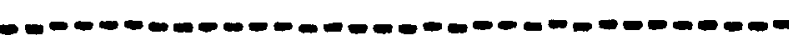

LOT NOI -- LOQ NO: 6484-74

ORIENTATIONI RADIAL LUCATIONI END-ONE THIRD RADIUS

CONTROL TENSILE TESTS

\begin{tabular}{|c|c|c|c|c|}
\hline BPFCIMFN NO. & $\begin{array}{l}\text { DENSITY } \\
(M G / M \circlearrowleft 3)\end{array}$ & $\begin{array}{l}\text { DIA. } \\
\text { (MM) }\end{array}$ & $\begin{array}{l}\text { FRACTURF } \\
\text { LOAD (KN) }\end{array}$ & $\begin{array}{c}\text { TENSTLE STRENGTH } \\
\text { (MPA) }\end{array}$ \\
\hline $\begin{array}{l}1 A \\
3 A \\
5 C \\
70 \\
9 A \\
11 B \\
13 C \\
150 \\
17 A \\
198 \\
21 C \\
230 \\
25 A \\
278 \\
29 C \\
310 \\
314 \\
35 A \\
37 C \\
390 \\
41 A \\
43 R \\
45 C \\
470 \\
49 A \\
518 \\
53 C \\
550 \\
57 A \\
59 A \\
61 C \\
630 \\
65 A \\
671 \\
69 C\end{array}$ & $\begin{array}{l}1.760 \\
1.745 \\
1.762 \\
1.760 \\
1.761 \\
1.768 \\
1.761 \\
1.754 \\
1.761 \\
1.754 \\
1.756 \\
1.765 \\
1.745 \\
1.762 \\
1.756 \\
1.761 \\
1.759 \\
1.762 \\
1.757 \\
1.770 \\
1.761 \\
1.762 \\
1.764 \\
1.757 \\
1.756 \\
1.772 \\
1.763 \\
1.760 \\
1.763 \\
1.753 \\
1.755 \\
1.769 \\
1.757 \\
1.770 \\
1.762\end{array}$ & $\begin{array}{l}12.69 \\
12.69 \\
12.70 \\
12.70 \\
12.70 \\
12.71 \\
12.71 \\
12.70 \\
12.70 \\
12.70 \\
12.70 \\
12.70 \\
12.70 \\
12.70 \\
12.70 \\
12.70 \\
12.70 \\
12.70 \\
12.70 \\
12.70 \\
12.70 \\
12.70 \\
12.70 \\
12.70 \\
12.70 \\
12.68 \\
12.68 \\
12.68 \\
12.70 \\
12.70 \\
12.71 \\
12.68 \\
12.70 \\
12.58 \\
12.69\end{array}$ & $\begin{array}{l}1 \cdot 21 \\
1 \cdot 29 \\
1 \cdot 37 \\
1 \cdot 34 \\
1 \cdot 26 \\
1 \cdot 26 \\
1 \cdot 16 \\
1 \cdot 29 \\
1 \cdot 21 \\
1 \cdot 26 \\
1 \cdot 31 \\
1 \cdot 26 \\
1 \cdot 05 \\
1 \cdot 31 \\
1 \cdot 21 \\
1.79 \\
1 \cdot 16 \\
1 \cdot 24 \\
1 \cdot 18 \\
1 \cdot 00 \\
1 \cdot 31 \\
1 \cdot 34 \\
1 \cdot 00 \\
1 \cdot 31 \\
1 \cdot 16 \\
1 \cdot 18 \\
1 \cdot 26 \\
1 \cdot 31 \\
1 \cdot 24 \\
1 \cdot 16 \\
1 \cdot 16 \\
1 \cdot 10 \\
1 \cdot 03 \\
1 \cdot 21 \\
1 \cdot 10\end{array}$ & $\begin{array}{r}9.6 \\
10.2 \\
10.8 \\
10.6 \\
10.0 \\
9.9 \\
9.1 \\
10.2 \\
9.5 \\
10.0 \\
10.4 \\
10.0 \\
8.3 \\
10.4 \\
9.5 \\
6.2 \\
9.1 \\
9.8 \\
9.3 \\
7.9 \\
10.4 \\
10.6 \\
7.9 \\
10.4 \\
9.1 \\
9.4 \\
10.0 \\
10.4 \\
9.7 \\
9.1 \\
9.1 \\
8.7 \\
8.1 \\
9.6 \\
8.7\end{array}$ \\
\hline MEAN & 1.761 & & MEAR & $\begin{array}{c}9.5 \text { MPA } \\
(1376 . \text { PSI })\end{array}$ \\
\hline STO. D & .006 & & Stue & $\begin{array}{ll}\text { DEV: } & 1.0 \text { MPA } \\
& (139 . \text { PSI }\end{array}$ \\
\hline
\end{tabular}


TABLE A-15

FATIGUE TESTS ON PGX GRAPHITE

- -

LOT NOI - LOG NOI $6484-74$

ORIFNTATION: RADTAL LOCATIONI ENNOONE THIRD RADIUS

STPESS RATIO, R (MIN. STRESS / MAX. STRESS) I - 1.0

SPECIMEN NO. OENSITY MAX. MIN. CYCLES TO FAILURE
(MG/MQZZ) STRESS STRESS
(MPA)

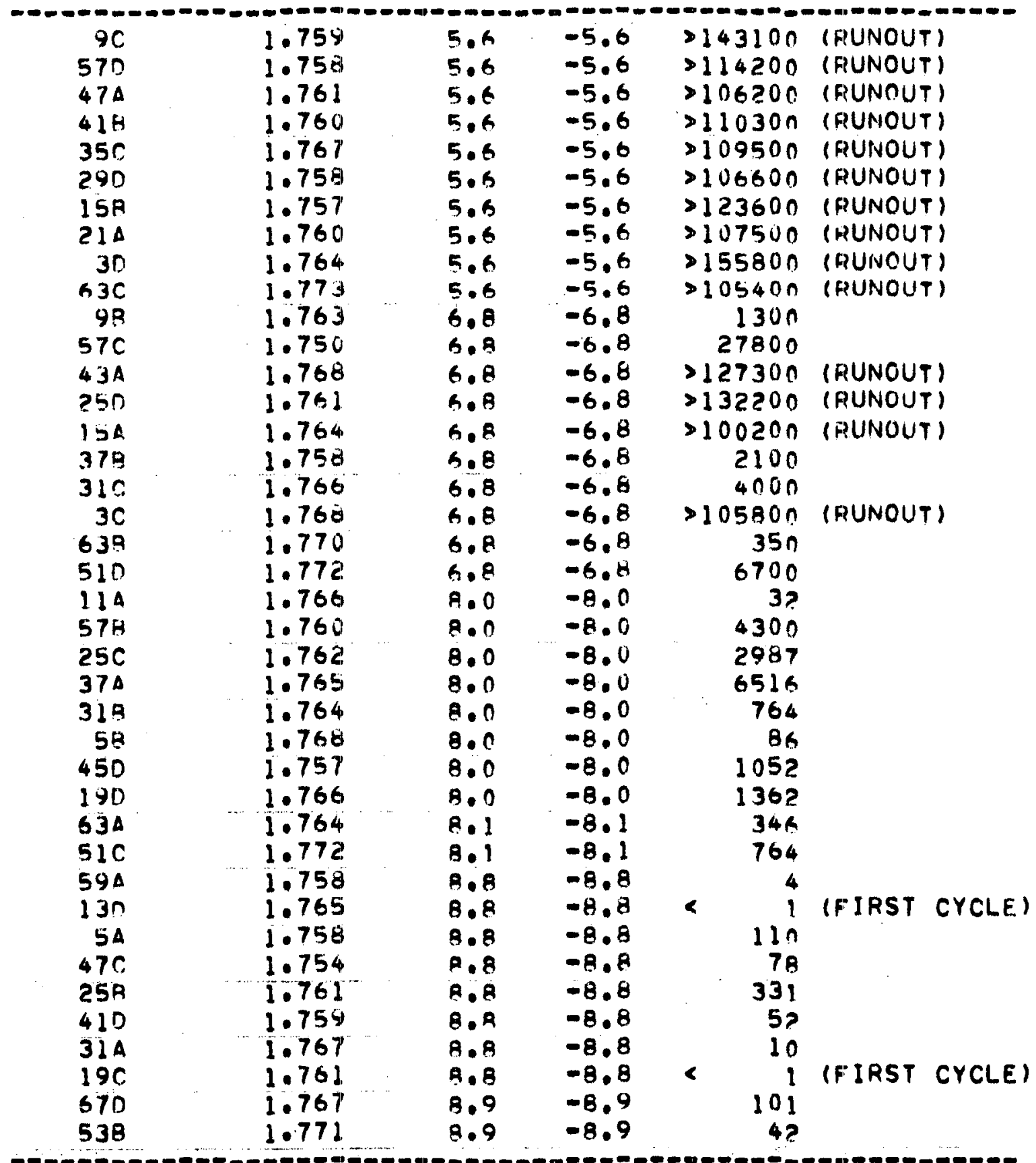


TABLE A-16

FATIGUE TESTS ON PGX GRAPHITE

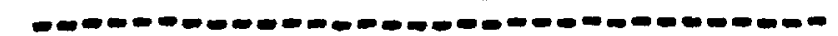

LOT NOI -- LOG NOI $6484-74$

ORIENTATIONI RADIAL LOCATIUNI ENA-ONE THIRD RADIUS

STPESS RATIU, R (MIN. STPESS, MAX. STRESS): I

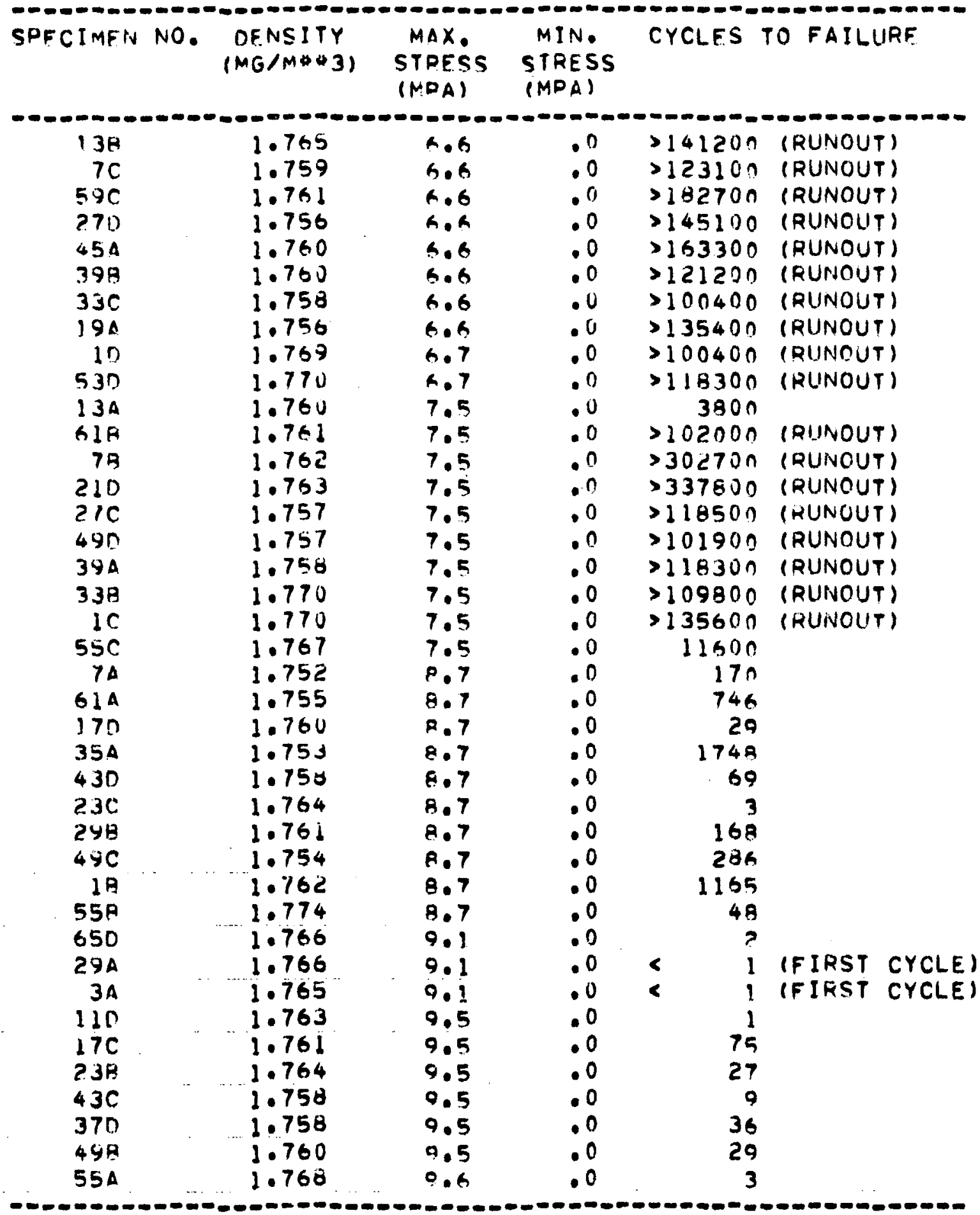


CAPSULE IRRADIATION OG-1.

FATIGUE TESTS ON H=45I GRAPHITE

- - - -

LOT NOI 266

LOG NOI $5651-2 B$

ORIENTATION: AXIAL

LOCATIONI MIDLENGTH-CENTER

CONTROL TENSILE TESTS

\begin{tabular}{|c|c|c|c|c|}
\hline SPECIMEN NO & $\begin{array}{l}\text { - RENSITY } \\
\text { (MO/M\$3) }\end{array}$ & $\begin{array}{l}\text { DIA. } \\
\text { (MM) }\end{array}$ & $\begin{array}{l}\text { FRACTURE } \\
\text { LOAD (KN) }\end{array}$ & $\begin{array}{c}\text { TENSILE STRENGTH } \\
\text { (MPA) }\end{array}$ \\
\hline $\begin{array}{l}F-22 A \\
F-24 A \\
F-26 A \\
F-28 A \\
F=30 A \\
F-32 A \\
F-34 A \\
F-36 A \\
F-38 A \\
F=40 A\end{array}$ & $\begin{array}{l}.000 \\
.000 \\
.000 \\
.000 \\
.000 \\
.000 \\
.000 \\
.000 \\
.000 \\
.000\end{array}$ & $\begin{array}{l}5.08 \\
5.07 \\
5.08 \\
5.08 \\
5.07 \\
5.08 \\
5.07 \\
5.08 \\
5.07 \\
5.07\end{array}$ & $\begin{array}{l}.24 \\
.25 \\
.35 \\
.32 \\
.27 \\
.32 \\
.27 \\
.28 \\
.36 \\
.28\end{array}$ & $\begin{array}{l}11.9 \\
12.1 \\
17.3 \\
15.9 \\
13.2 \\
15.9 \\
13.2 \\
13.8 \\
18.0 \\
13.9\end{array}$ \\
\hline MFAN: & .000 & & MEA & $\begin{array}{l}14.5 \mathrm{MPA} \\
(2105 . \mathrm{PSI})\end{array}$ \\
\hline STD. & 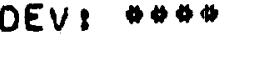 & & STU & $\begin{array}{ll}\text { DEV: } & 2.1 \text { MPA } \\
& (308 . P S I)\end{array}$ \\
\hline
\end{tabular}


TABLE A-18

CAPSULE IRRADIATION OG-1

FATIGUE TESTS ON H-45I GRAPHITE

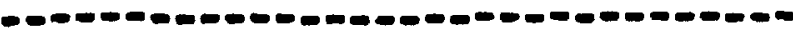

LOT NOI 206

ORIENTATIONI AXIAL
LOG NO: 5651-2B

LOCATION: MIOLENGTH-CENTER

STRESS RATIO. R (MIN. STRESS, MAX. STRESS): -1.0

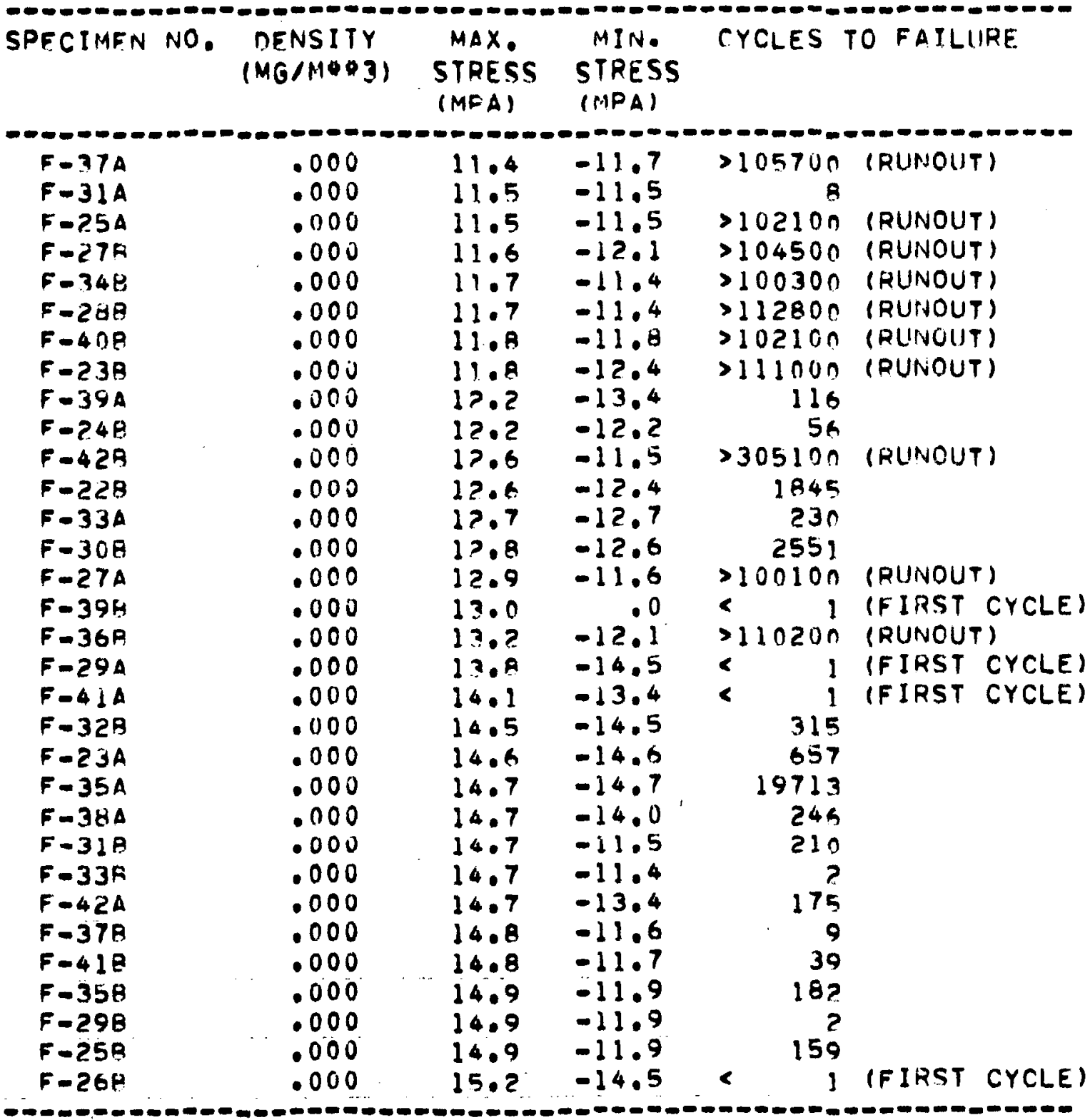


TABLE A-19

CAPSULE IRRADIATIONS OG-1 AND OG-2

FATIGUE TESTS ON H-45I GRAPHITE

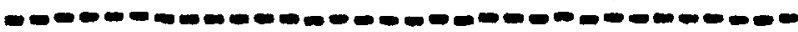

LOT NOI 266

LOO NOI $5651-28$

ORIENTATIONI RADIAL

LOCATIONI MIDLENGTH-CENTER

CONTROL TENSILE TESTS

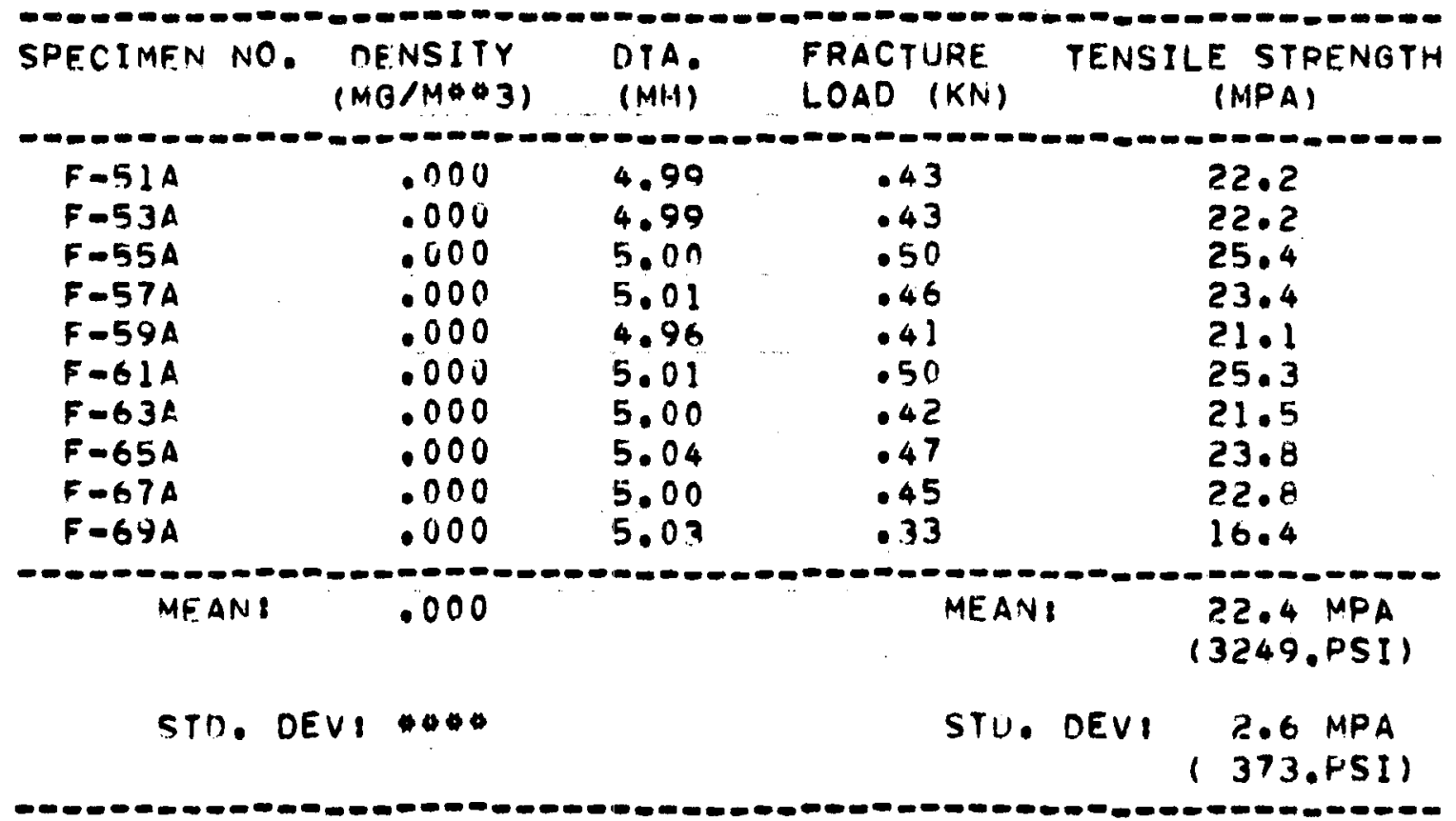


TABLE A-18

CAPSULE IRRADIATION OG-I

FATIGUE TESTS ON H-45I GRAPHITE

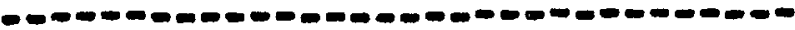

LOT NOI 266

LOG NOI $5651-28$

ORIENTATIONI AXIAL LOCATION: MIOLENGTH-CENTER

STRESS RATIO, R (MIN, STRESS, MAX. STRESS): -1.0

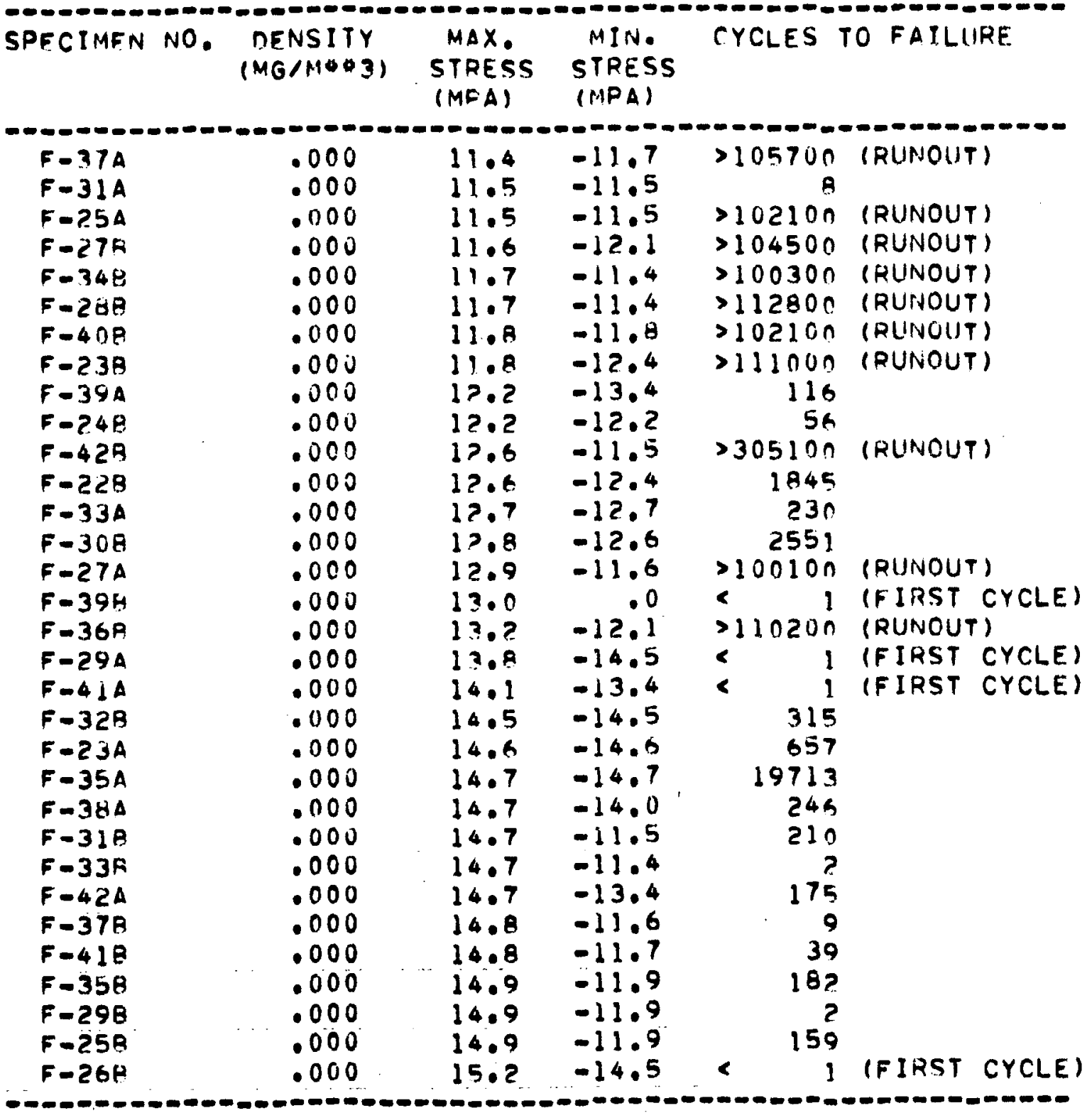


TABLE A-19

CAPSULE IRRADIATIONS OG-1 AND OG-2

FATIGUE TESTS ON H-45I GRAPHITE

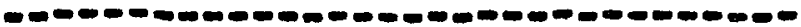

LOT NOI 266

ORIENTATION: RADIAL LOCATIONI MIOLENGTH-CENTER

CONTROL TENSILE TESTS

\begin{tabular}{|c|c|c|c|c|}
\hline SPECIMEN NO. & $\begin{array}{l}\text { DENSITY } \\
(M G / M \otimes 3)\end{array}$ & $\begin{array}{l}\text { DIA. } \\
\text { (MIII) }\end{array}$ & $\begin{array}{l}\text { FRACTURE } \\
\text { LOAD (KN) }\end{array}$ & $\begin{array}{c}\text { TENSILE STRENGTH } \\
\text { (MPA) }\end{array}$ \\
\hline $\begin{array}{l}F-51 A \\
F=53 A \\
F-55 A \\
F-57 A \\
F-59 A \\
F-61 A \\
F=63 A \\
F-65 A \\
F-67 A \\
F=69 A\end{array}$ & $\begin{array}{l}.000 \\
.000 \\
.000 \\
.000 \\
.000 \\
.000 \\
.000 \\
.000 \\
.000 \\
.000\end{array}$ & $\begin{array}{l}4.99 \\
4.99 \\
5.01 \\
5.01 \\
4.96 \\
5.01 \\
5.00 \\
5.04 \\
5.00 \\
5.03\end{array}$ & $\begin{array}{l}.43 \\
.43 \\
.50 \\
.46 \\
.41 \\
.50 \\
.42 \\
.47 \\
.45 \\
.33\end{array}$ & $\begin{array}{l}22.2 \\
22.2 \\
25.4 \\
23.4 \\
21.1 \\
25.3 \\
21.5 \\
23.8 \\
22.8 \\
16.4\end{array}$ \\
\hline MEANI & .000 & & MEAN & $\begin{array}{l}22.4 \mathrm{MPA} \\
(3249 . \mathrm{PSI})\end{array}$ \\
\hline$S T D \cdot 0$ & 110000 & & STU. & $\begin{array}{ll}\text { DEV } & 2.6 \text { MPA } \\
& (373 . \text {.PSI }\end{array}$ \\
\hline
\end{tabular}


FATIGUE TESTS ON H-45I GRAPHITE

- - - - -

LOT NOI 266

ORIENTATION: RADIAL.
LOG NOI 5651-28

LOCATIONI MIOLENGTH-CENTER STRESS RATIO, R (MIN. STRESS / MAX. STRESS) $1-1.0$

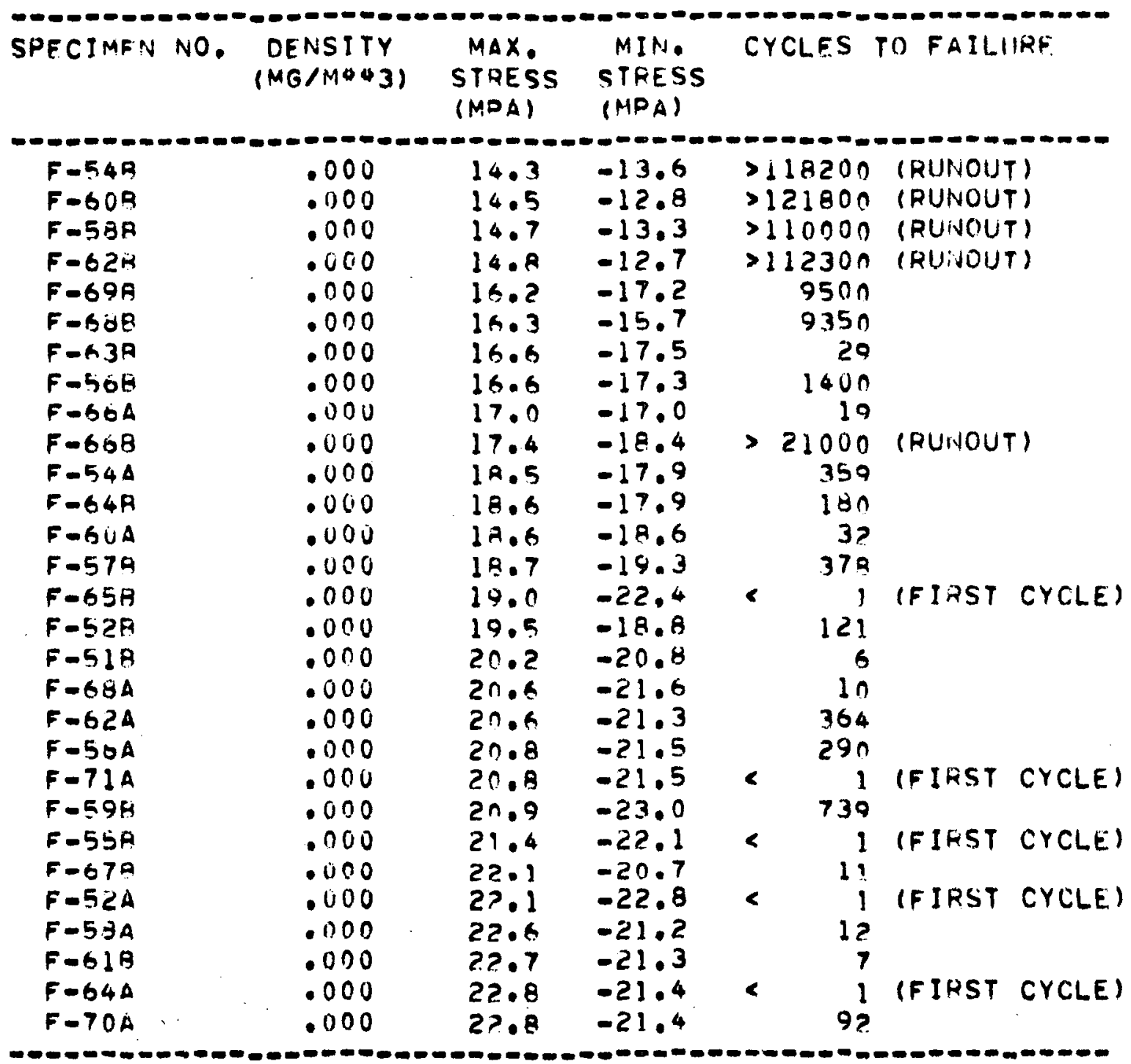


TABLE A-21

CAPSULE IRRADIATIONS OG-1, 2 AND 3

FATIGUE TESTS ON H-45I GRAPHITE

СATIGUE TESTS ON H.

LOT NOI 266

ORIENTATION: AXIAL
LOG NO: $5651-20$

LOCATION: MIDLENGTH-CENTER

CONTROL TENSILF TESTS

\begin{tabular}{|c|c|c|c|c|}
\hline SPECIMEN NO. & $\begin{array}{l}\text { NENSITY } \\
\text { (MG/M\&3) }\end{array}$ & $\begin{array}{l}\text { DTA. } \\
(M M)\end{array}$ & $\begin{array}{l}\text { FRACTURE } \\
\text { LOAD (KN) }\end{array}$ & $\begin{array}{c}\text { TENSILF STRENGTH } \\
\text { (MPA) }\end{array}$ \\
\hline $\begin{array}{l}F=01 A \\
F=03 A \\
F=05 A \\
F=07 A \\
F=09 A \\
F=11 A \\
F=13 A \\
F-15 A \\
F=17 A \\
F=19 A\end{array}$ & $\begin{array}{l}.000 \\
.000 \\
.000 \\
.000 \\
.000 \\
.000 \\
.000 \\
.000 \\
.000 \\
.000\end{array}$ & $\begin{array}{l}5.08 \\
5.06 \\
5.07 \\
5.07 \\
5.08 \\
5.08 \\
5.08 \\
5.08 \\
5.06 \\
5.03\end{array}$ & $\begin{array}{l}.37 \\
.44 \\
.37 \\
.43 \\
.46 \\
.46 \\
.42 \\
.35 \\
.37 \\
.41\end{array}$ & $\begin{array}{l}18.4 \\
21.6 \\
18.5 \\
21.3 \\
22.6 \\
22.8 \\
20.8 \\
17.4 \\
18.4 \\
20.4\end{array}$ \\
\hline ME $\triangle N I$ & .000 & & MEA & $\begin{array}{r}20.2 \text { MPA } \\
(2935 . P S I)\end{array}$ \\
\hline STD. i & 110000 & & STO & $\begin{array}{ll}\text { OEV: } & 1.9 \text { MPA } \\
& 1281 . \text { PSI) }\end{array}$ \\
\hline
\end{tabular}


TABLE A-22

CAPSULE IRRADIATIONS OG-1,2 AND 3

FATIGUE TESTS ON H-45I GRAPHITE

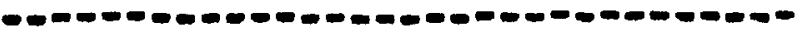

LOT NOI 266

ORIENTATIUN: AXIAL
LOG NO: $5651-28$

LOCATION: MIDLENGTH-CENTER

STRESS RATIO. R (MIN. STRESS / MAX. STRESS): - 1.0

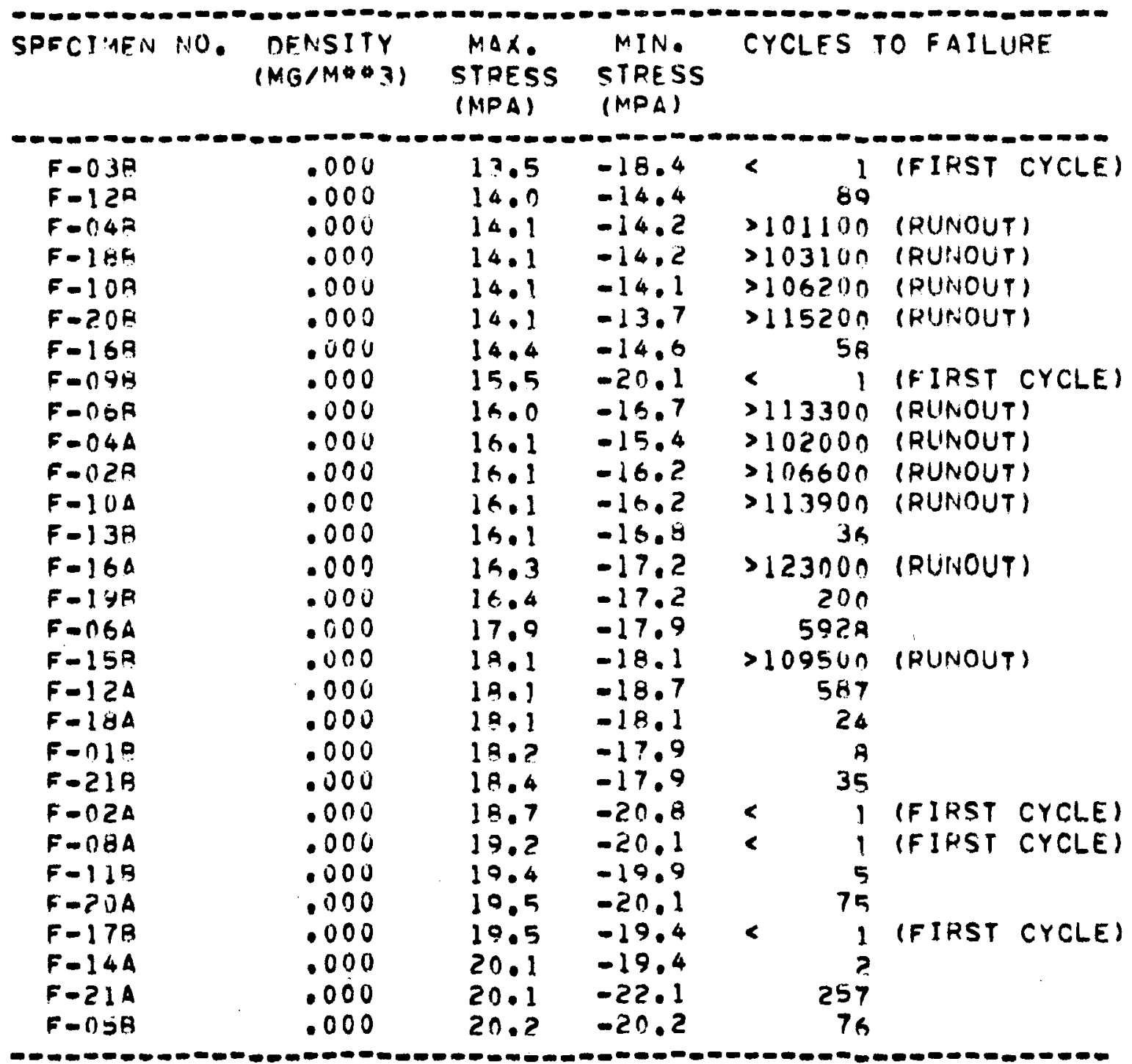




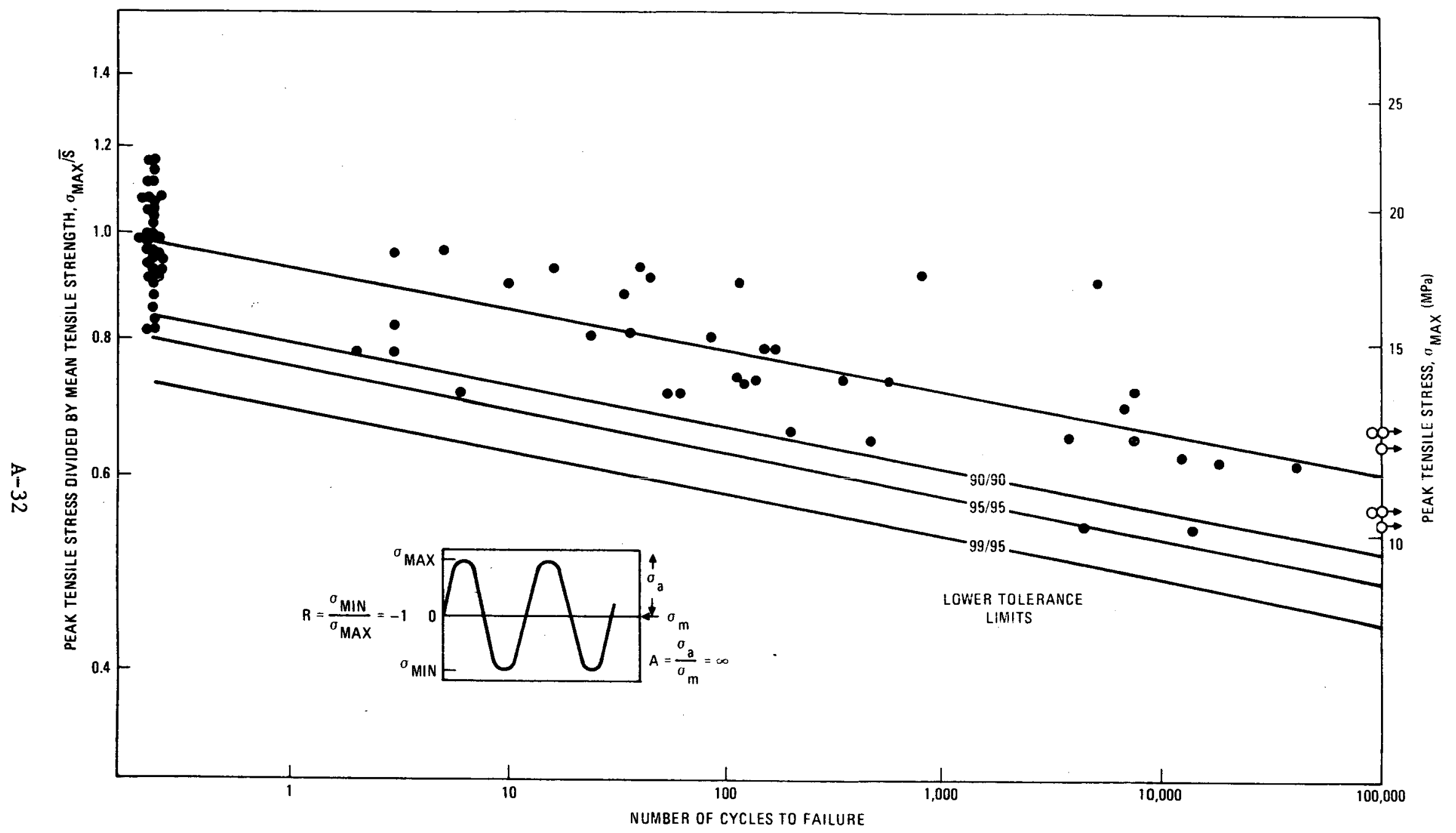

Fig. A-5. Fatigue test data on H-451 graphite, axial orientation, quarter-length edge location, in air at ambient temperature. Log-log plot of normalized maximum stress versus number of cycles to failure with $R=-1$. Lower $x / y$ tolerance limits represent the limits above which at 1 east $x \%$ of all data would fall, with y\% confidence. 


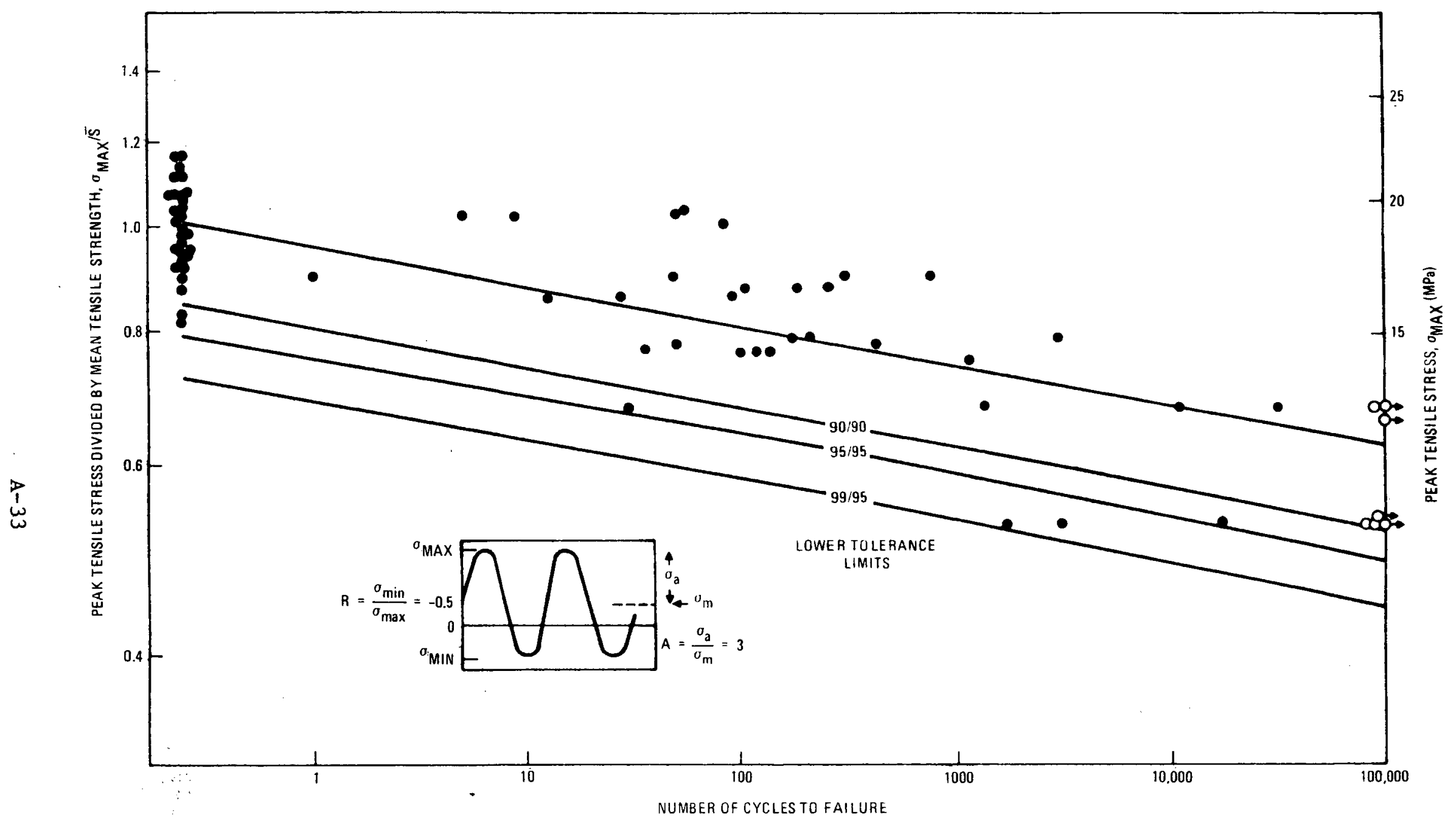

Fig. A-6. Fatigue test data on H-451 graphite, axial orientation, quarter-length edge location, in air at ambient temperature. Log-log plot of normalized maximum stress versus number of cycles to failure with $\mathrm{R}=-0.5$. Lower $\mathrm{x} / \mathrm{y}$ tolerance limits represent the limits above which at least $x \%$ of all data would fall, with $y \%$ confidence. 


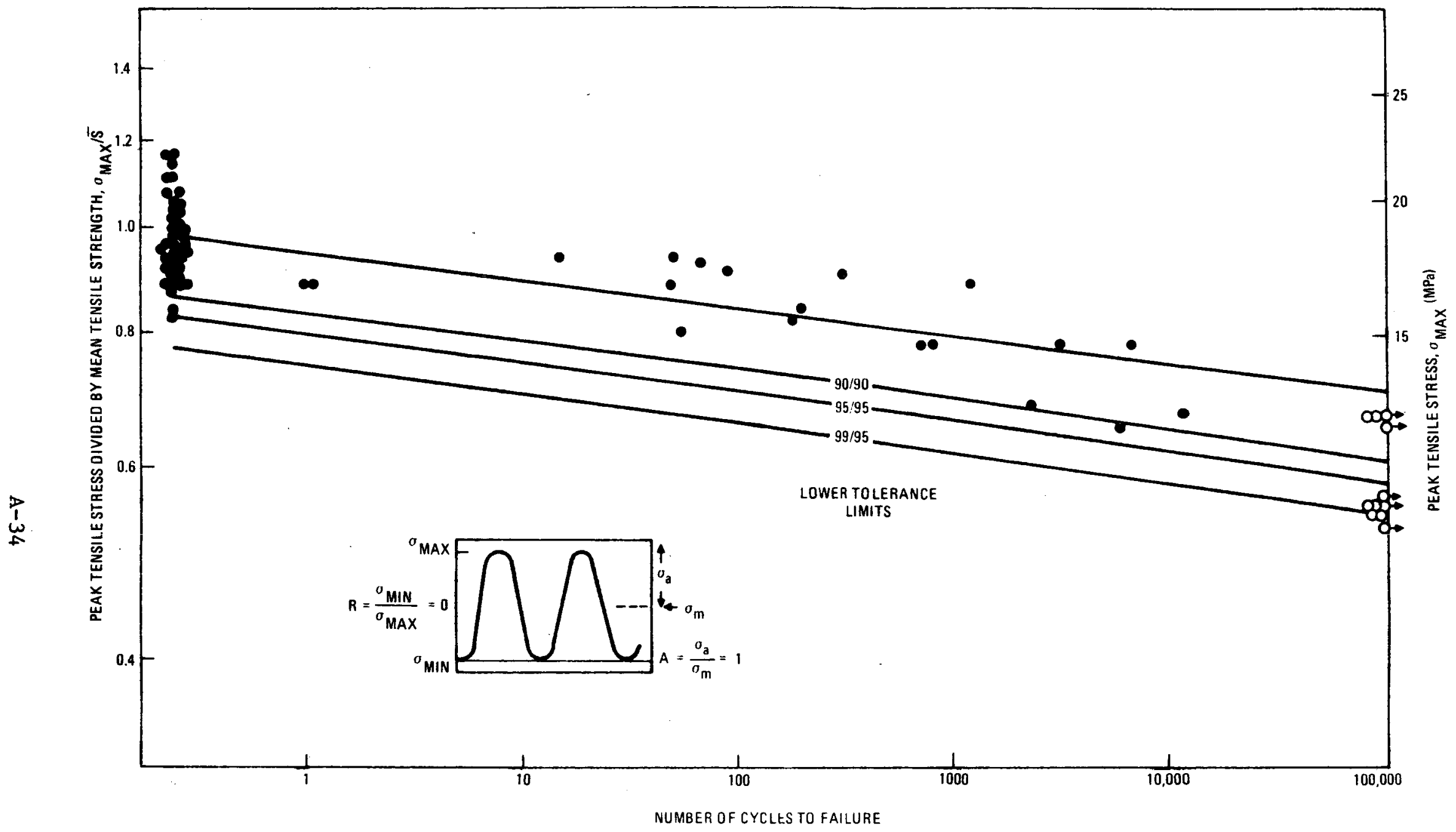

Fig. A-7. Fatigue test data on H-451 graphite, axial orientation, quarter-length edge 1ocation, in air at ambient temperature. Log-log plot of normalized maximim stress versus number of cycles to failure with $R=0$. Lower $x / y$ tolerance limits represent the limits above which at least $\mathrm{x} \%$ of all data would fall, with $\mathrm{y} \%$ confidence. 


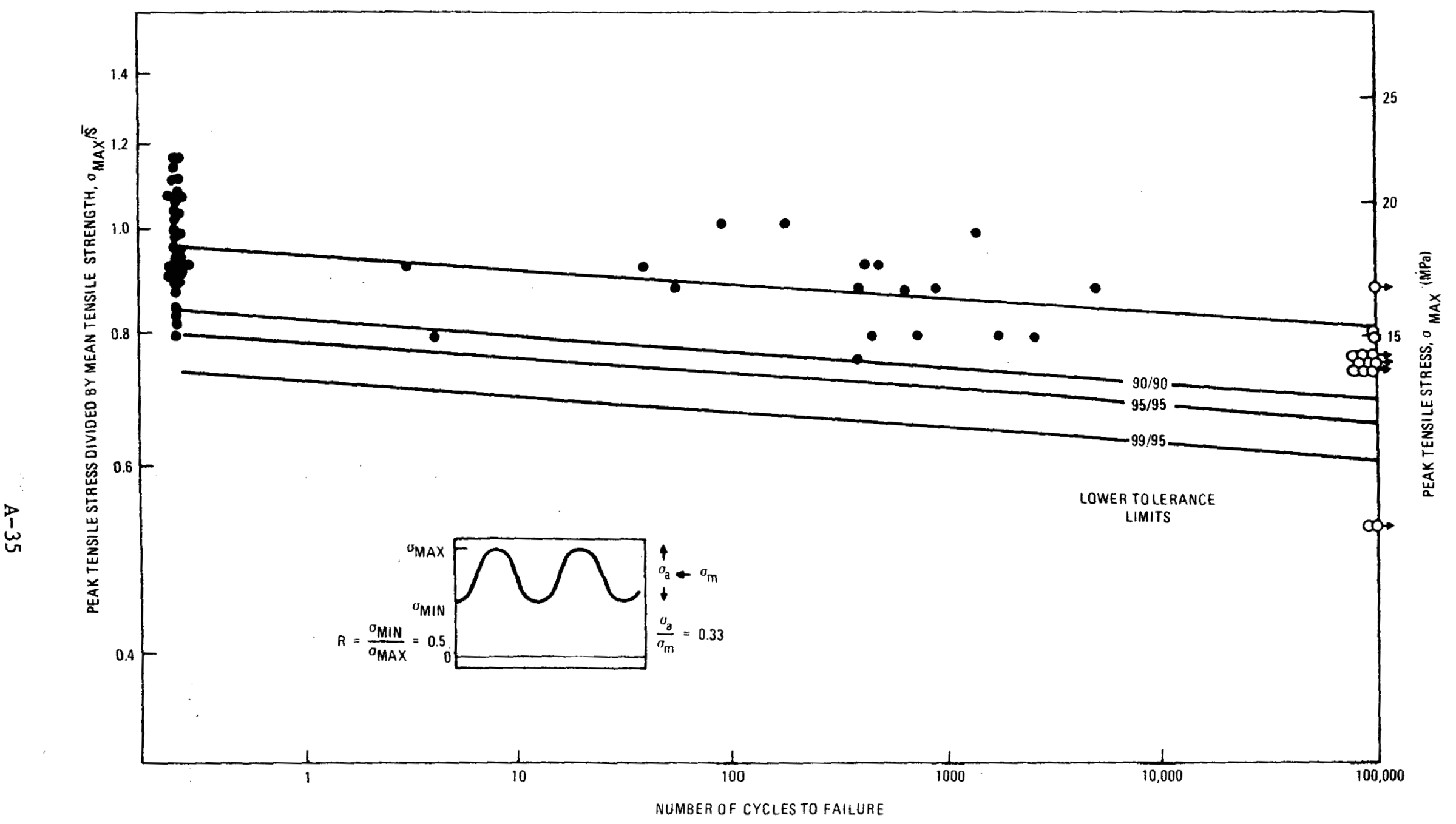

Fig. A-8. Fatigue test data on H-451 graphite, axial orientation, quarter-length edge location, in air at ambient temperature. Log-log plot of normalized maximum stress versus number of cycles to failure with $R=0.5$. Lower $x / y$ tolerance limits represent the limits above which at least $x \%$ of all data would fall, with $y \%$ confidence. 


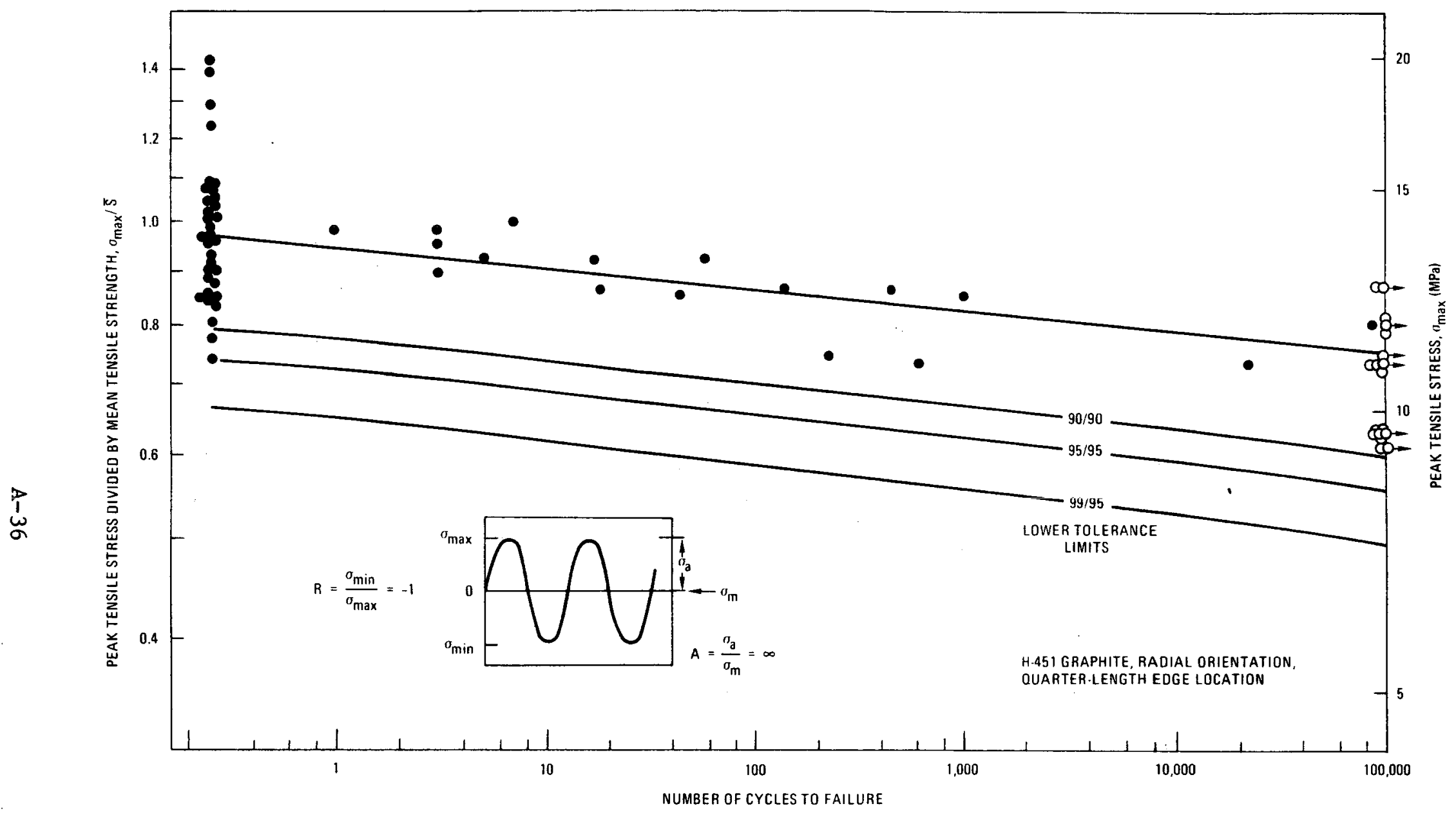

Fig. A-9. Fatigue test data on H-451 graphite, radial orientation, quarter-length edge location, in air at ambient temperature. Log-log plot of normalized maximum stress versus number of cycles to failure with $R=-1$. Lower $x / y$ tolerance limits represent the limits above which at 1 east $x \%$ of all data would fall, with y\% confidence. 


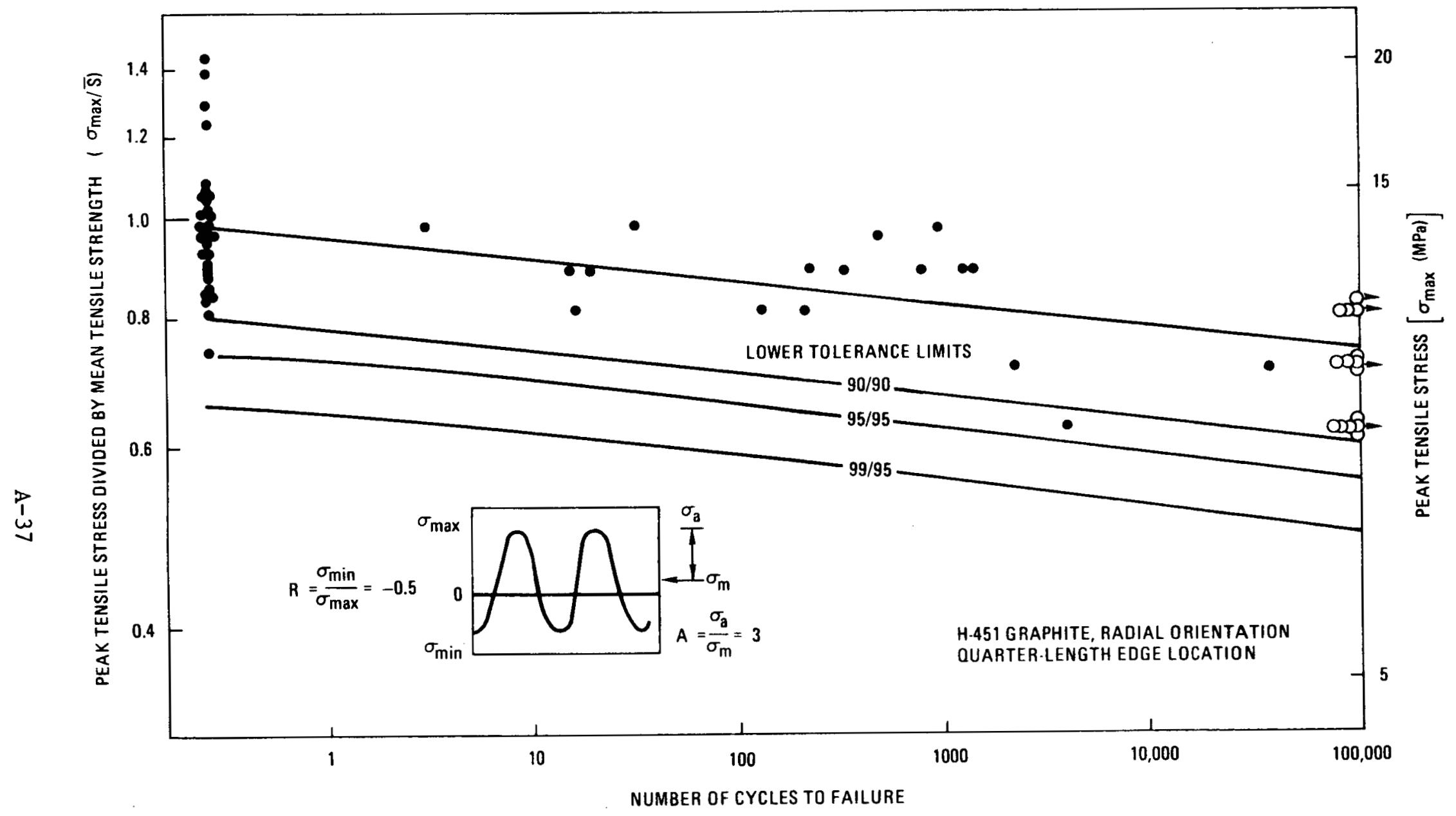

Fig. A-10. Fatigue test data on H-451 graphite, radial orientation, quarter-length edge location, in air at ambient temperature. Log-log plot of normalized maximum stress versus number of cycles to failure with $\mathrm{R}=-0.5$. Lower $\mathrm{x} / \mathrm{y}$ tolerance limits represent the limits above which at least $x \%$ of all data would fall, with $y \%$ confidence. 


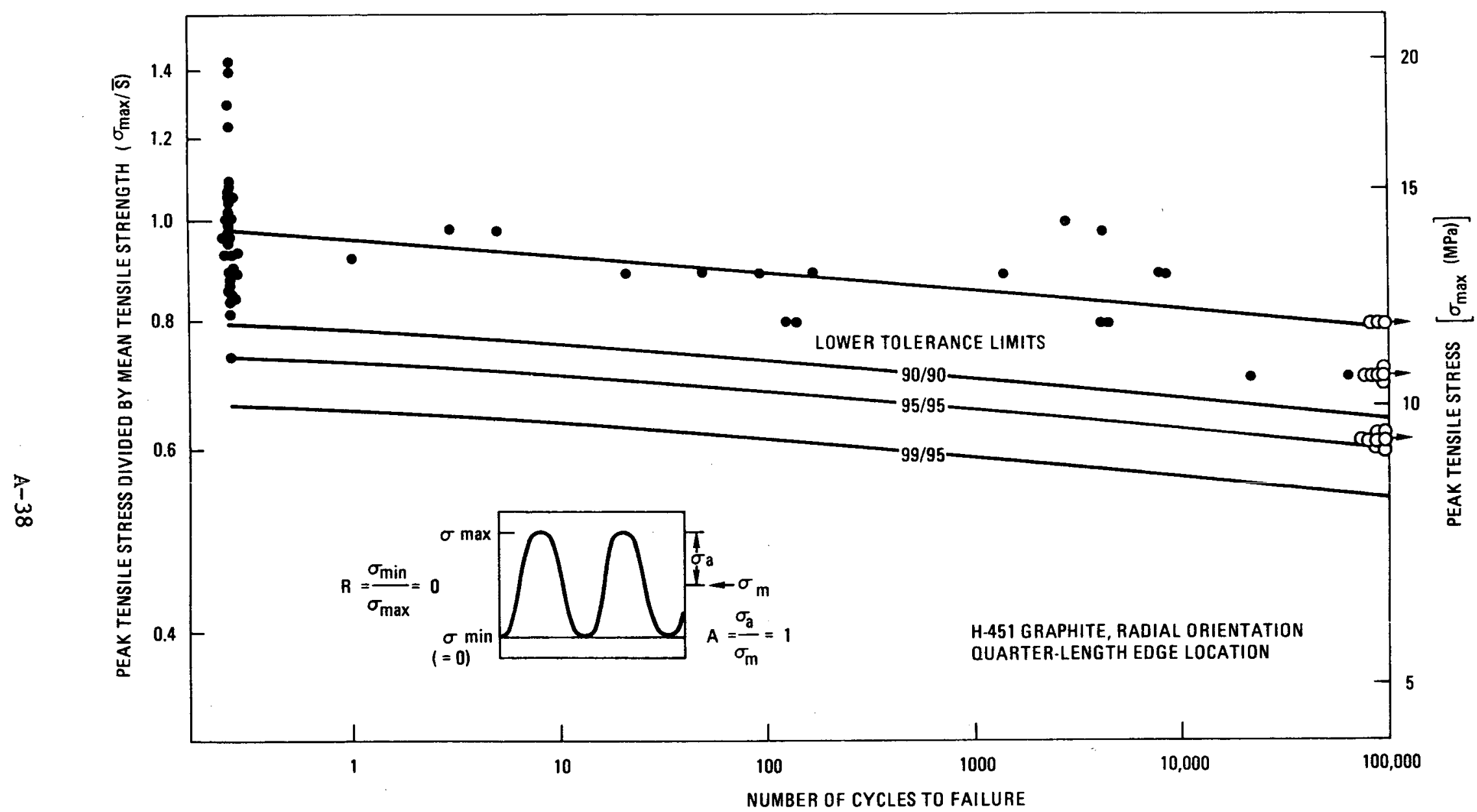

Fig. A-11. Fatigue test data on $\mathrm{H}-451$ graphite, radial orientation, quarter-length edge location, in air at ambient temperature. Log-log plot of normalized maximum stress versus number of cycles to failure with $\mathrm{R}=0$. Lower $\mathrm{x} / \mathrm{y}$ tolerance limits represent the limits above which at least $\mathrm{x} \%$ of all data would fall, with y\% confidence. 


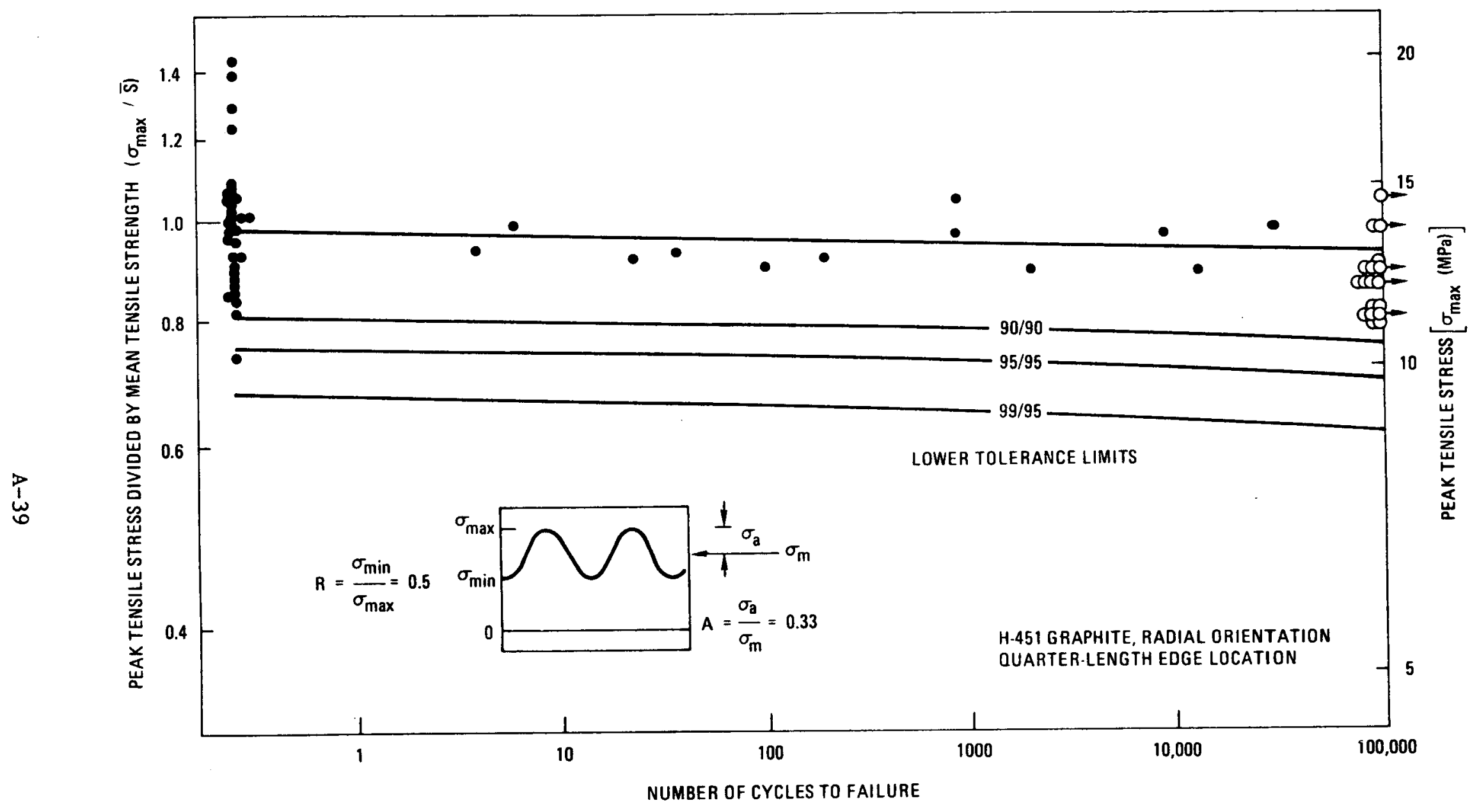

Fig. A-12. Fatigue test data on H-451 graphite, radial orientation, quarter-length edge location, in air at ambient temperature. Log-log plot of normalized maximum stress versus number of cycles to failure with $\mathrm{R}=0.5$. Lower $\mathrm{x} / \mathrm{y}$ tolerance limits represent the limits above which at least $\mathbf{x} \%$ of all data would fall, with $\mathrm{y} \%$ confidence. 


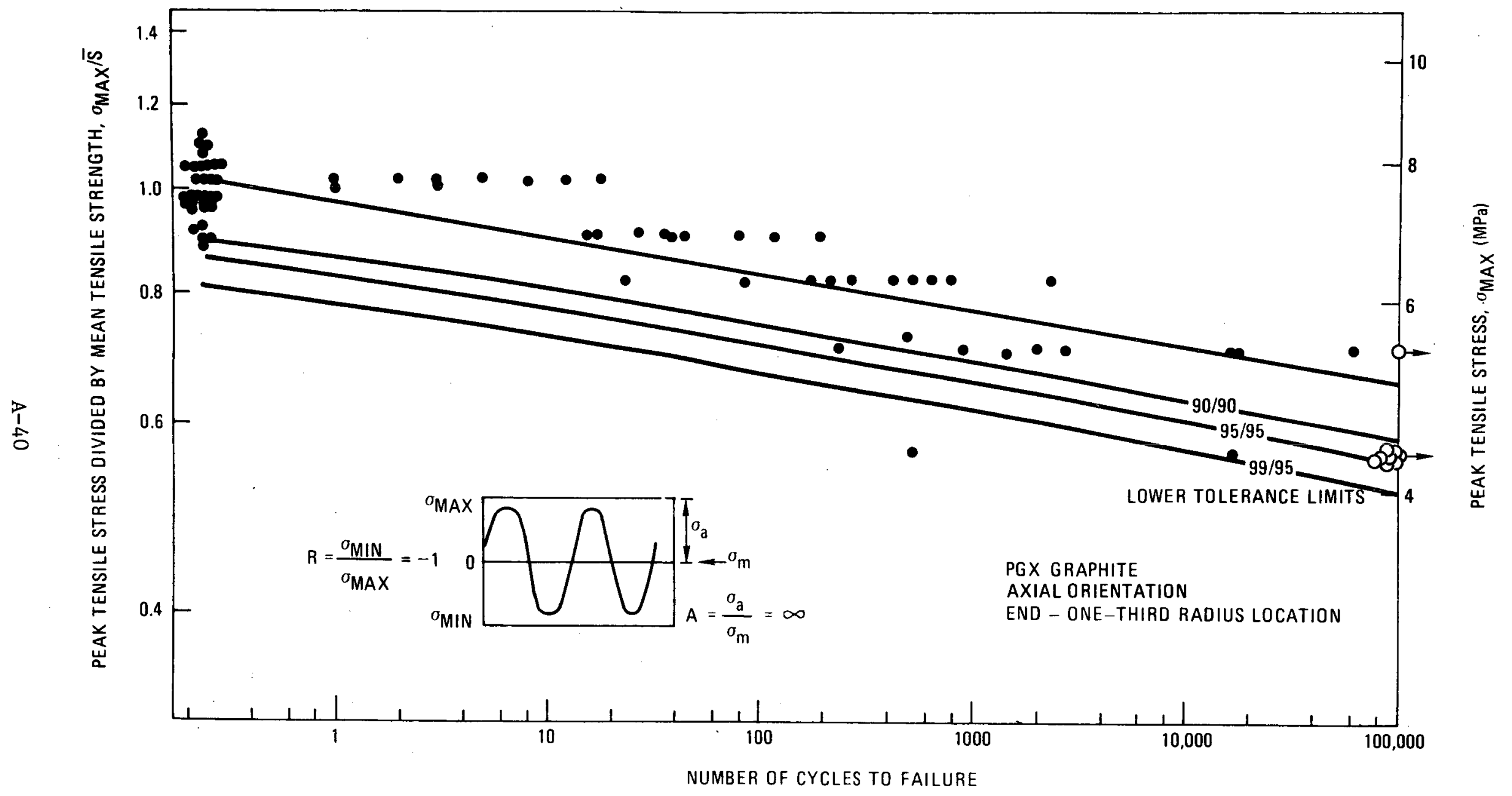

Fig. A-13. Fatigue test data for PGX graphite, axial orientation, end - one-third radius location, in air at ambient temperature. Log-log plot of normalized maximum stress versus number of cycles to failure with stress ratio $\mathrm{R}=-1$. Lower $\mathrm{x} / \mathrm{y}$ tolerance limits represent the limits above which at least $x \%$ of all points would fall, with $y \%$ confidence. Open circles represent run-outs. 


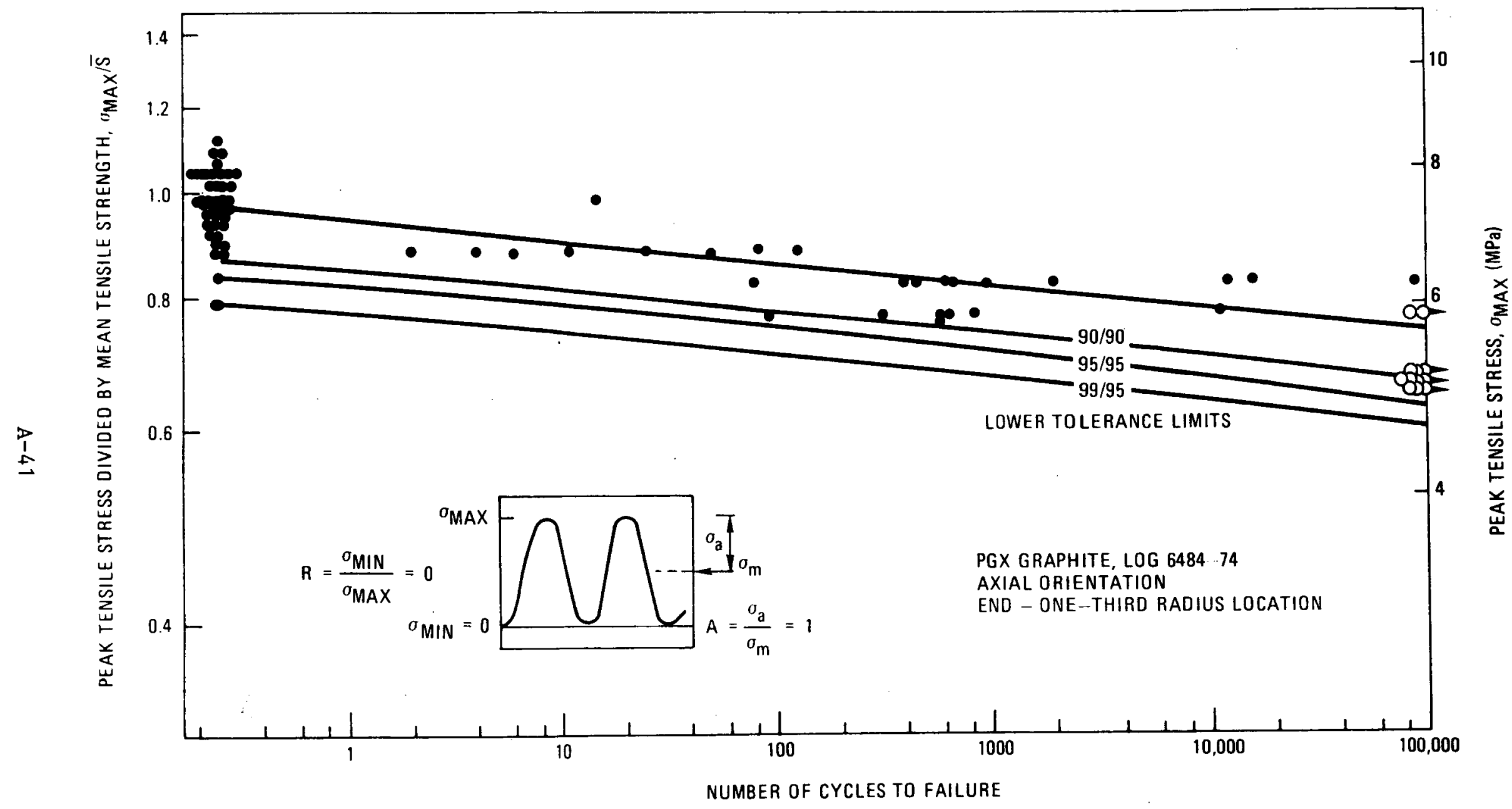

Fig. A-14. Fatigue test data for PGX graphite, axial orientation, end - one-third radius location, in air at ambient temperature. Log-log plot of normalized maximum stress versus number of cycles to failure with stress ratio $\mathrm{R}=0$. Lower $\mathrm{s} / \mathrm{y}$ tolerance limits represent the limits above which at least $x \%$ of all points would fall, with $y \%$ confidence. Open circles represent run-outs. 


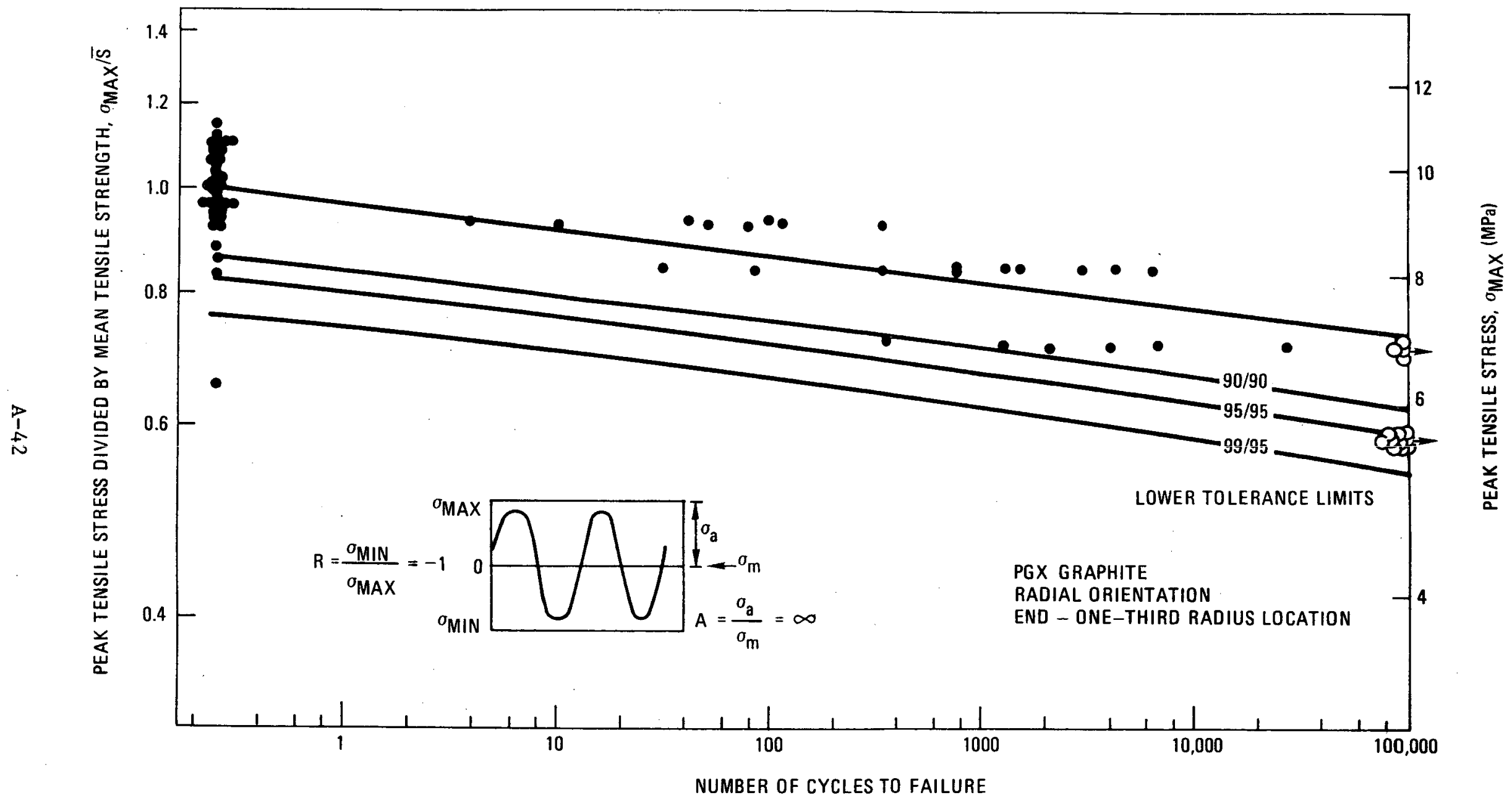

Fig. A-15. Fatigue test data for PGX graphite, radial orientation, end - one-third radius location, in air at ambient temperature. Log-log plot of normalized maximum stress versus number of cycles to failure with stress ratio $\mathrm{R}=-1$. Lower $\mathrm{x} / \mathrm{y}$ tolerance limits represent the limits above which at least $x \%$ of all points would fall, with $y \%$ confidence. Open circles represent run-outs. 


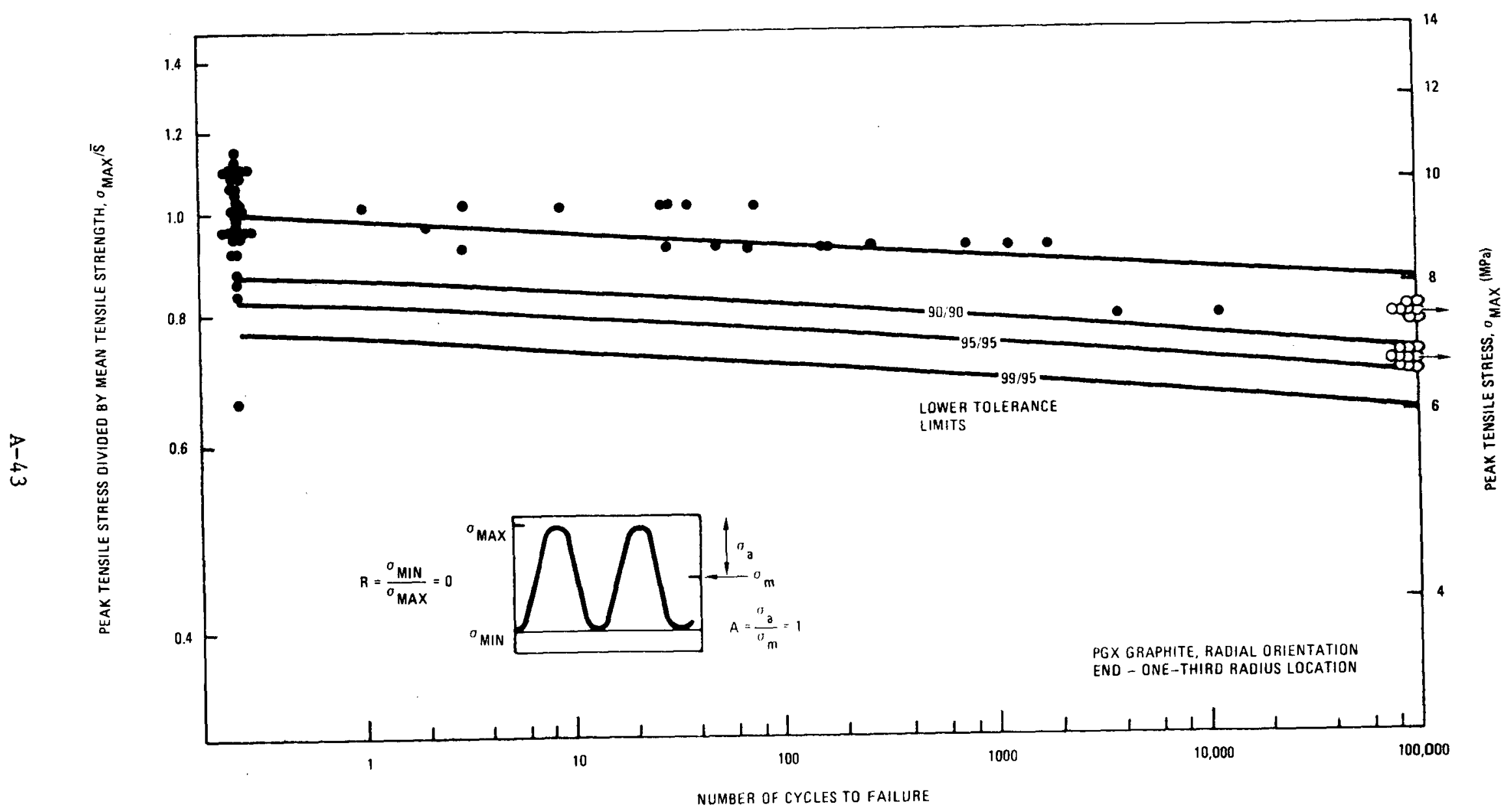

Fig. A-16. Fatigue test data for PGX graphite, radial orientation, end - one-third radius location, in air at ambient temperature. Log-log plot of normalized maximum stress versus number of cycles to failure with stress ratio $\mathrm{R}=0$. Lower $\mathrm{x} / \mathrm{y}$ tolerance limits represent the limits above which at least $x \%$ of all points would fall, with $y \%$ confidence. Open circles represent run-outs. 


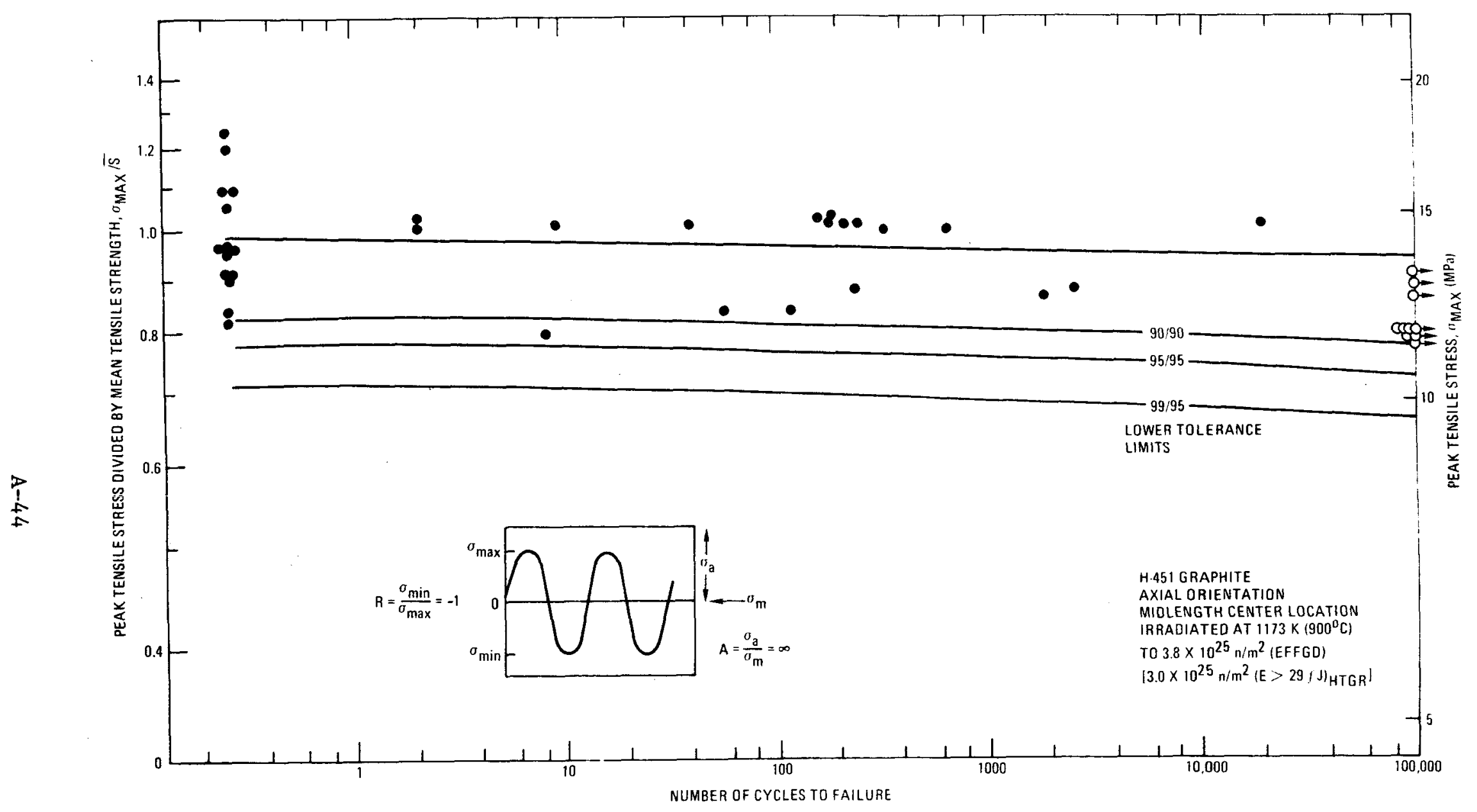

Fig. A-17. Ambient temperature fatigue test data for $\mathrm{H}-451$ graphite, axial orientation, irradiated to $3.8 \times 1025 \mathrm{n} / \mathrm{m}^{2}$ (equivalent fission fluence) at $1173 \mathrm{~K}\left(900^{\circ} \mathrm{C}\right)$. Log $-10 \mathrm{og}$ plot of normalized peak stress versus number of cycles to failure, with stress ratio, $R=-1$. Lower $x / y$ tolerance limits represent the limits above which $x \%$ of all observations would fall, with $y \%$ confidence. Open circles represent run-outs. 


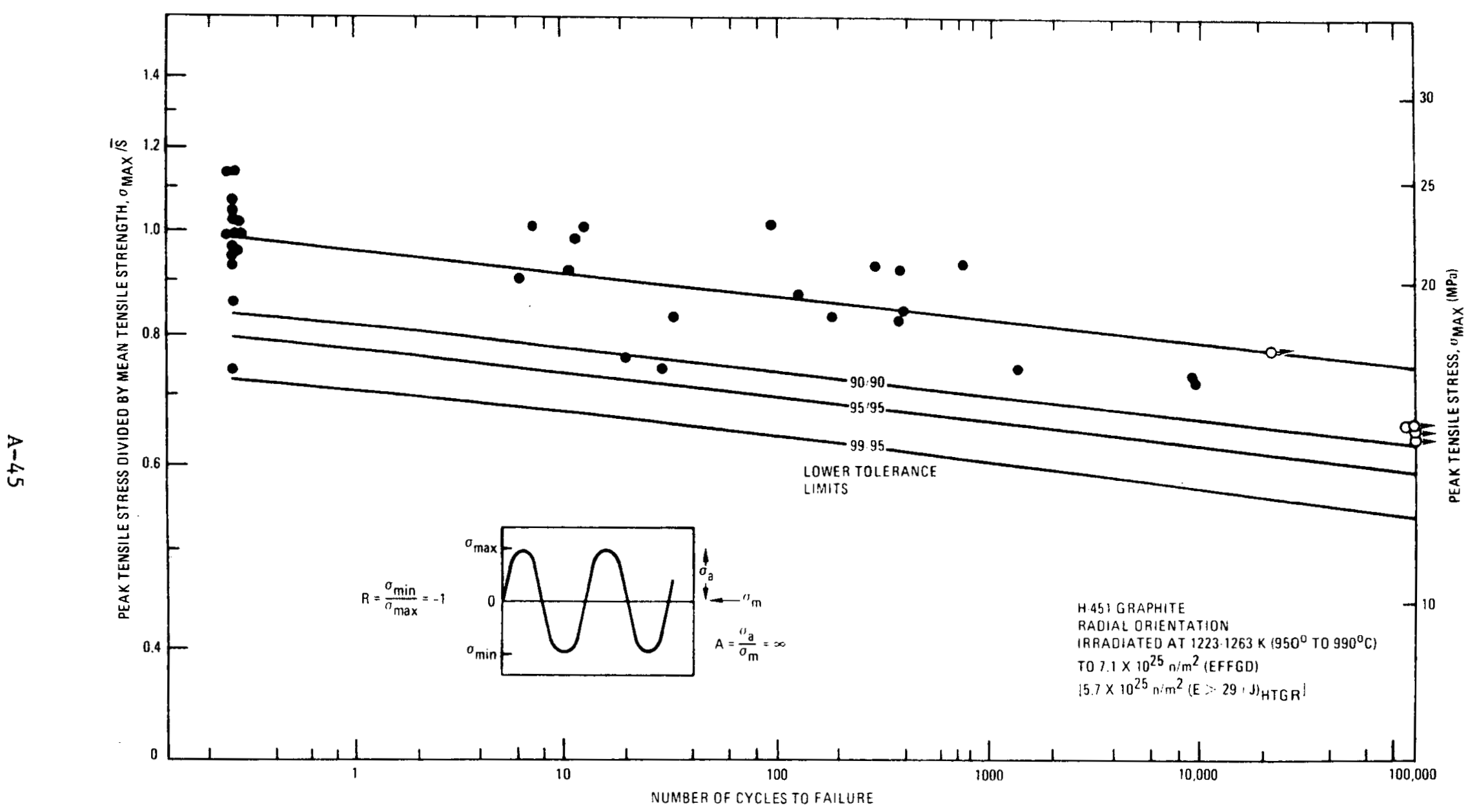

Fig. A-18. Ambient temperature fatigue test data for H-451 graphite, radial orientation, irradiated to $5.7 \times 10^{25} \mathrm{n} / \mathrm{m}^{2}$ (E > $\left.29 \mathrm{fJ}\right)_{\mathrm{HTGR}}$ at 1223 to $1263 \mathrm{~K}\left(950^{\circ}\right.$ to $\left.990^{\circ} \mathrm{C}\right)$. Log $\log$ plot of normalized peak stress versus number of cycles to failure, with stress ratio, $R=-1$. Lower $x / y$ tolerance limits represent the limits above which $x \%$ of all observations would fall, with $y \%$ confidence. Open circles represent run-outs. 


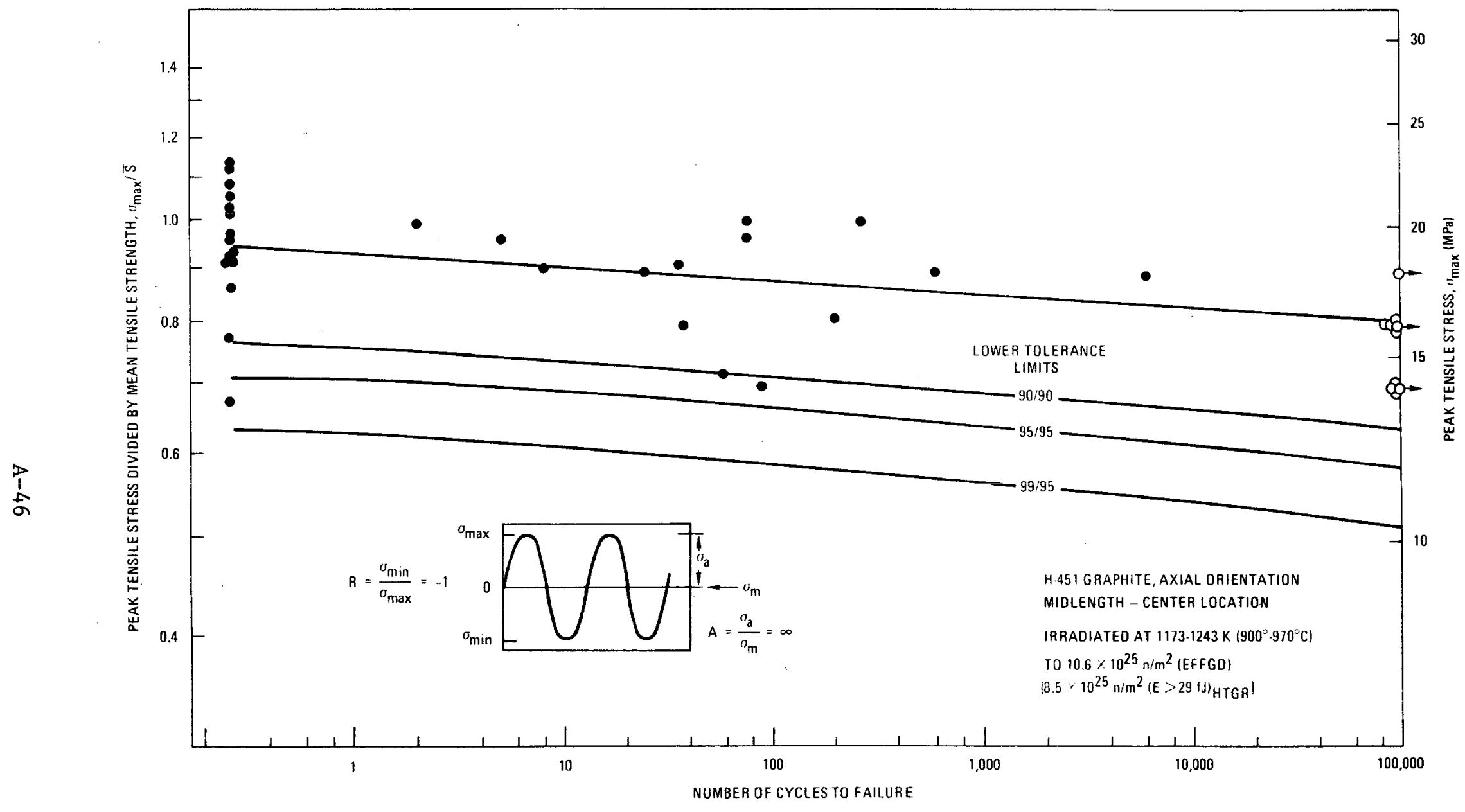

Fig. A-19. Ambient temperature fatigue test data for $\mathrm{H}-451$ graphite, axial orientation, irradiated to $8.5 \times 10^{25} \mathrm{n} / \mathrm{m}^{2}(\mathrm{E}>29 \mathrm{fJ})_{\mathrm{HTGR}}$ at 1223 to $1263 \mathrm{~K}\left(950^{\circ}\right.$ to $\left.990^{\circ} \mathrm{C}\right)$. Log-log plot of normalized peak stress versus the number of cycles to failure, with stress ratio, $R=-1$. Lower $x / y$ tolerance limits represent the limits above which $x \%$ of all observations would fall, with y\% confidence. Open circles represent run-outs. 


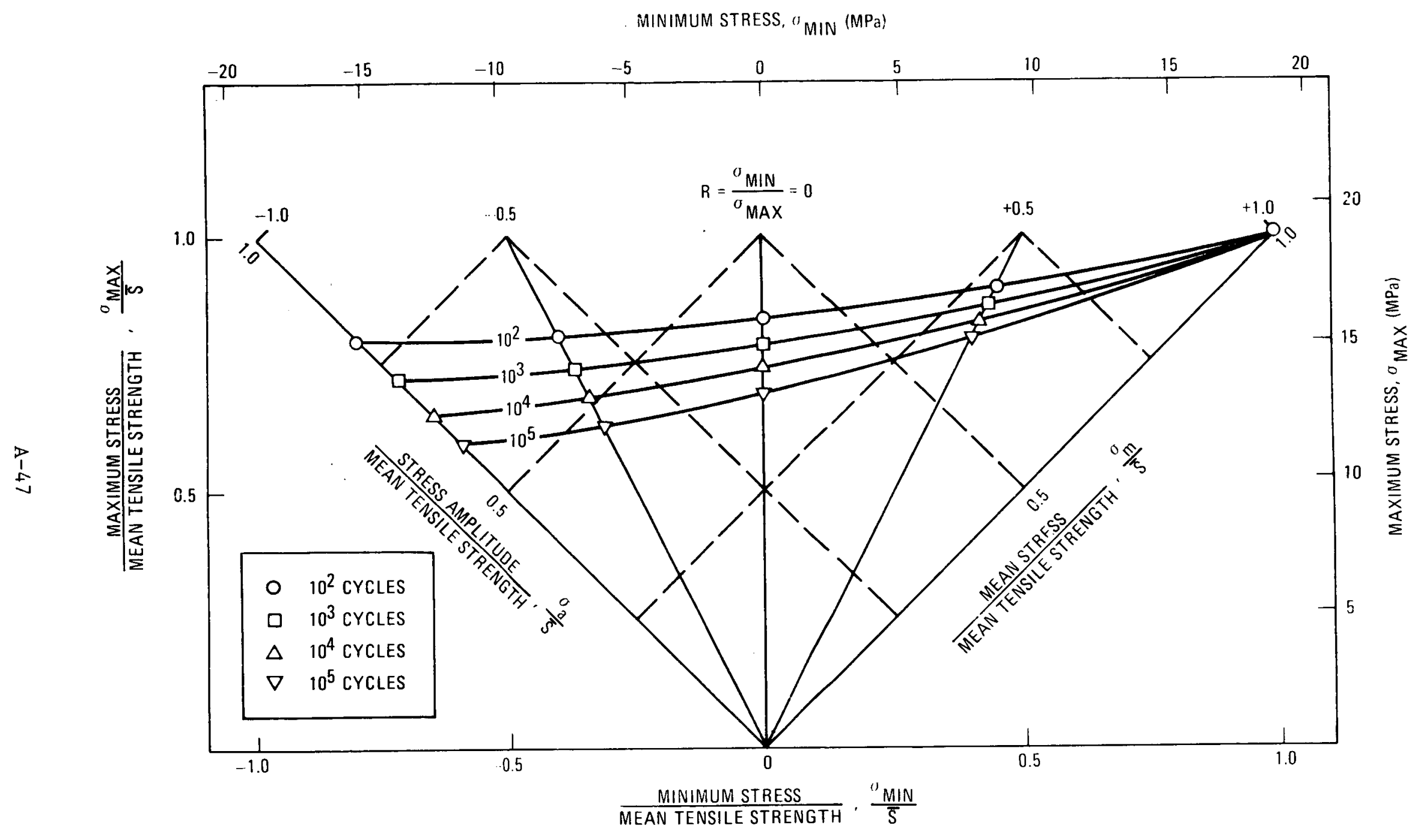

Fig. A-20. Constant life fatigue diagram (Goodman diagram) for H-451 graphite, axial orientation, tested in air at ambient temperature 


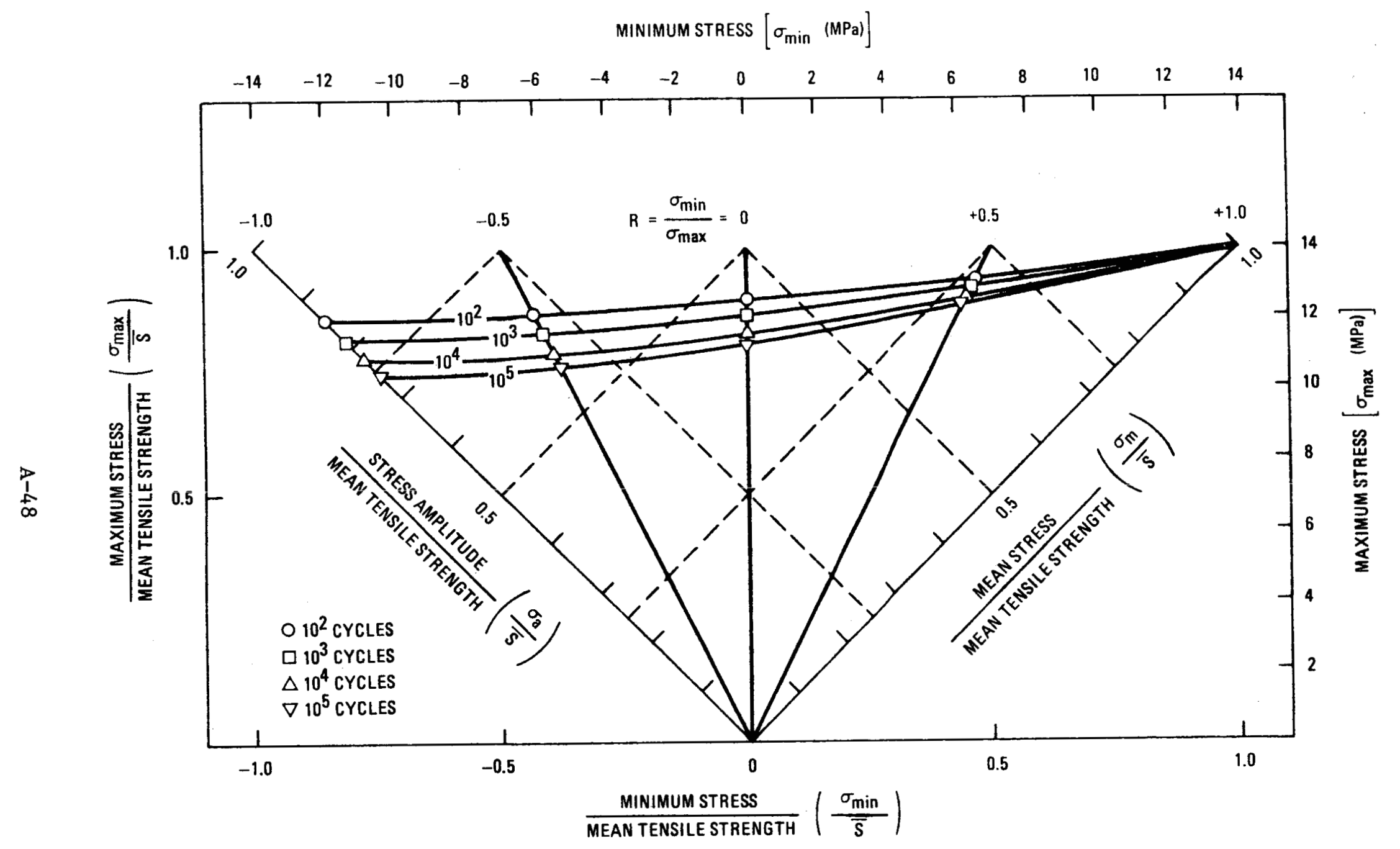

Fig. A-21. Constant life fatigue diagram (Goodman diagram) for H-451 graphite, radial orientation, tested in air at ambient temperature 


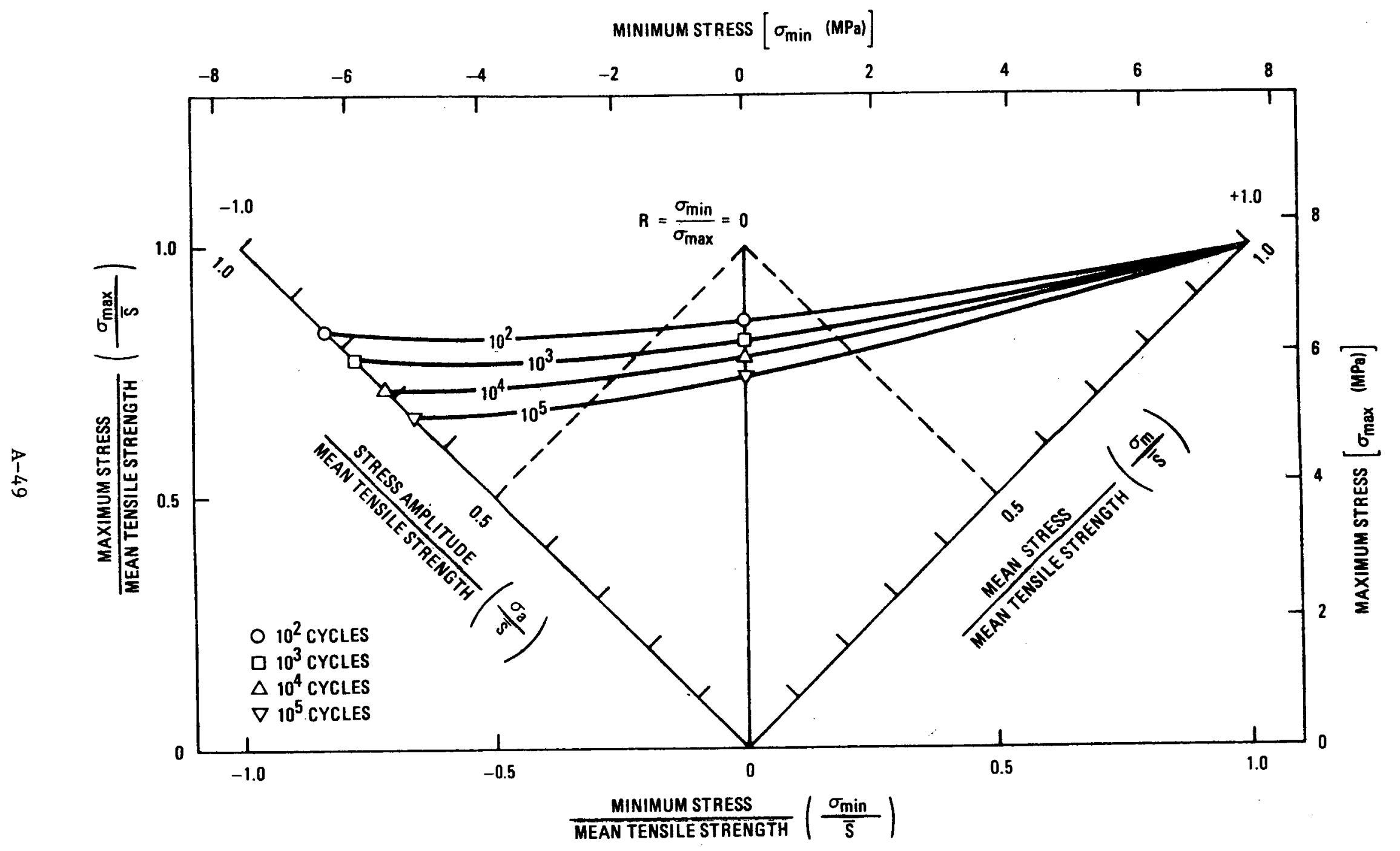

Fig. A-22. Constant life fatigue diagram (Goodman diagram) for PGX graphite, axial orientation, tested in air at ambient temperature 


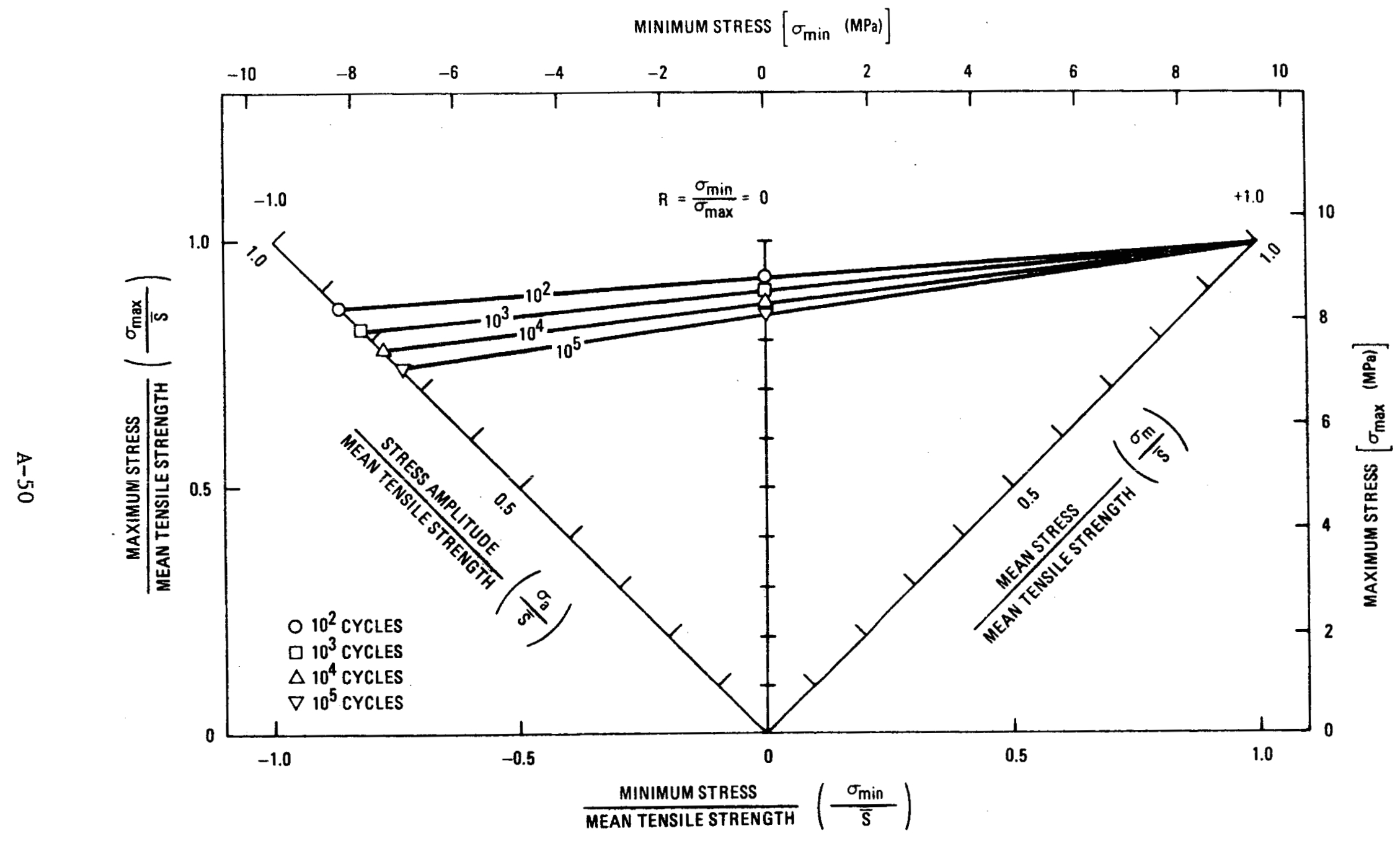

Fig. A-23. Constant life fatigue diagram (Goodman diagram) for PGX graphite, radial orientation, tested in air at ambient temperature 